\title{
AN EXPERIMENTAL STUDY ON THE EFFECTS OF COMPRESSION ON THE ACOUSTIC PERFORMANCE OF POROUS FIBROUS MATERIALS
}

\author{
By \\ Ching Chi Suen \\ Bachelor of Applied Science \\ University of Waterloo, 2010
}

\begin{abstract}
An MRP presented to Ryerson University
in partial fulfillment of the requirements

for the Master of Building Science

in the Department of Architectural Sciences
\end{abstract}

Toronto, Ontario, Canada, 2016

(C) Ching Chi Suen, 2016 


\section{Authors Declaration}

I hereby declare that I am the sole author of this MRP. This is a true copy of the MRP, including any required final revisions.

I authorize Ryerson University to lend this MRP to other institutions or individuals for the purpose of scholarly research.

I further authorize Ryerson University to reproduce this MRP by photocopying or by other means, in total or in part, at the request of other institutions or individuals for the purpose of scholarly research.

I understand that my MRP may be made electronically available to the public. 


\begin{abstract}
MBSc, 2016. Master of Building Science, in the department of Architectural Sciences. Ching Chi Suen. Ryerson University.
\end{abstract}

The current investigation experimentally studied the effects of compression on the acoustic performance of porous fibrous material. Two inch and four inch thick samples of fiberglass and three varying densities of mineral wool were tested using two different impedance tube sizes at compression rates of $1,1.3$ and 2 . The absorption coefficient was measured using Chung and Blaser's method. The flow resistivity was measured using Tao et al.'s method. Overall, the 4" samples resulted in steadier results than the 2" samples. Compression generally led to a decrease in absorption coefficient and an increase in flow resistivity. These effects were most evident in the lower frequency range. Although there were some experimental errors in sample preparation, sample variation, compression technique, testing order and other initial errors, the current study demonstrated that the effects of compression on insulation should be not be overlooked. 


\section{Acknowledgement}

I would like to thank my supervisor Dr. Ramakrishnan for his guidance and support throughout this process.

I would also like to thank my friends and family for their support. In particular I must

thank my husband and best friend, Oscar, for his unwavering patience, love and support. 


\section{Table of Contents}

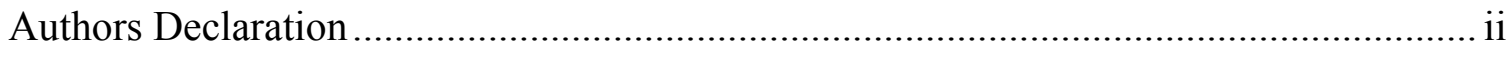

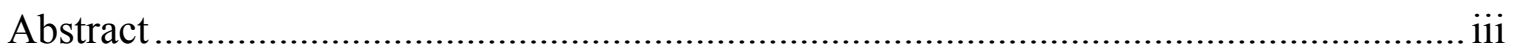

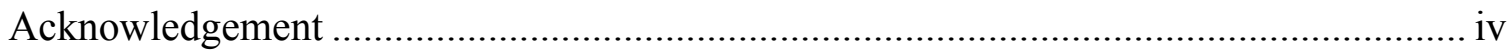

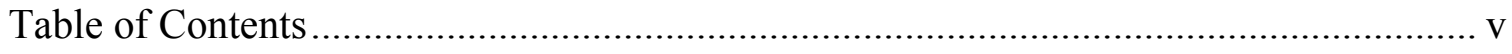

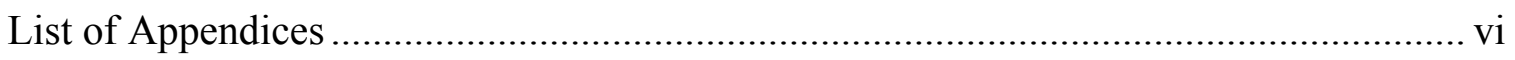

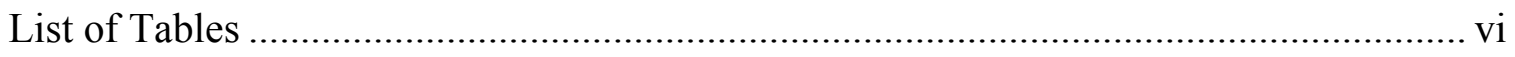

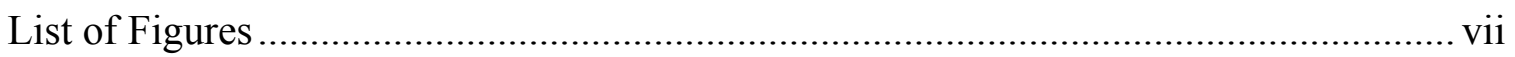

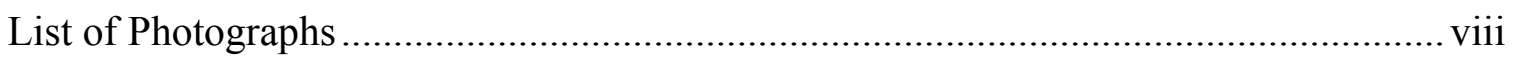

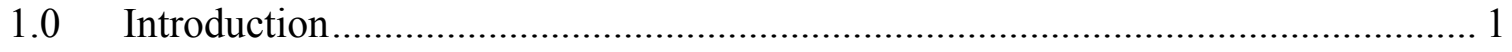

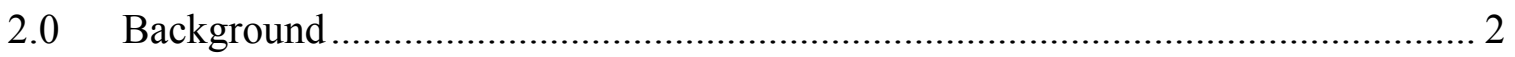

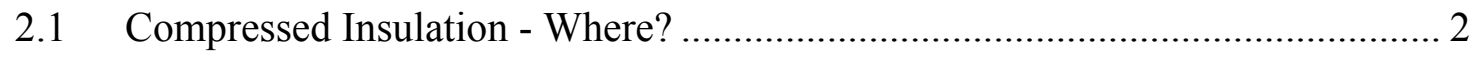

2.2 Porous Fibrous Materials - What are they? ………........................................ 5

2.3 Acoustic and Non-Acoustic Parameters - What can we find?............................ 5

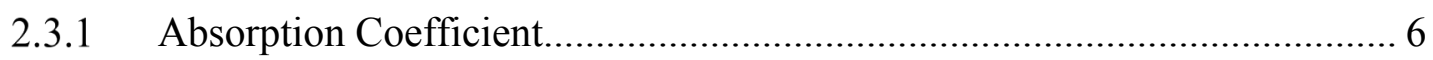

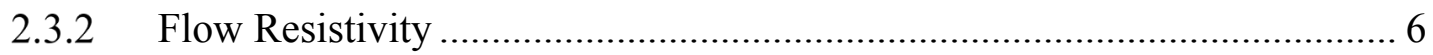

2.4 Impedance Tube - How can it be done? .................................................... 7

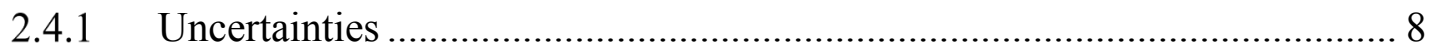

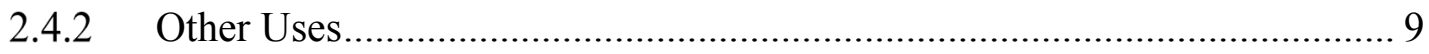

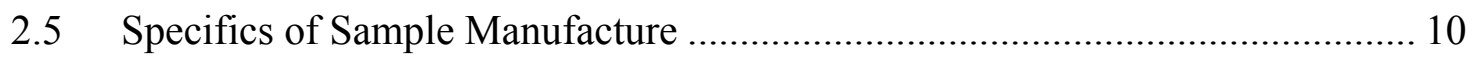

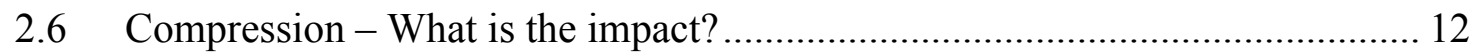

2.6.1 Absorption Coefficient Compression Impact …………............................ 12

2.6.2 Flow Resistivity Compression Impact ......................................................... 13

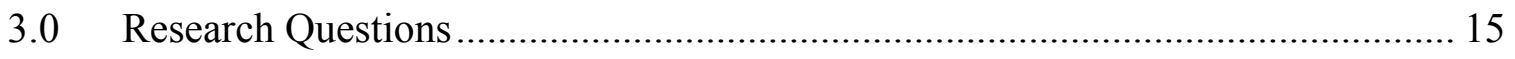

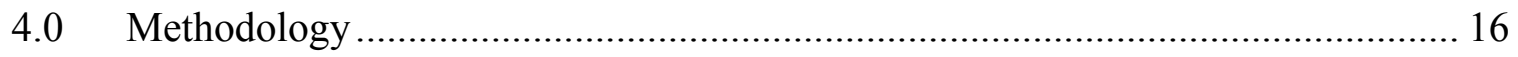

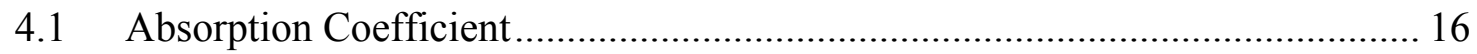

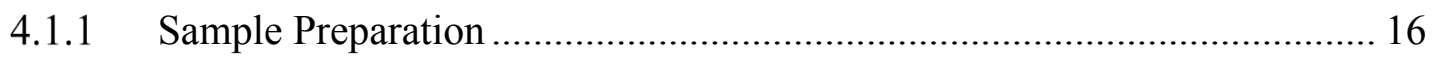

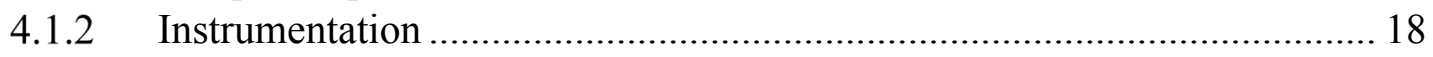

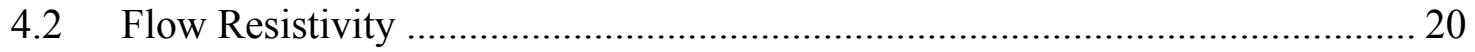

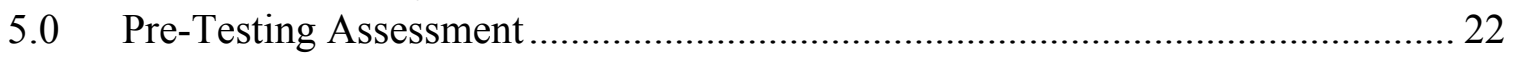

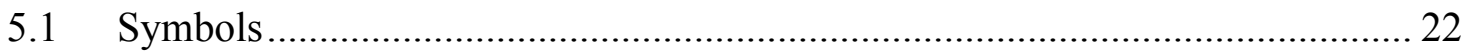

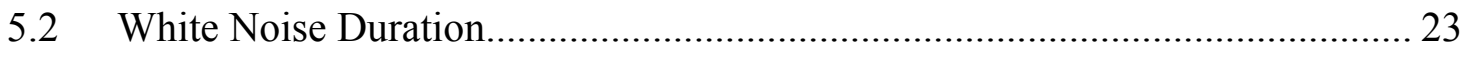

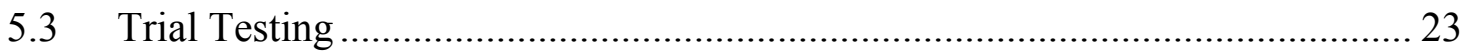

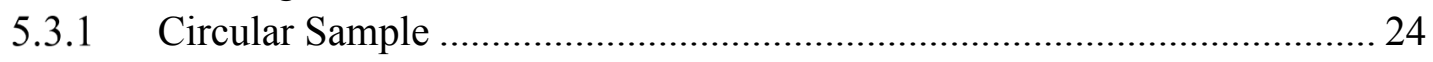

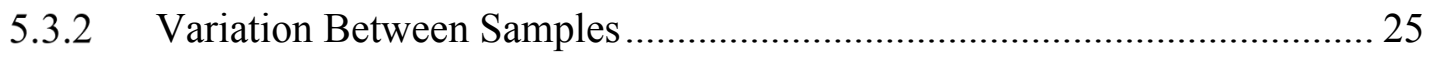

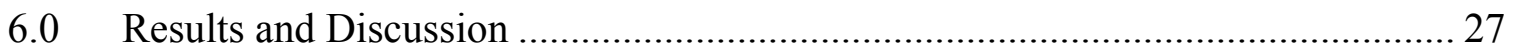

6.1 Absorption Coefficient ............................................................................... 27

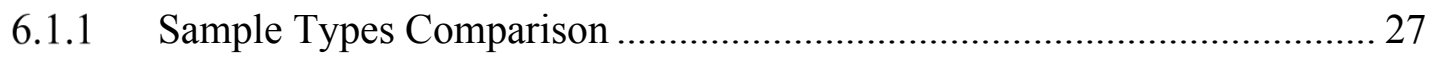

6.1.2 Fiberglass …………………………………........................................ 29 
6.1.3 R24

6.1.4 AFB

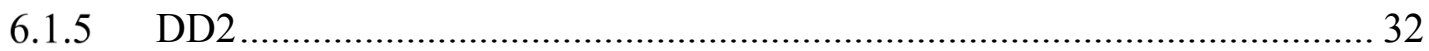

6.1.6 Absorption Coefficient Results Summary ................................................ 34

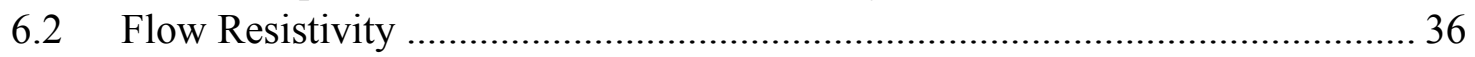

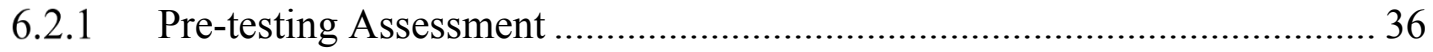

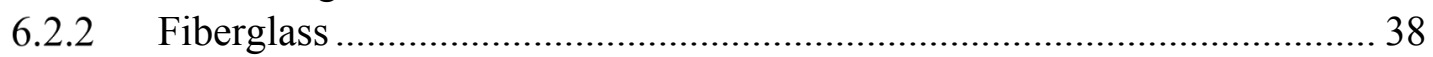

6.2.3 R24 .

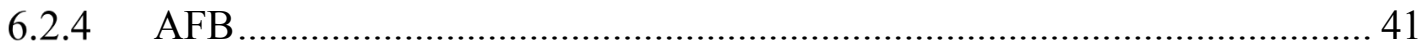

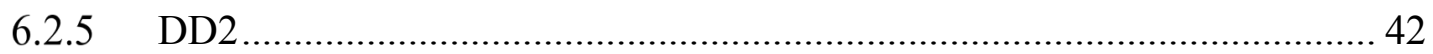

6.2.6 Flow Resistivity Results Summary ……………...................................... 44

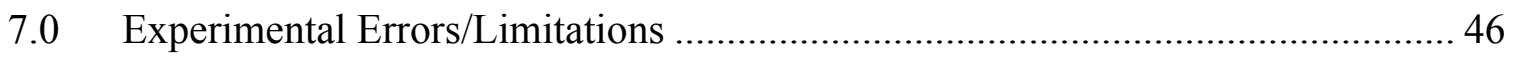

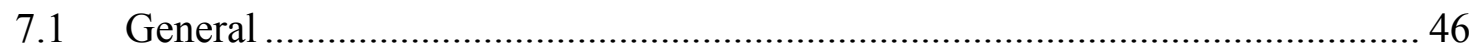

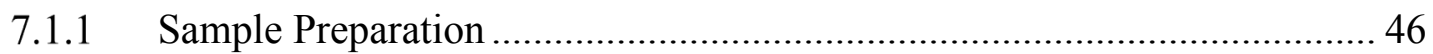

7.1.2 Compression Technique............................................................................. 47

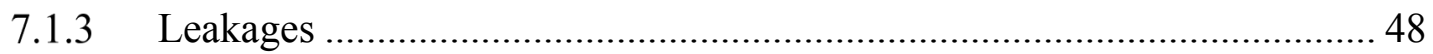

7.1.4 Varying Back End Depths (Circular tube) (................................................ 52

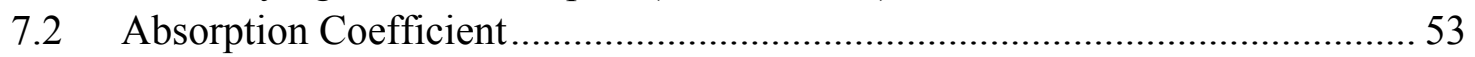

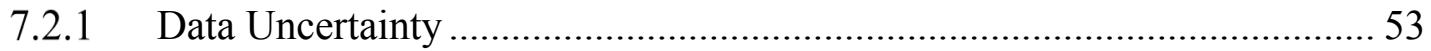

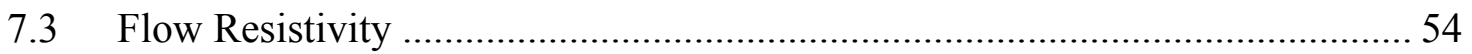

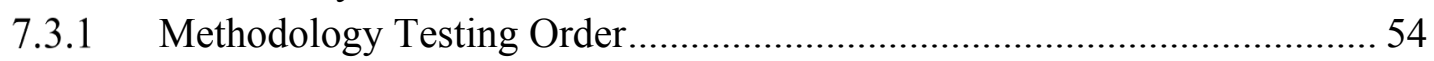

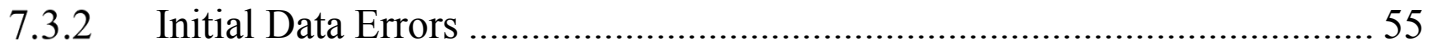

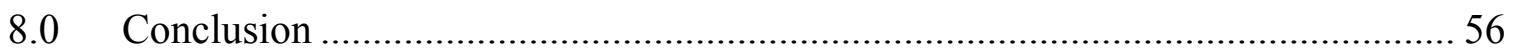

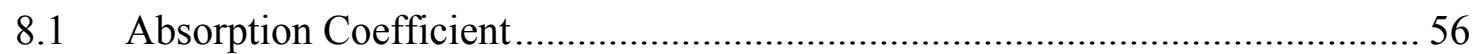

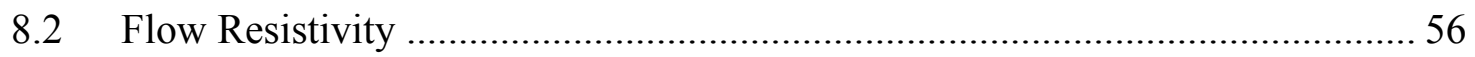

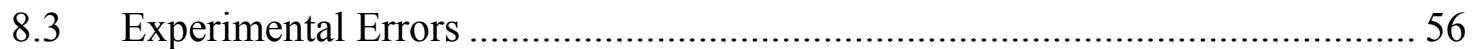

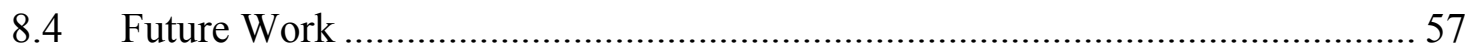

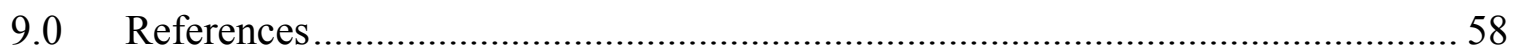

\section{List of Appendices}

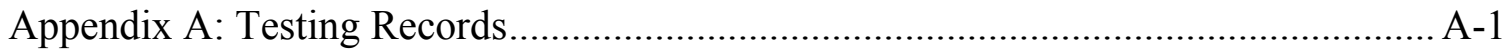

Appendix B: Fortran and Matlab Scripts ........................................................... B-1

\section{List of Tables}

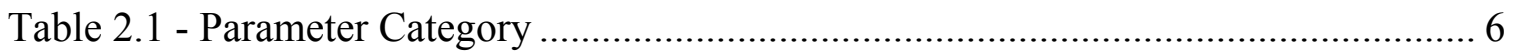

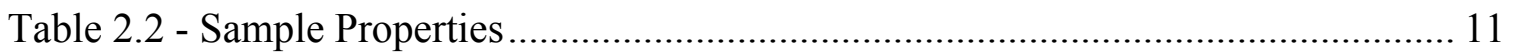

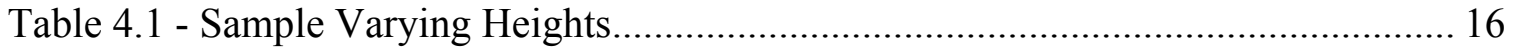

Table 4.2 - Impedance Tubes Details........................................................................ 18 
Table 5.1 - Graph and Terminology Definition ........................................................ 22

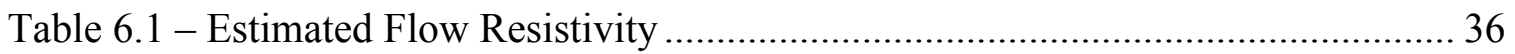

Table 7.1 - Test Specimen Cutting Techniques based on Stanley [26] ......................... 46

Table 7.2 - Current vs. proposed testing order ........................................................... 55

\section{List of Figures}

Figure 2.1 - Step\#2 in properly installing duct wraps [14] ............................................ 4

Figure 2.2 - Insulation R-values when compressed in framing cavity [15] ...................... 4

Figure 2.3 - Cross sectional view of solid porous material [3] ....................................... 5

Figure 2.4 - Three types of porous absorbing materials [3] ............................................... 5

Figure 2.5 - Two-microphone impedance tube setup (adapted [21]) ………………....... 8

Figure 2.6 - Three-microphone impedance tube setup [21] .......................................... 9

Figure 2.7 - Two-microphone impedance tube setup for flow resistivity [28] ............... 10

Figure 2.8 - Manufacturer's data based on ASTM C423 [30, 31] .............................. 11

Figure 2.9 - Absorption coefficient vs frequency of a layer of polyester fiber [35] ........ 13

Figure 4.1 - Schematic of test equipment layout (adapted [21, 22]) ………………...... 19

Figure 5.1 - Absorption coefficient of DD2 samples for different white noise durations 23

Figure 5.2 - Absorption coefficient for DD2 sample tested twice (Narrow band).......... 24

Figure 5.3 - Absorption coefficient for DD2 sample tested twice ( $1 / 3$ Octave band)........ 25

Figure 5.4 - Comparison of absorption coefficient for DD2 2" and 4" square samples .. 26

Figure 6.1 - Combination of absorption coefficient for AFB 4" samples......................... 27

Figure 6.2 - Absorption coefficient for various uncompressed 4" samples ..................... 28

Figure 6.3 - Absorption coefficient for various uncompressed 2" samples ..................... 29

Figure 6.4 - Absorption coefficient results for fiberglass 2" and 4" samples .................. 30

Figure 6.5 - Absorption coefficient results for R24 2" and 4" samples ........................... 31

Figure 6.6 - Absorption coefficient for AFB 2" and 4" samples .................................. 32

Figure 6.7 - Absorption coefficient results for DD2 samples ........................................ 33

Figure 6.8 - Absorption coefficient results for DD2 with external noise disturbance .... 34

Figure 6.9 - Graphical representation of the decrease in absorption coefficient.............. 35

Figure 6.10 - Flow resistivity of AFB 4" samples for different white noise durations.... 37

Figure 6.11 - Three-microphone method: Flow resistivity of fiberglass 8" sample [39]. 38

Figure 6.12 - Flow resistivity of fiberglass square samples........................................... 39

Figure 6.13 - Three microphone method: Flow resistivity of R24 4" sample [39]......... 40

Figure 6.14 - Flow Resistivity for R24 square samples .............................................. 40

Figure 6.15 - Three microphone method: Flow resistivity of AFB 4" sample [39] ......... 41

Figure 6.16 - Flow resistivity of AFB square samples .................................................. 42 
Figure 6.17- Three microphone method: Flow resistivity of DD2 4" sample [39] ......... 43

Figure 6.18 - Flow resistivity of DD2 square samples.......................................... 43

Figure 6.19 - Graphical representation of increasing flow resistivity............................ 44

Figure 7.1- Components and Schematic of Li's Compression Method [37] ................... 47

Figure 7.2- Components and Schematic of Li's Compression Method............................ 48

Figure 7.3 - Absorption coefficient: Fiberglass 2" compressed sample ........................ 49

Figure 7.4 - Absorption coefficient for R24 varying 4" samples................................... 50

Figure 7.5 - Absorption coefficient of fiberglass varying 2" samples ........................... 51

Figure 7.6 - Absorption coefficient for fiberglass 4" samples of varying depths ........... 52

Figure 7.7 - Absorption coefficient of polyurethane with different air gaps [43]........... 53

Figure 7.8 - Resonance regions matching [25] ........................................................ 54

\section{List of Photographs}

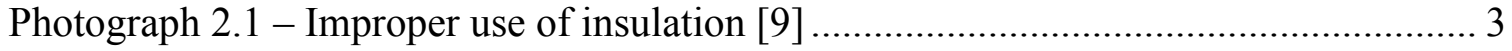

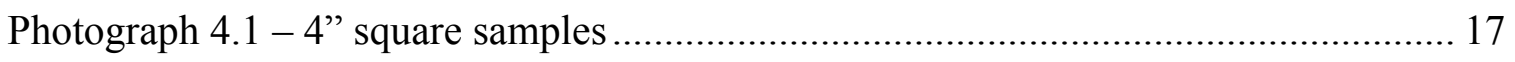

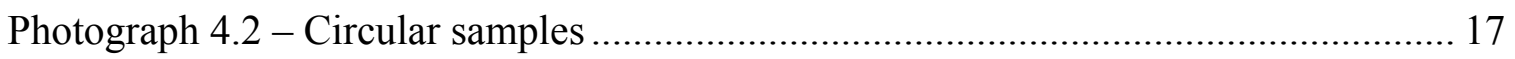

Photograph 4.3 - Lab instrumentation.................................................................... 19

Photograph 4.4 - Custom square frames and proposed layout..................................... 21

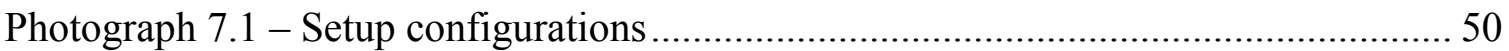




\subsection{Introduction}

Porous fibrous materials such as fiberglass and mineral wool are commonly used to attenuate sound waves as well as for thermal insulation. These materials can be used for passive absorption applications in HVAC systems, and corner-vane treatments in wind tunnels [1]. The material may experience unintentional compression during poor installation in wall sections or around ducts. Alternatively, during operation, insulation can be compressed under the weight of green roof assemblies or the vibration of mechanical units. The effect of compression on the acoustical performance of these materials is unclear [2].

In March 2014, the Ontario Centres of Excellence (OCE) awarded Ryerson University's Professor Ramani Ramakrishnan a grant to study the acoustic performance of porous materials under compression. The first part of the research was completed in 2014 with the completion of a series of impedance tube tests to find the absorption coefficient of porous materials under various compressive loads. The current study intends to complete the second part of the ongoing research. Further extensive impedance tube testing and a novel approach for calculating flow resistivity were conducted.

Understanding the effects of compression could affect the industry's understanding of manufacture reporting and design. The aim of the current study is to empirically determine the effects of compression on the absorption coefficient and flow resistivity of porous insulation. 


\subsection{Background}

Fiberglass and mineral wool are common insulation materials. They are commercially available in various dimensions, thermal, acoustical and mechanical properties [3]. An overview of the insulation, acoustic properties, parameters, sample data and testing methods are discussed below.

\subsection{Compressed Insulation - Where?}

There are many ways in which insulation can be compressed. One is intentional compressive design for firestopping. Others are unintentional, such as when forcing insulation around obstructions, stacking insulation for attic retrofits, bearing the load for green roof assemblies, and wrapping mechanical insulation. Listed below are some instances where insulation might be compressed.

- The California Energy Star Home Program has a checklist to verify the quality of the installation for insulation and thermal barrier. The report describes that up to $50 \%$ of compression for Batt insulation may occur at obstructions (plumbing vents and non-standard cavities) "but compression of more than 50\% in any dimension is excessive and shall not be allowed." [4].

- The Oak Ridge National Laboratory suggest during attic retrofits to stack new insulation on top of existing insulation. If the new insulation is denser, the existing insulation will compress under the weight and the R-value will decrease.

To balance the thermal loss an additional 1 " or 0.5 " of insulation is recommended if the old insulation is fiberglass, or mineral wool/cellulose, respectively [5].

- Due to its fire resistive properties, compressed mineral wool is typically recommended for firestopping. Valiulis and Philips identified many common deficiencies for these installations. One issue is that mineral wool may not be installed with its correct or higher compression ratio. While another issue is a lower density mineral wool is often inadequately used for ease of installation [6].

- Based on reported test results by a green roof company, Furbish, for $128 \mathrm{~kg} / \mathrm{m}^{3}$ dense mineral wool (bounded with resin) used in green roof assemblies, there was a $15-35 \%$ compression under high foot traffic. For comparison, a $25 \%$ compression was found for mineral wool without a chemical binder [7]. 
- Compression is expected for duct blanket insulation. However, Stein pointed out that a $50 \%$ compression is assumed since most authorities recommend doubling the normal thickness [8].

- A white paper commissioned by the Heat and Frost Insulation Union included several examples of improper installation for mechanical insulation in BC. One example in Photograph 2.1 shows the use of pink insulation that does not match the density of the pipe covering with no vapour barrier. Unintended compression of the insulation is revealed [9].

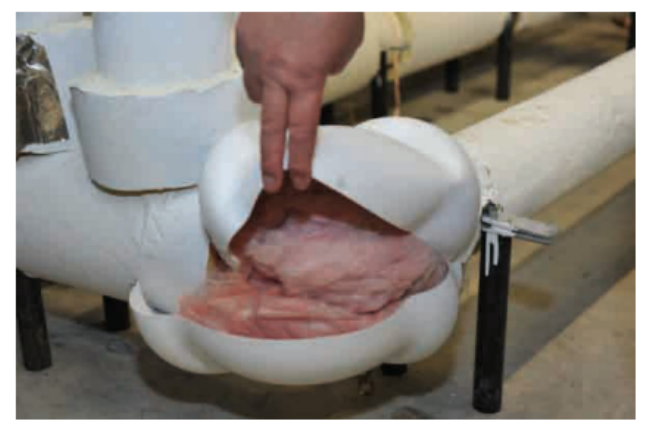

\section{Photograph 2.1 - Improper use of insulation [9]}

- Collier stated that an increase in temperature in industrial applications can decrease the compressive strength and thermal performance for several types of insulations. Compression and vibration can impact the insulation performance used for tank foundations, digesters and underground installations, floors with heavy loads, pipe supports, roofs and self-supporting walls [10].

- The Foamglas Industrial Insulation Handbook included a statement from a 1978 technical bulletin where five US petrochemical facilities were tested for their insulation systems. Horr found that mineral wool insulation compressed 5-10\% by its own weight in new builds and were compressed $10-50 \%$ in older insulation [11].

Many reports and construction guides most notably by Canada Mortgage Housing Corporation (CMHC), Oak Ridges National Laboratory (ORNL), and the US Department of Energy (DOE) instruct that compression of insulation must be avoided during construction [12]-[14]. In a guide published by the DOE also illustrates, Figure 2.1 that care must be taken around the bends of the duct when installing duct wraps [14]. 


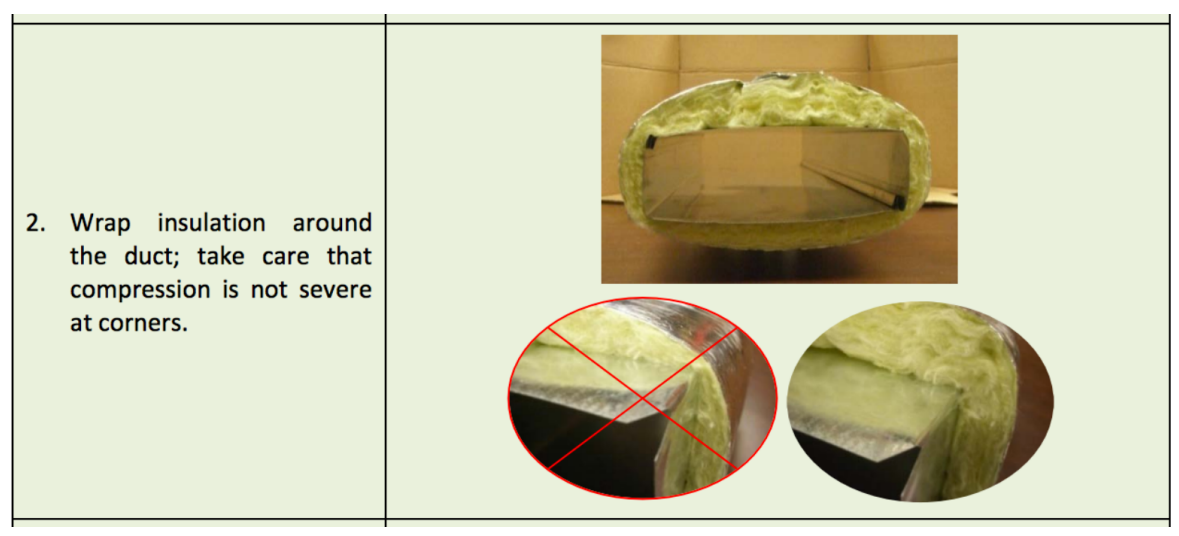

Figure 2.1 - Step\#2 in properly installing duct wraps [14]

The same reports caution that compression of the insulation will lead to a decrease in the $\mathrm{R}$-value resulting in a thermal reduction in the insulation. A manufacturer even published how the fiberglass insulation product's R-values can be affected by compression in Figure $2.2[15]$.

\begin{tabular}{|c|c|c|c|c|c|c|c|c|c|c|c|c|c|}
\hline Nominal & Cavity & \multicolumn{12}{|c|}{ Insulation R-Values When Compressed In Framing Cavity } \\
\hline $2 \times 12$ & $1 \mid 1 / 4 "$ & 37 & 38 & & & & & & & & & & \\
\hline $2 \times 10$ & $91 / 4 "$ & 32 & 35 & 28 & & & & & & & & & \\
\hline $2 \times 8$ & $71 / 4 "$ & 27 & 29 & 25 & 27 & 24 & & & & & & & \\
\hline $2 \times 6$ & $51 / 2 "$ & & & 21 & 22 & 20 & 19 & 21 & 18 & & & & \\
\hline $2 \times 4$ & $31 / 2 "$ & & & & & & 14 & 15 & 13 & 15 & 13 & 11 & \\
\hline $2 \times 3$ & $21 / 2 "$ & & & & & & & & & II & 10 & 8.9 & 8.0 \\
\hline $2 \times 2$ & $11 / 2 "$ & & & & & & & & & & 6.6 & 6.1 & 5.7 \\
\hline $2 \times 1$ & $3 / 4^{\prime \prime}$ & & & & & & & & & & & & 3.3 \\
\hline \multicolumn{2}{|c|}{ Product R-Value } & R-38 & $\mathrm{R}-38 \mathrm{C}$ & $\mathrm{R}-30$ & $\mathrm{R}-30 \mathrm{C}$ & R-25 & R-22 & R-2I & $R-19$ & R-I5 & $\mathrm{R}-13$ & R-II & R-8 \\
\hline \multicolumn{2}{|c|}{ Label Thickness } & 12" & $101 / 4 "$ & $91 / 2 "$ & $81 / 4 "$ & $8^{\prime \prime}$ & $63 / 4^{\prime \prime}$ & $51 / 2 "$ & $61 / 4 "$ & $31 / 2 "$ & $31 / 2 "$ & $31 / 2 "$ & $21 / 2 "$ \\
\hline
\end{tabular}

Notes: I. Minimum dressed lumber thickness per U.S. Dept. of Commerce/NIST publication PS 20-I0.

2. Above listing for information only; some products will resist compression into framing cavities.

Figure 2.2 - Insulation R-values when compressed in framing cavity [15]

The compressive strength of the insulation is often reported suggesting the ability for the material to be compressed. Like the R-value reduction, the acoustic performance may also be decreased or negatively affected when the insulation is compressed. However, unlike the R-values reduction, the effect on the acoustic performance is not well defined or documented. 


\subsection{Porous Fibrous Materials - What are they?}

Unlike gypsum boards, fiberglass and mineral wool are sound absorbers rather than sound blockers. Fiberglass and mineral wool are defined as porous fibrous material with tunnel-like openings [3]. These materials have fiber strands that entrap air. Porous material contains several tiny pores interconnected that allow sound to travel through. The sound waves can cause the fibers to vibrate or to rub against each other while most of the energy is absorbed from scattering due to the fibers. Some of the energy loss is converted to thermal heat. Figure 2.3 and Figure 2.4 show schematically and microscopically the structure of porous materials.

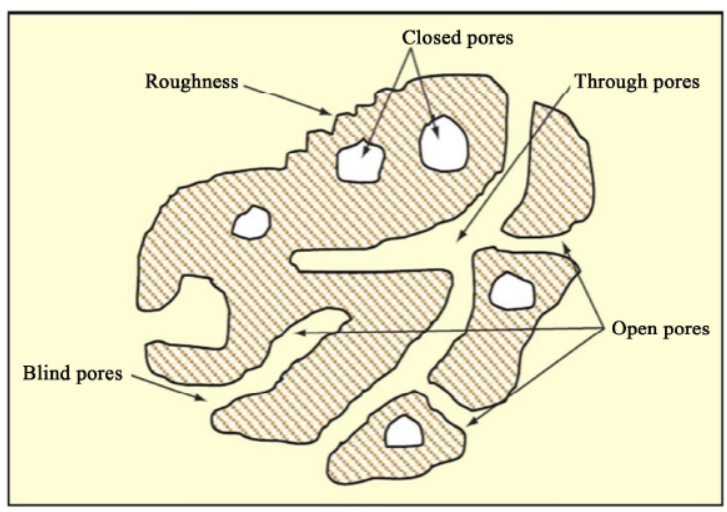

Figure 2.3 - Cross sectional view of solid porous material [3]
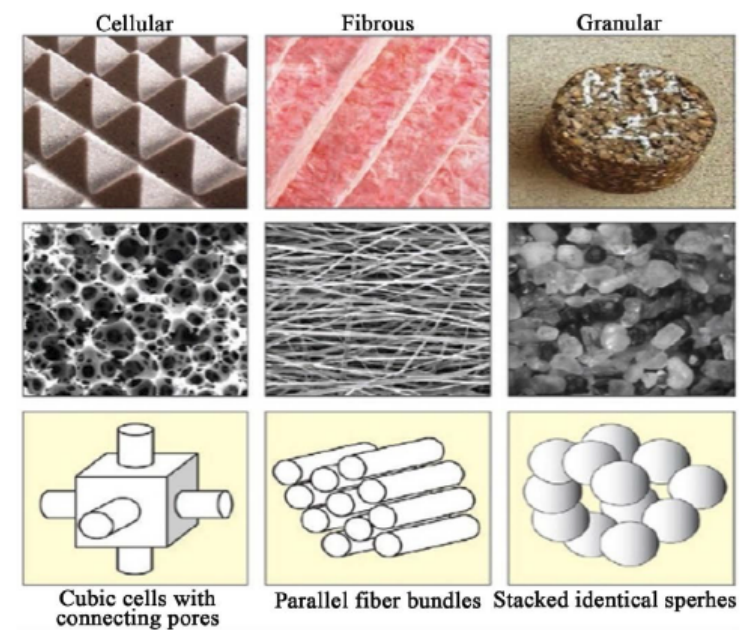

Figure 2.4 - Three types of porous absorbing materials [3]

\subsection{Acoustic and Non-Acoustic Parameters - What can we find?}

The absorption behaviour can be influenced by material properties such as fiber size, thickness, density, airflow resistance, porosity, and tortuosity [2]. Some of these properties are described herein.

- Fiber size: is an important factor for sound absorption. The thinner the fiber size, the easier it is for it to move with the sound wave instead of absorbing it.

- Material Thickness: many authors have found that thickness is directly related to low frequency sound absorption and has less effect for higher frequencies.

- Density: is associated to the number of fibers within a unit area. 
- Airflow resistance: is defined as the ratio of the static pressure drop over a volume flow for a thickness of sample. Airflow is a closely related to density. The denser the material, the higher the flow resistance.

- Porosity: is the ratio of the volume of voids over the total volume. Porosity is very difficult to measure since the porous fibrous material is compressible.

- Tortuosity: is the amount of elongation of the pathway through the pores compared to the thickness.

Even though there are many more acoustic and non-acoustic parameters, only the following significant parameters in Table 2.1 were studied within the current project scope.

Table 2.1 - Parameter Category

\begin{tabular}{|c|c|c|c|}
\hline \multicolumn{2}{|c|}{ Acoustic parameter } & \multicolumn{2}{c|}{ Non-acoustic parameter } \\
\hline$\alpha$ & $\begin{array}{c}\text { Absorption coefficient } \\
\text { (dimensionless) }\end{array}$ & $\sigma$ & $\begin{array}{c}\text { Airflow resistivity } \\
\text { (MKS rayls } / \mathrm{m})\end{array}$ \\
\hline
\end{tabular}

\subsubsection{Absorption Coefficient}

Absorption coefficient $(\alpha)$ is a frequency dependent property used to define a material's acoustic characteristic. It is a dimensionless coefficient defined as the ratio of the absorbed energy over incident sound energy. $\alpha$ ranges between the values 0 and 1 , where 1 means $100 \%$ of the sound is absorbed or transmitted through with no reflection of the sound energy. Absorption coefficient can be measured using either a reverberation room or an impedance tube. Design of acoustic panels and reducing room noise rely on the absorption coefficient values.

\subsubsection{Flow Resistivity}

Another important parameter is the airflow resistivity ( $\sigma)$, which is a measure of the resistance to airflow through a material. It is a physical property that is independent of the area or thickness of the sample [16]. A widely accepted paper completed in 1970 by Delany-Bazley presented empirical expressions using only airflow resistivity to predict the acoustic properties of fibrous sound-absorbing materials (wave number and 
characteristic impedance) [17]. In 1990 Miki modified the coefficients in Delany-Bazley's model to improve the accuracy in the low frequency range [18].

Flow resistivity can be measured by numerous means. A typical apparatus measures the pressure drop across a sample when exposed to a steady laminar flow of air. However, the flow resistivity of some materials may be frequency dependent, in which case it must be calculated from experimentally measured values of acoustic impedance [16]. Flow resistivity is an important parameter in understanding the physical properties of a material useful in firestopping and noise control field of study. Therefore, flow resistivity is an important parameter to measure.

The following section will explain how these parameters can be measured.

\subsection{Impedance Tube - How can it be done?}

The impedance tube is an inexpensive, quick and easy method to measure the sound absorption coefficient. There are two standards of measurement using an impedance tube: the standing-wave method and the transfer function method.

Chung and Blaser applied the transfer function method to find the reflection coefficient $(\mathrm{R})$, and absorption coefficient $(\propto)$ as given by Equation 2.1 and $2.2[19,20]$.

$$
\begin{aligned}
& \propto=1-|R|^{2} \\
& R=\frac{H-e^{-j k s}}{e^{-j k s}-H} e^{j 2 k(L+s)}
\end{aligned}
$$

where $k$ is the wave number $2 \pi f / c, f$ is the frequency, $c$ is the speed of sound, $s$ is the

distance between the two microphone centres, $L$ is the length between microphone and front face of the porous sample, and $H$ is the transfer function between the two microphones corrected for gain and phase mismatch. Figure 2.5 shows a typical twomicrophone tube setup adapted by Doutres et al. [21]. 


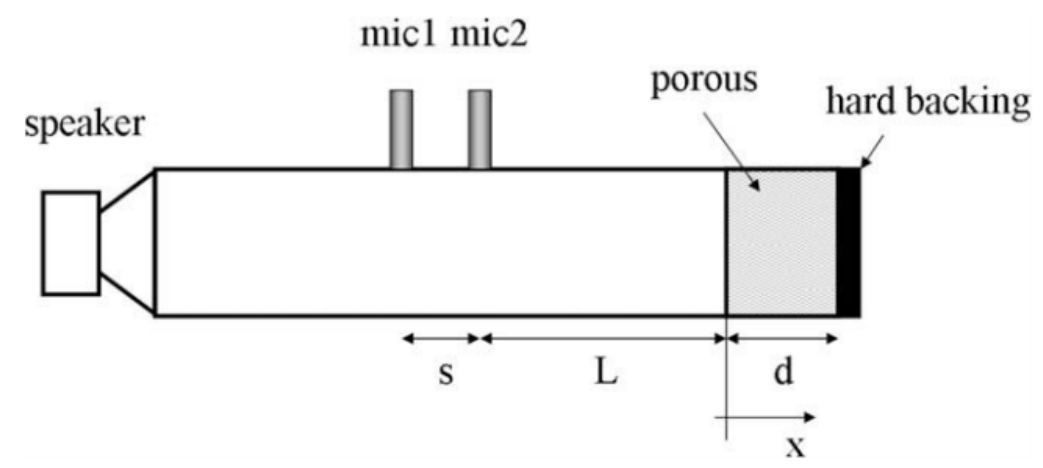

Figure 2.5 - Two-microphone impedance tube setup (adapted [21])

Chung and Blaser's method for finding acoustic properties has been shown to be reliable and is part of an international standard ISO 10534-2:1998 (Acoustics - Determination of sound absorption coefficient and impedance in impedance tubes - Part 2: Transferfunction method) as well as in the American standard ASTM E1050 [22, 23]. It is important to measure over a range of frequencies since the absorption coefficient is frequency dependent.

It is noted that there are several theoretical models developed to obtain the absorption coefficient. Oliva and Hongisto compared seven methods of predicting absorption coefficient with experimental data on several configurations of mineral wool samples [24].

\subsubsection{Uncertainties}

A review completed by Hua and Herrin examined how to reduce uncertainty in absorption coeffficient measurements using the transfer function method. The authors concluded that three variabilities can occur during the measurements of absorption coefficients using an impedance tube: resonance, low frequency variability and high frequency variability [25].

Even though the standards address some techniques to reduce variability, it is still difficult to obtain consistent and repeatable results. Factors such as sample cutting and preparation [26], sample fit and position in the tube and the material variability [25] affect the resulting coefficient. Another problem with the method is the tester has no 
sound absorbing material to reference and compare their results to [25]. The paper examined some methods to reduce these uncertainties.

\subsubsection{Other Uses}

The impedance tubes can also be used to find non-acoustic parameters of porous materials. Among several methods proposed, Doutres et al. demonstrated that a threemicrophone impedance tube setup can measure both the acoustic and non-acoustic properties as shown in Figure 2.6 [21]. The authors verified that the static airflow resistivity can then be indirectly extrapolated and is comparable to the inverse method. However, their method requires that the tube be modified to include a third microphone. Dr. Ramakrishnan applied the three-microphone method in a previous study using similar sample sizes and equipment as the current study [39].

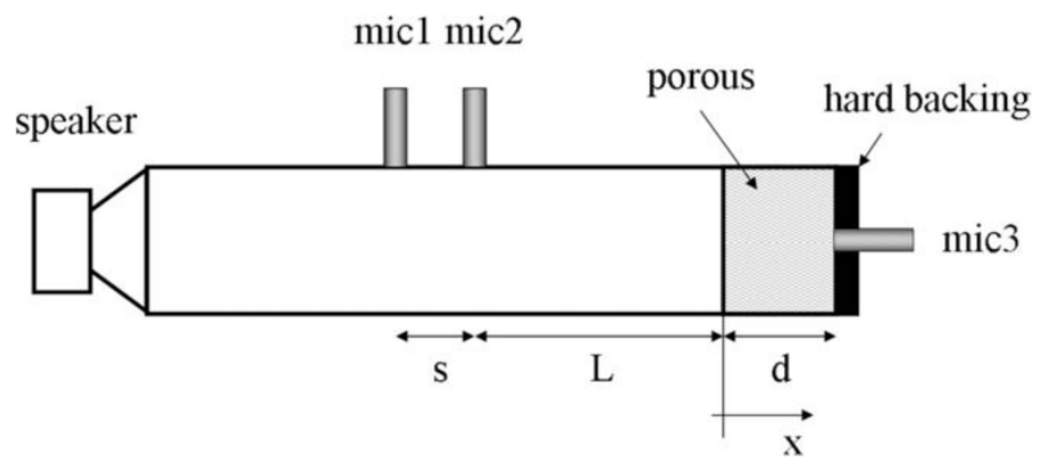

Figure 2.6 - Three-microphone impedance tube setup [21]

The thesis by Wolkesson stated that he was not able to obtain useful data from the initial three-microphone method [27]. He found that he required additional transfer function measurements.

An alternative method, proposed by Tao, Wang, Qiu, \& Pan, evaluated the static flow resistivity without modifying the tube or changing the sensor location for $2-8 \mathrm{~cm}$ thick samples [28]. Tao et al.'s method requires the sample to be positioned at a distance from the rigid end as shown in Figure 2.7. 


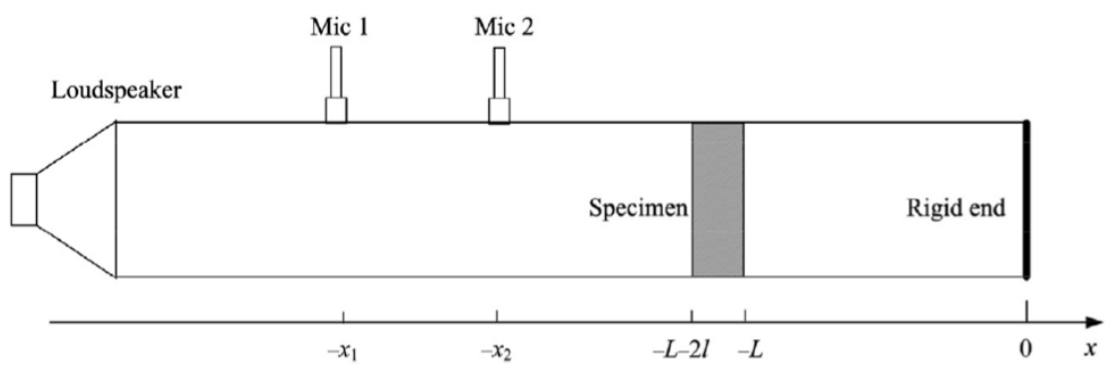

Figure 2.7 - Two-microphone impedance tube setup for flow resistivity [28]

Tao et al. applied the following Equations 2.3 to 2.6 that then led to the final flow resistivity calculation shown in Equation 2.7 [28]. Beginning with the specific acoustic impedance at the front face of the sample defined as $Z_{S}$.

$$
Z_{s}=\rho c \frac{1+r}{1-r}
$$

where $\rho$ is the air density, $c$ is the speed of sound and $r$ is the reflection coefficient. $Z_{m}$ is the characteristic impedance, $K_{m}$ is the propagation constant, and $Z_{L}$ is the acoustic impedance at the back surface of the sample. These parameters are defined below:

$$
\begin{aligned}
& Z_{L}=-j \rho \operatorname{ccot}\left(K_{m} L\right) \\
& Z_{m}=j Z_{s} \tan \left(2 K_{m} l\right) \\
& K_{m}= \pm \arctan \sqrt{\frac{Z_{L}}{Z_{s}}-\frac{Z_{s}^{\prime}\left(Z_{s}+Z_{L}\right)}{Z_{s}{ }^{2}}}
\end{aligned}
$$

where $Z_{S}$ is derived from when $L=0$ and $Z_{S}$ ' is from when $L$ is non zero. Finally, $\sigma$ is the flow resistivity.

$$
\sigma=-\lim _{\omega \rightarrow 0} \operatorname{Im}\left(Z_{m} * K_{m}\right)
$$

\subsection{Specifics of Sample Manufacture}

Prior to testing the specimens, available data on these materials were first analysed. One fiberglass sample and three varying dense mineral wool were selected for testing. At the time of testing, general material properties were obtained from the manufacturer and from a related paper. These properties are summarized in the following table. It appears that the sample type name has been updated from DD2 to DD. 
Table 2.2 - Sample Properties

\begin{tabular}{|c|c|c|c|}
\hline Material Type & Sample Type & Density $\left(\mathbf{k g} / \mathbf{m}^{\mathbf{3}}\right)$ & Fiber diameter $(\boldsymbol{\mu m})$ [3] \\
\hline \multirow{3}{*}{ Mineral wool } & R24 & $32[29]$ & \multirow{2}{*}{$3-10$} \\
\cline { 2 - 3 } & AFB & $45[30]$ & \multirow{2}{*}{$3-10$} \\
\cline { 2 - 3 } & DD & $\begin{array}{c}\text { Outer layer: 100 } \\
\text { Inner layer: 65 [31] }\end{array}$ & \\
\hline Fiberglass & EcoTouch & $12.2[32]$ & $6-13$ \\
\hline
\end{tabular}

Figure 2.8 is a graph showing testing data of absorption coefficient over $1 / 3$ octave frequency band using a reverberation room based on ASTM C423 for the sample types DD and AFB based on manufacturer's data. There was no acoustic data available for the R24 or fiberglass material.

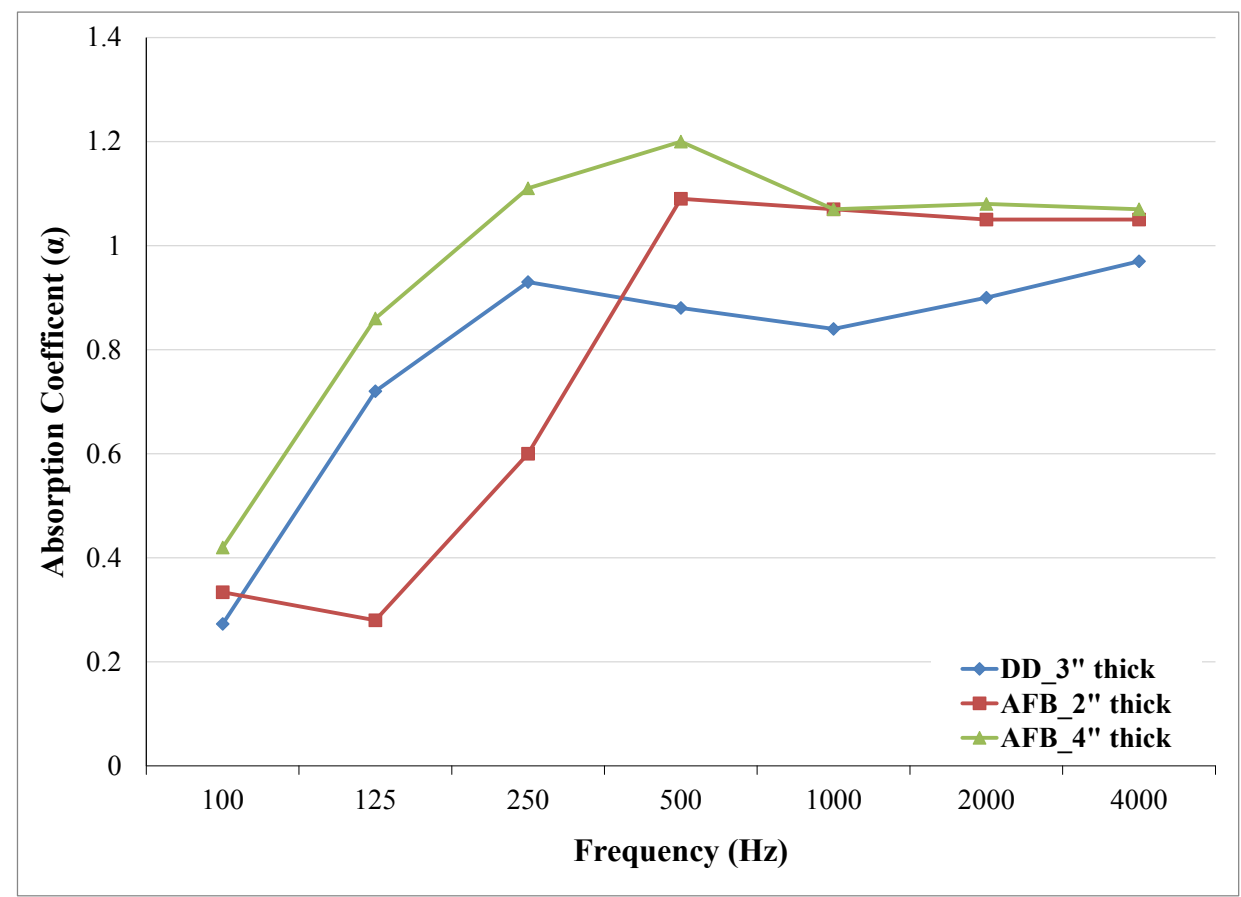

Figure 2.8 - Manufacturer's data based on ASTM C423 [30, 31]

The difference in testing methods and standards between the manufacturer's data and the current paper's study indicate the two data sets cannot be used for comparison. However, a general observation within the data set in Figure 2.8 can still be analyzed. Based on the graph, between the AFB samples, the 4" sample has a higher absorption coefficient than the 2" sample until $1000 \mathrm{~Hz}$. The difference in absorption coefficient between the two thicknesses is less noticeable above $1000 \mathrm{~Hz}$, as the lines begin to merge. The 3" DD sample has the lowest absorption performance among all the samples past $400 \mathrm{~Hz}$. 
Manufacturers commonly use the reverberation room method (ASTM C423 and ISO 354) to obtain absorption coefficient measurements. As shown in Figure 2.8, the absorption coefficient reaches beyond 1.0, which suggests that the energy absorbed is greater than the incident energy applied. An acoustic coefficient greater than 1.0 is a common misrepresentation mainly due to edge refraction or edge effect in the reverberation room testing method. A large difference was found when trying to correlate the results following various standards for obtaining the absorption coefficient [33]. The authors explored different shapes (circular or rectangular), orientations, areas and perimeters when testing in a reverberation room. The paper concluded that the edge effect plays a dominant role, and the authors believe that ASTM C423 and ISO 354 may be inaccurate in determining the absorption coefficient.

\subsection{Compression - What is the impact?}

Seddeq stated that there is little published research available on the absorption behaviour of compressed insulation [2]. However, a widely cited paper by Castagnède, Aknine, Brouard and Tarnow compared uncompressed and compressed fibrous material used in the automotive industry [34]. The authors found that, as the material is compressed, there is a strong decrease in absorption coefficient due to a "thickness effect". The thickness effect, or change in thickness from compression, was thought to be the main explanation that led to a decrease in results; even though Castagnède et al. found that compression of the porous layers affected other properties such as porosity, characteristic length, tortuosity and flow resistivity.

\subsubsection{Absorption Coefficient Compression Impact}

Iannace, Ianniello and Basturk combined Castagnède et al.'s previously reported graphs. The result was a comparison between the uncompressed $50 \mathrm{~mm}$ thick polyester fiber sample and compressed $31 \mathrm{~mm}$ thick sample's absorption performance shown in Figure $2.9[35]$. 


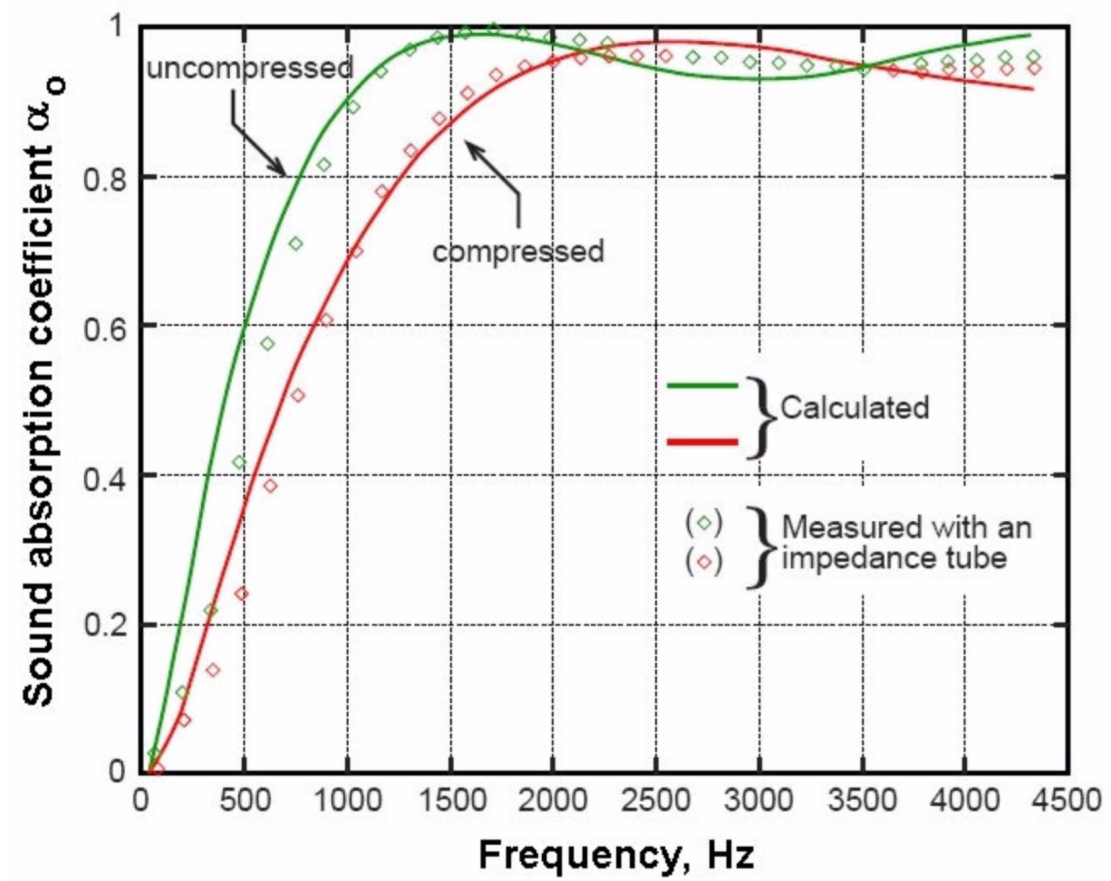

$(-)$ calculated uncompressed (50 mm thick); $(-$ ) calculated compressed (31 $\mathrm{mm}$ thick); $(\diamond)$ measured uncompressed; $(\diamond)$ measured compressed.

Figure 2.9 - Absorption coefficient vs frequency of a layer of polyester fiber [35]

Figure 2.9 illustrates a decrease in absorption coefficient associated with compression (green to red lines) from $250 \mathrm{~Hz}$ to $2000 \mathrm{~Hz}$. In the higher frequency range, past $2000 \mathrm{~Hz}$, the difference is not as significant and it appears that the lines crisscross and merge. Iannace et al. also pointed out that the behaviour identified may be specific to the samples used.

\subsubsection{Flow Resistivity Compression Impact}

Wang, Kuo and Chen proposed to treat the material under an elastic frame rather than a rigid frame [36]. They concluded that if the resistivity is large, then the effect of frame elasticity should be applied. In agreement with Castagnède et al., the authors concluded that compression improves the flow resistivity. Castagnède et al. concluded that the flow resistivity of a porous material is proportional to the 1D compression rate [34].

Numerically, the compression rate can be defined by Equation 2.8.

$$
\mathrm{n}=\frac{\mathrm{t}_{\mathrm{o}}}{\mathrm{t}_{\mathrm{n}}}
$$

where $t_{o}$ is the original thickness, and $t_{n}$ is the compressed thickness. 
The compression rate can then be used to calculate the compressed flow resistivity, as shown in Equation 2.9.

$$
\sigma_{\mathrm{c}}=\mathrm{n} \sigma
$$

where $\sigma$ is the original flow resistivity, and $\sigma_{c}$ is the compressed flow resistivity. Besides the study by Castagnède et al. there is relatively little research available in flow resistivity of compressed insulation. 


\subsection{Research Questions}

The main objective of the current research is to experimentally study the effects of various compressive loads on the acoustic performance of porous fibrous materials (fiberglass and mineral wool). The overall objective can be divided into the following sub-objectives:

1) Experimentally examine the absorption coefficient and flow resistivity for various compressive loads.

2) Determine the steps to experimentally perform Tao et al.'s novel approach on compressed insulation to find flow resistivity.

3) Compare results based on Tao et al.'s approach with the previous results based on Doutres et al.'s three-microphone method.

4) Explore the various experimental errors that might have occurred during setup and testing. 


\subsection{Methodology}

A total of 64 samples of fiberglass and mineral wool specimens with various thicknesses and under various compressive loads were tested in accordance to ISO 10534-2:1998 [22]. The testing lab was measured to be at $23^{\circ} \mathrm{C}$.

\subsection{Absorption Coefficient}

\subsubsection{Sample Preparation}

Li stated that the experimental variation can occur due to three factors [37]. The first one is manufacturing inconsistency that leads to uneven thickness and density. Secondly, inconsistent sample size and shape. Lastly, impedance tube mounting. Portions of the sample preparation and test methodology were designed to control for these three factors.

To control sample size and shape, the samples were cut using a band saw and a compass cutter to the desired dimensions and thickness. The circular samples were prepared by piercing a hole through the centre to act as a holder. The process was completed as an attempt to maintain a uniform shape between all the samples.

To test for manufacturing inconsistency, two different samples of each type were tested for each tube. In total, 64 samples were used in the experiment. Thirty-two samples were only tested in their uncompressed state. Thirty-two more samples were first tested in their original thickness before being tested in a compressed state. Table 4.1 details the type of samples and varying thicknesses tested.

Table 4.1 - Sample Varying Heights

\begin{tabular}{|c|c|c|c|c|c|}
\hline Material Type & Sample Type & $\begin{array}{l}\text { Un } \\
\text { (Ori }\end{array}$ & $\begin{array}{l}\text { ssed } \\
\text { leight }\end{array}$ & \multicolumn{2}{|c|}{$\begin{array}{c}\text { Compressed } \\
\text { Height }\end{array}$} \\
\hline Fiberglass & Fiberglass & \multirow{4}{*}{$2 "$} & \multirow{4}{*}{$4 "$} & $2 "$ to $1 "$ & 4" to 2" \\
\hline \multirow{3}{*}{ Mineral wool } & R24 & & & $2 "$ to $1 "$ & 4" to 2" \\
\hline & AFB & & & 2" to $1.5 "$ & 4" to 3" \\
\hline & DD2 & & & $\mathrm{N} / \mathrm{A}$ & $\mathrm{N} / \mathrm{A}$ \\
\hline
\end{tabular}

Photograph 4.1 shows the 4" thick square samples used, while Photograph 4.2 shows different thicknesses and compression rates of circular samples tested. 


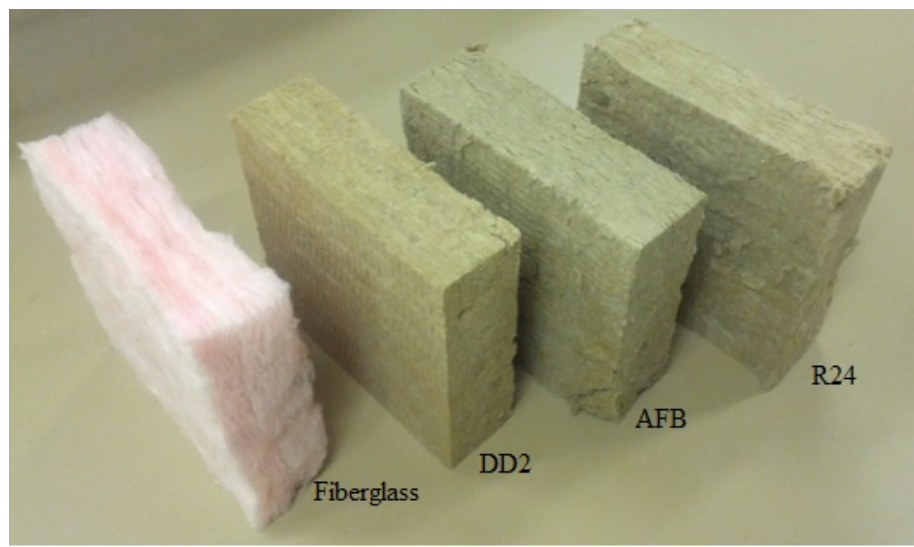

Photograph 4.1 - 4" square samples

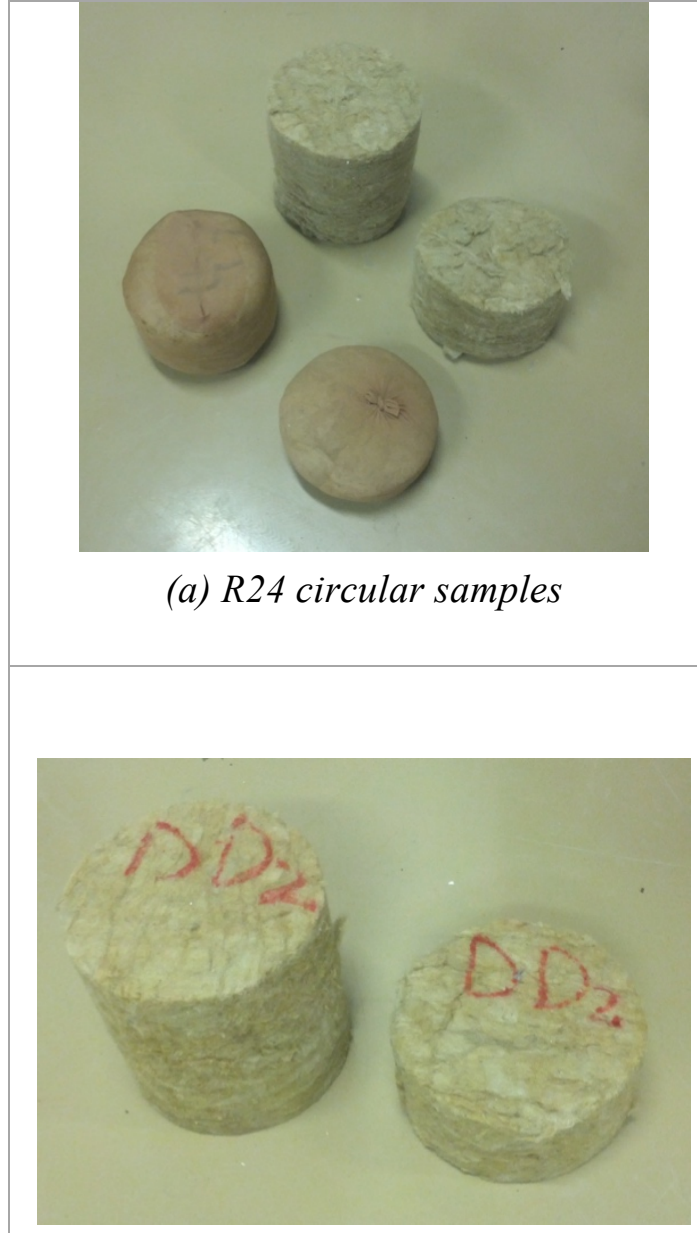

(c) DD2 circular samples

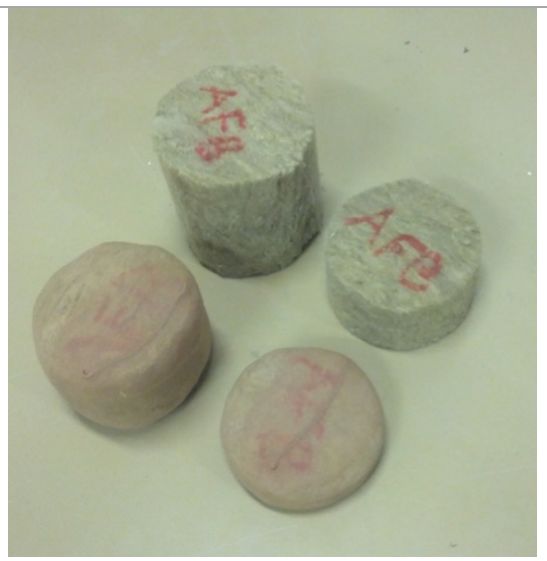

(b) AFB circular samples

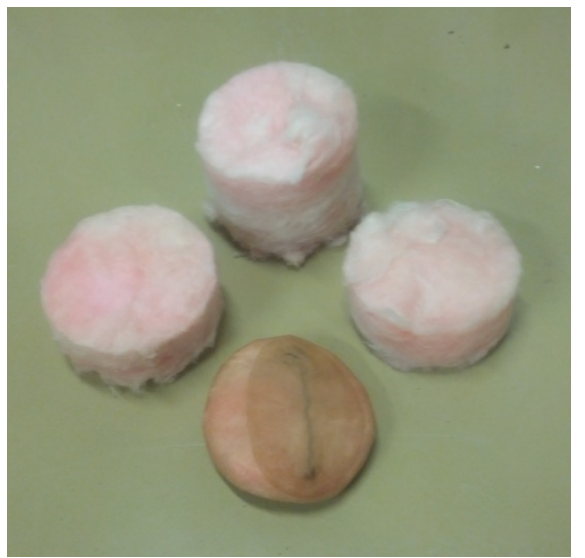

(d) Fiberglass circular samples

Photograph 4.2 - Circular samples

It is important to note that the uncompressed sample was tested first, followed by compressing the same sample and testing again. In the current study, compression rates of 1 and 2 were investigated. However, for some of the denser samples, only a 
compression rate of 1.3 could be achieved. The DD2 samples were too dense to enable compression.

The circular impedance tube does not have a sample holder. Therefore, the compression of the circular samples was achieved by wrapping the samples using nylon stockings. The stockings were knotted at the end to keep the enclosed samples compressed. Several variations of the compression were tested and compared to find the best orientation. The nylon was believed to act as an acoustically transparent membrane without causing much resonance effect.

Unlike the circular samples, the compression for the larger square samples was accomplished by pushing the rigid end plunger into the sample holder. For the denser samples such as R24 and AFB, eight blocks of bricks were built up at the back of the plunger to help maintain the hold of the compressive state, as seen in Photograph 4.3.

\subsubsection{Instrumentation}

Two different impedance tube types were used for the current experiment. Table 4.2 tabulates the two sizes, dimensions, and frequency ranges. Figure 4.1 shows the layout of the equipment, and Photograph 4.3 shows the equipment.

The lower and upper frequency ranges for these impedance tubes were previously determined using Equations 4.1 and 4.2 respectively.

$$
\begin{aligned}
& f_{L_{-} t u b e}=\frac{0.05 c}{s} \\
& f_{u_{-} t u b e}=\min \left(\frac{0.5 c}{\text { diameter }}, \frac{0.45 c}{s}\right)
\end{aligned}
$$

where $c$ is the speed of sound, and $s$ is the distance between the microphones.

Table 4.2 - Impedance Tubes Details

\begin{tabular}{|c|c|c|c|c|}
\hline Description & $\begin{array}{c}\text { Diameter or Side } \\
\text { Length ' } \boldsymbol{\varnothing} \text { ' }(\mathbf{c m})\end{array}$ & $\begin{array}{c}\text { Distance 's' } \\
\mathbf{( c m )}\end{array}$ & $\begin{array}{c}\text { Distance } \\
\text { 'L' (cm) }\end{array}$ & $\begin{array}{c}\text { Frequency } \\
\text { Range (Hz) }\end{array}$ \\
\hline Small Circular Tube & 10.2 & 5.1 & 10.2 & $335-1650$ \\
\hline Custom Square Tube & 34.3 & 30.5 & 16.5 & $50-500$ \\
\hline
\end{tabular}




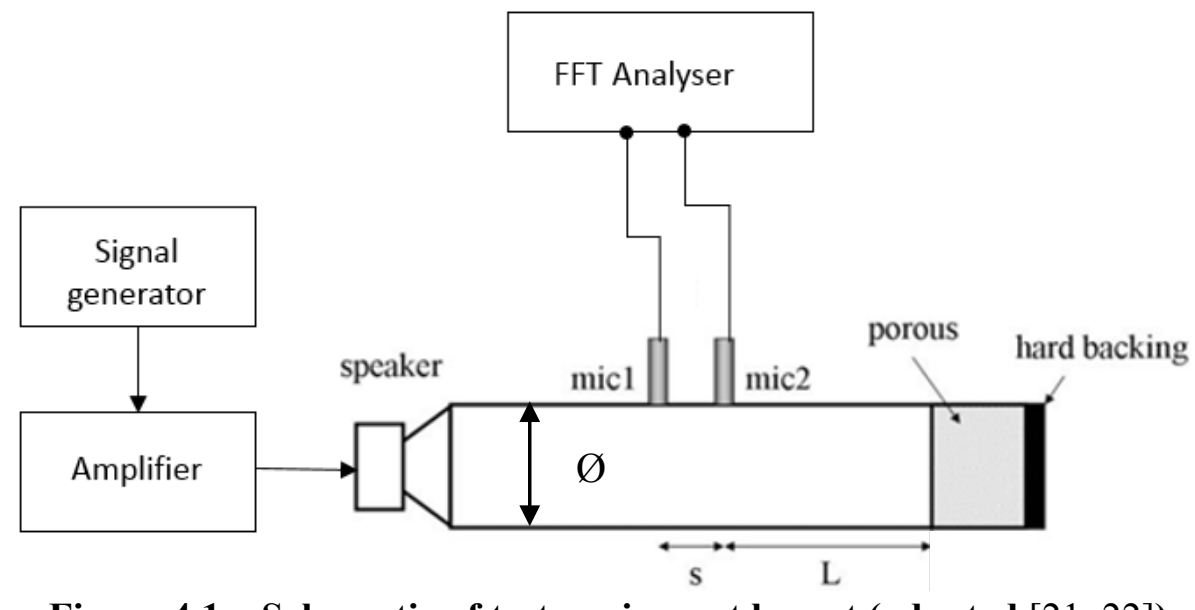

Figure 4.1 - Schematic of test equipment layout (adapted [21, 22])

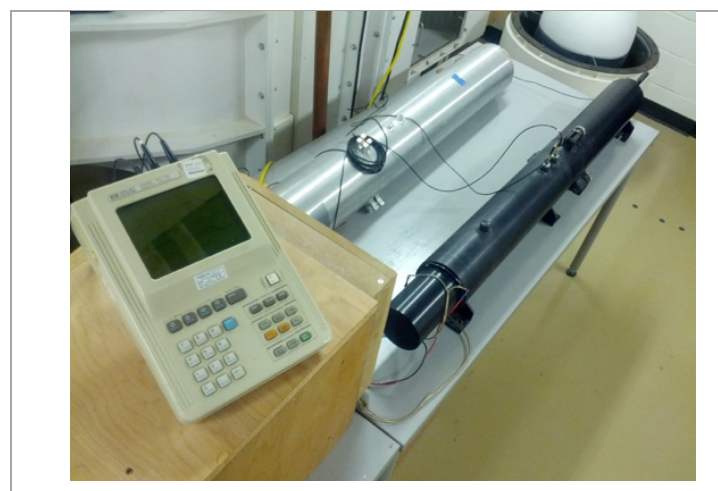

(a) Circular impedance tube and FFT Analyser

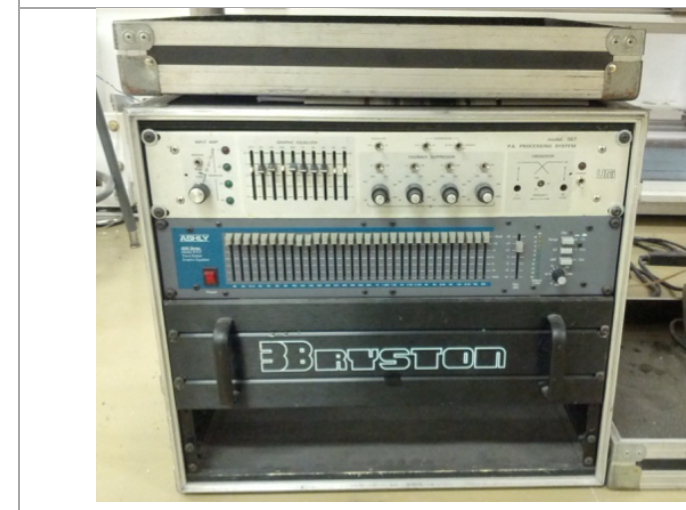

(b) Signal generator and amplifier

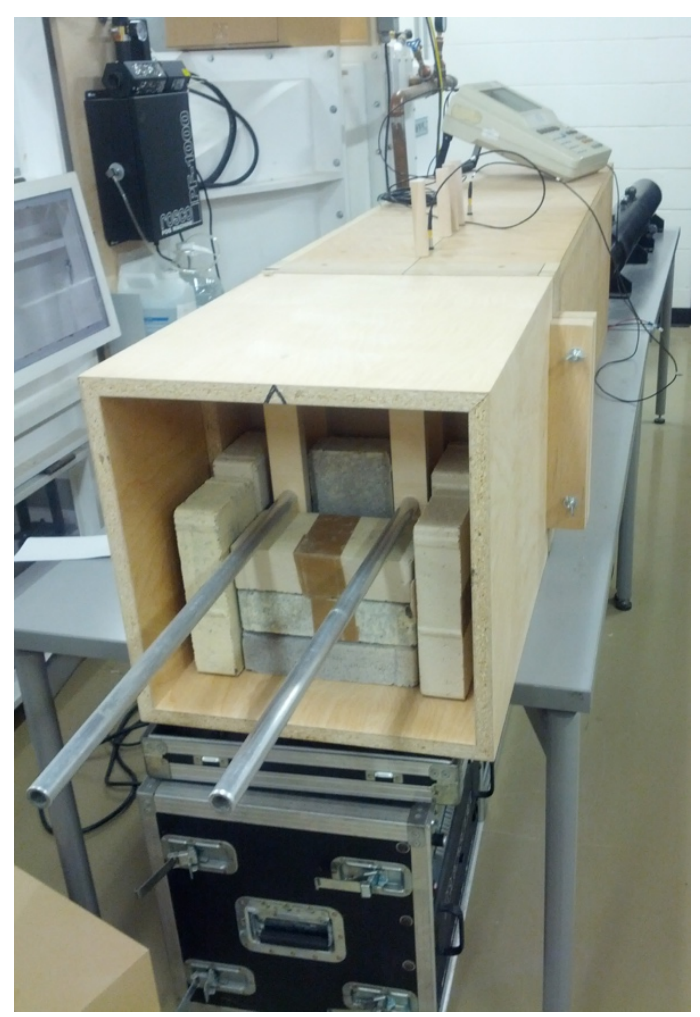

(c) Square impedance tube with bricks

\section{Photograph 4.3 - Lab instrumentation}

A stationary random acoustic signal (white noise) was generated using the PA processing system (Model 567) and amplified by a 3Bryston which was connected to the speaker attached at the end of the impedance tube. Two $6.4 \mathrm{~mm}(1 / 4$ ") microphones (MPA416) were connected to a two-channel Fast Fourier Transform (FFT)/Real Time analyzer 
(HP3569A) and inserted into the impedance tube. Prior to each test, the microphones were checked to see if they were flush to the crown of the impedance tube.

Regular calibration was not completed, so the microphones may not be phase-matched. However, Chung and Blaser's switch method allows for data correction to minimize the phase difference. The transfer function $\mathrm{H}_{12}$ was measured first with the two microphones in their respective place. Then the transfer function $\mathrm{H}_{21}$ was measured by switching the connectors of microphone 1 and microphone 2 at the FFT analyzer. The FFT analyzer was used to calculate the transfer function between the signals from the two microphones.

Following Chung and Blaser's method, Dr. Ramakrishnan developed a Fortran code that transformed the transfer functions to find the reflection coefficient. The code - provided in Appendix B - outputs the frequency, real normalized surface impedance, imaginary normalized surface impedance and the absorption coefficient.

\subsection{Flow Resistivity}

Following the procedure outlined by Tao et al., the flow resistivity was experimentally calculated [28]. As discussed in Section 2.4.2, the method requires the experimental data of the surface impedance $(Z)$ from two scenarios:

- 1) when the rigid backing is flush with the sample $(\mathrm{L}=0)$

- 2) when there is a specific air gap behind the sample $(\mathrm{L}>0)$

Data collected from absorption coefficient tests accounted for the first scenario. Using the same samples and compressive loads, an air gap was added, and the switch method was repeated to fulfill the second scenario. In order to accommodate the air gap, a slight modification to the experimental setup, described below, was required. In the current study, a 2" air gap was chosen as the base case. A selected few samples were tested with a 4" and 6" gap.

For the circular impedance tube, the exact measured length (sample thickness plus either a 2" or a 4" air gap, as shown in Figure 2.7) was set for the rigid backing prior to mounting the sample. The sample was then placed into the tube for testing. 
For the square tube, three frames of 2", 4" and 6" shown in Photograph 4.4(a) were custom built to act as the air gap behind the sample. For samples that were denser, such as the R24 and AFB, a wire mesh was placed between the frame and sample to help maintain a uniform compression. Photograph 4.4(b) illustrates the proposed layout for a 2" frame air gap behind a wire mesh for a 4 " thick sample.

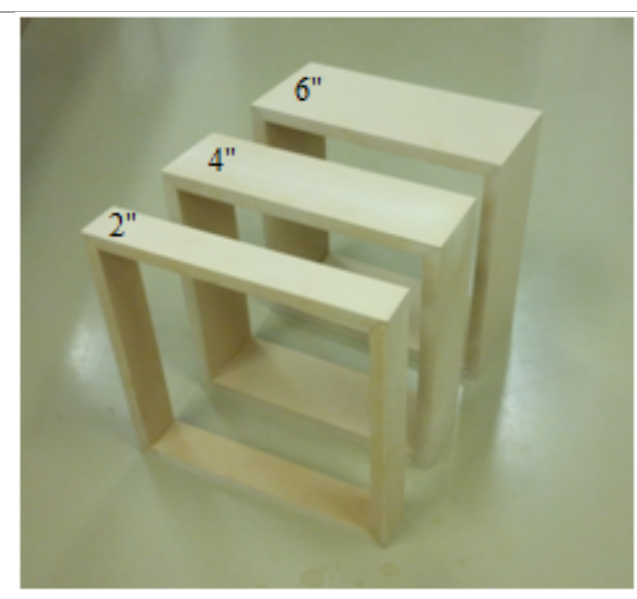

(a) Custom frames

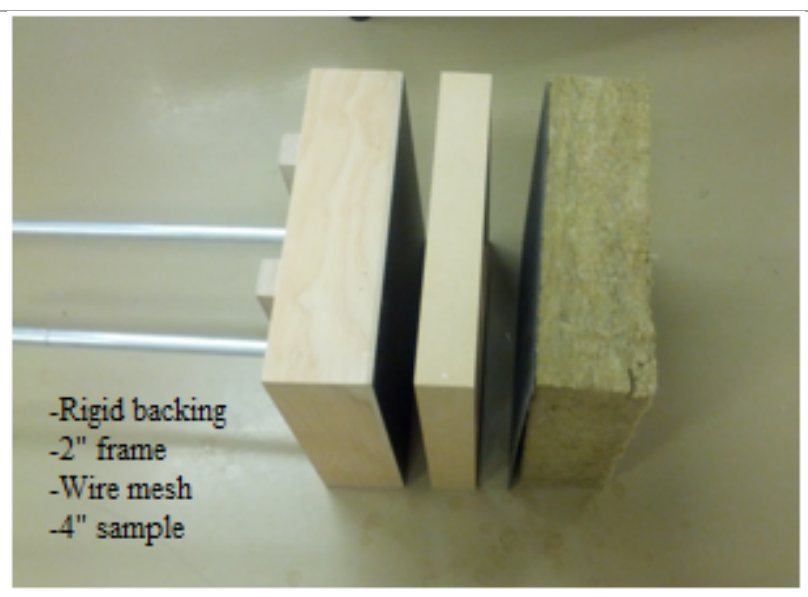

(b) Proposed Layout

\section{Photograph 4.4 - Custom square frames and proposed layout}

After the setup, the data was collected the same way as it was when testing the absorption coefficient, processed using the Fortran script. A Matlab script (found in Appendix B) was developed to follow Tao et al.'s method to calculate the flow resistivity. The Matlab script required two input files ( $\mathrm{L}=0$ and $\mathrm{L}>0$ ) generated by the Fortran script, in particular the values for frequency, real normalized surface impedance, and imaginary normalized surface impedance were used the Matlab script. 


\subsection{Pre-Testing Assessment}

Prior to testing, several parameters were checked and analysed.

\subsection{Symbols}

To help summarize and organize the findings, the following code system was developed and used in the graphs for ease of identification.

Table 5.1 - Graph and Terminology Definition

\begin{tabular}{|c|c|c|c|c|c|}
\hline & $\begin{array}{l}\text { Sample } \\
\text { and } \\
\text { Thickness }\end{array}$ & $\begin{array}{l}\text { Uncompressed } \\
\text { or Compressed }\end{array}$ & $\begin{array}{c}\text { Air Gap } \\
\text { behind } \\
\text { Sample }^{I}\end{array}$ & $\begin{array}{c}\text { White } \\
\text { Noise } \\
\text { Duration } \\
\text { (\# Taken) }\end{array}$ & Other $^{2}$ \\
\hline Symbol & $\begin{array}{l}\text { Letter plus } \\
\text { Numerical } \\
\text { (inches) }\end{array}$ & $\begin{array}{l}\text { Letter plus } \\
\text { Numerical } \\
\text { (inches) }\end{array}$ & $\begin{array}{l}\text { Letter plus } \\
\text { Numerical } \\
\text { (inches) }\end{array}$ & $\begin{array}{l}\text { Letter plus } \\
\text { Numerical }\end{array}$ & Letter \\
\hline $\begin{array}{l}\text { Example } \\
\text { Options }\end{array}$ & $\begin{array}{l}\text { - } \mathrm{Sq}_{2 "} \\
\text { - } \mathrm{Sq}_{4 \prime} \\
\text { - } \mathrm{Cir}_{2 "} \\
\text { - } \mathrm{Cir}_{4},\end{array}$ & $\begin{array}{ll}\cdot & \mathrm{U}_{\text {Uncompressed }} \\
\text { thickness" } \\
- & \mathrm{C}_{\text {Compressed }} \\
\text { thickness" }\end{array}$ & $\begin{array}{l}\text { - } L_{2 "} \\
\text { - } L_{4}^{\prime \prime} \\
\text { - } L_{6}^{\prime \prime}\end{array}$ & $\begin{array}{l}\text { - } \mathrm{P}_{200} \\
\text { - } \mathrm{P}_{400} \\
\text { - } \mathrm{P}_{600} \\
\text { - } \mathrm{P}_{800}\end{array}$ & $\begin{array}{ll}\text { - } & \mathrm{S}_{\text {stocking }} \\
\text { - } & \mathrm{K}_{\text {knotted }} \\
\text { - } & \mathrm{R}_{\text {ring }} \\
\text { - } & \mathrm{J}_{\text {PetroleumJelly }} \\
\text { - } & \mathrm{F}_{\text {frame }} \\
\text { - } & \mathrm{M}_{\text {mesh }} \\
\text { - } & \text { *observations }\end{array}$ \\
\hline
\end{tabular}

IThe "air gap behind sample" field only applies to the flow resistivity testing data.

${ }^{2}$ Other materials that were used in certain configurations to help achieve compression or other observations noted

For example, for an absorption coefficient testing sample, the term $R 24 \mathrm{Cir}_{4}{ }^{\prime \prime} \mathrm{C}_{2}{ } \mathrm{P}_{800} \mathrm{SKJ}$ represents a R24 circular 4" thick sample that has been compressed to 2" with a knotted stocking, applied with petroleum jelly and had 800 points collected.

Another example, for a flow resistivity testing sample, the term $A F B \_S q_{2}{ }^{\prime \prime} C_{1}{ }^{\prime \prime} L_{2}{ }^{\prime \prime} P_{400} F$ represents a AFB square 2" thick sample that has been compressed to 1" with a 2" frame that used to help maintain an air gap and had 400 points collected.

The following section describes the difference between different numbers of points collected. 


\subsection{White Noise Duration}

The FFT analyser has the ability to adjust the duration of the white noise, which is expressed as the number of points collected. The options of 200, 400, 600 and 800 points (which roughly translated to durations of $2 \mathrm{~min}, 6 \mathrm{~min}, 10 \mathrm{~min}$, and $16 \mathrm{~min}$, respectively) were tested to determine if white noise duration changed the results. There appeared to be an increase in accuracy when the number of points was increased. The following graph, Figure 5.1, compares the number of points - 200, 400, 600 and 800 - collected for the same 4" thick circular DD2 sample. It was determined that collecting 800 points gave more precision with a trend line that has the least amount of fluctuations. In general, the longer the averaging time, the closer the absorption coefficient approaches the theoretical value and the greater the accuracy [38].

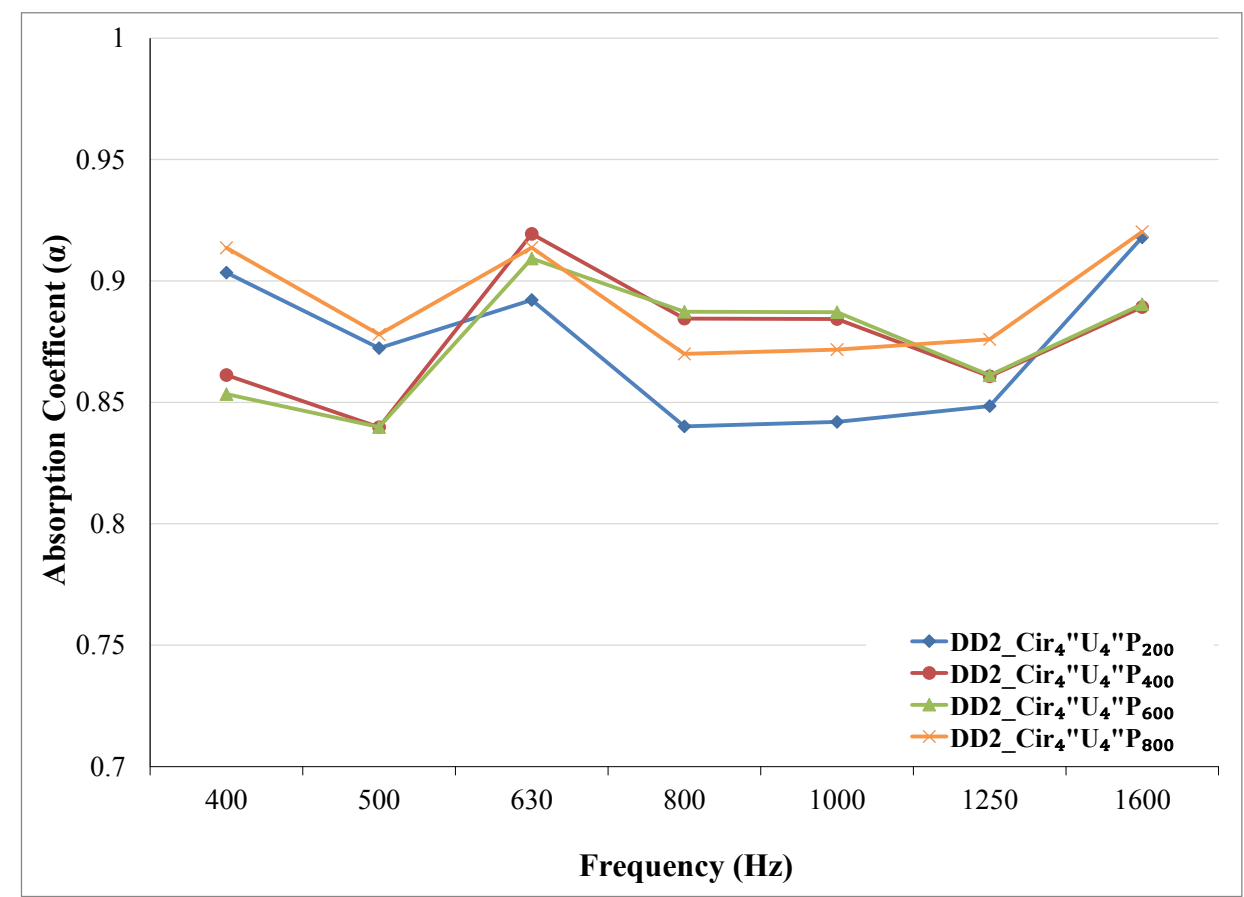

Figure 5.1 - Absorption coefficient of DD2 samples for different white noise durations

\subsection{Trial Testing}

A number of trial tests were completed to assess the variability of test results. 


\subsubsection{Circular Sample}

One particular 4" thick circular DD2 sample was repeatedly tested to validate the consistency of test results. Even though the data were not identical, there was a clear trend between the repeated results, as shown in Figure 5.2. A negligible difference can be seen in Figure 5.3, where the same results are presented in $1 / 3$ octave band rather than the narrow band shown in Figure 5.2.

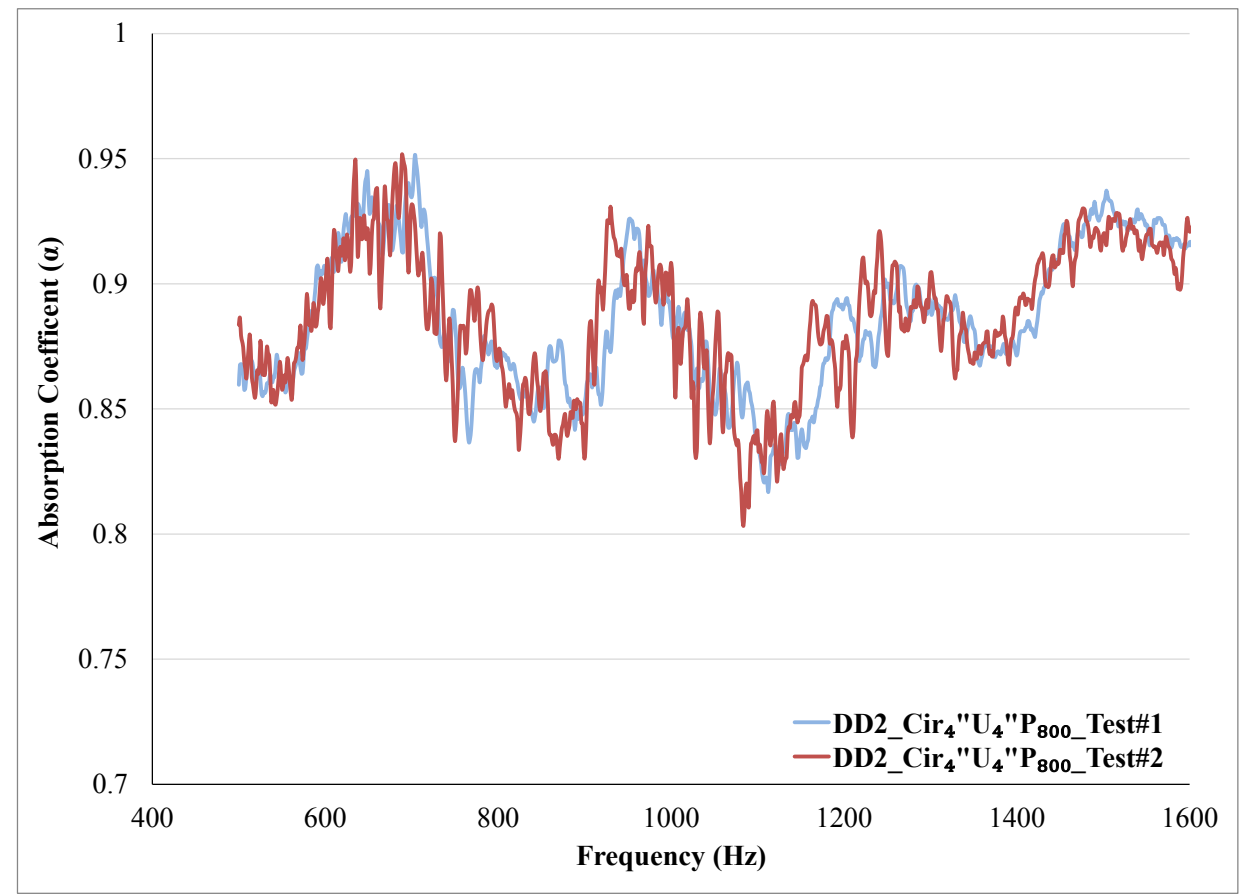

Figure 5.2 - Absorption coefficient for DD2 sample tested twice (Narrow band) 


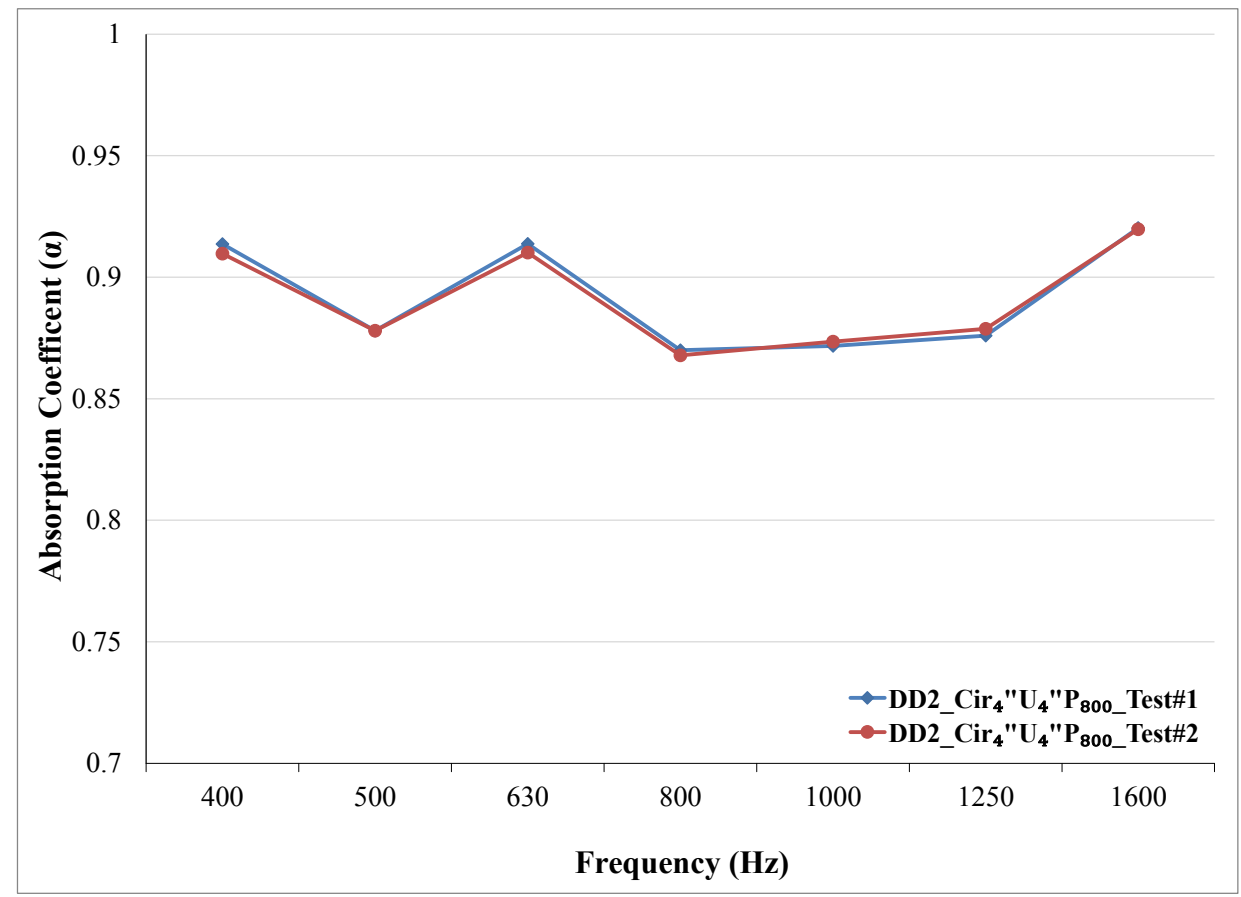

Figure 5.3 - Absorption coefficient for DD2 sample tested twice (1/3 Octave band)

\subsubsection{Variation Between Samples}

As indicated in the methodology, two different samples of each type were tested. Four separate circular DD2 samples were compared, in pairs of 2" and 4" thick samples, and are presented in Figure 5.4 below. 


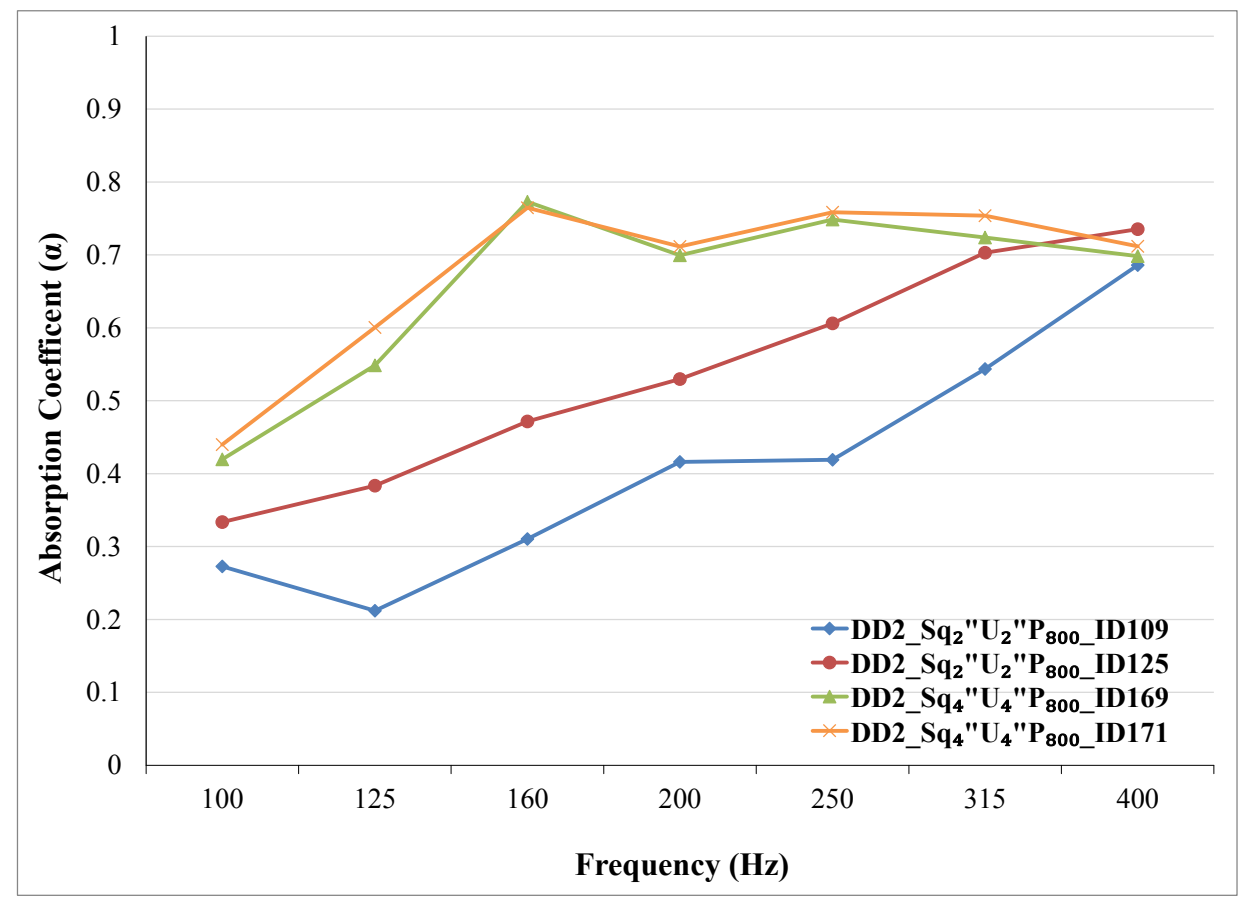

Figure 5.4 - Comparison of absorption coefficient for DD2 2" and 4" square samples

It is evident for these samples, that there was more variation among the 2" samples than among the 4" samples. The 4" thick samples showed a slightly larger difference than that shown in Figure 5.3 for repeated testing of the same sample. In contrast, there was, in average, a $25 \%$ difference in absorption performance between the two 2 " samples. Despite the difference, a similar pattern of gradual rise can be identified in both samples. 


\subsection{Results and Discussion}

As mentioned previously, the square and circular impedance tubes can measure the frequency ranges of $50-500 \mathrm{~Hz}$ and $350-1650 \mathrm{~Hz}$, respectively. To show continuity for samples of the same type, the results from two impedance tubes were combined into one graph. The results from two 4" AFB samples (one circular and one square) are shown in Figure 6.1. The cut-off at $400 \mathrm{~Hz}$ is marked by the orange dash line.

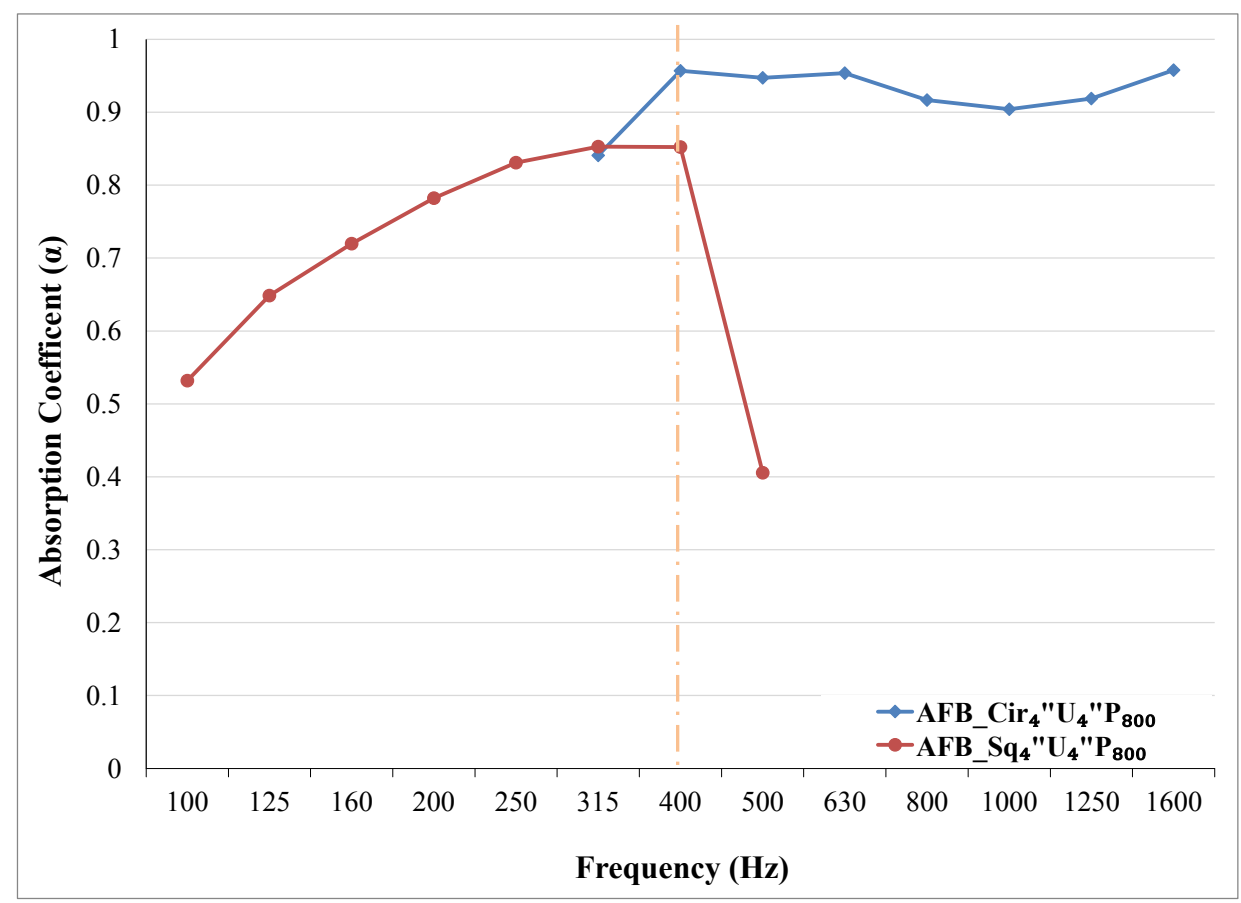

Figure 6.1 - Combination of absorption coefficient for AFB 4" samples

It is important to emphasize that there are two distinct samples (one circular and the other square) illustrated in Figure 6.1.

\subsection{Absorption Coefficient}

Results for the absorption coefficient are discussed in this section.

\subsubsection{Sample Types Comparison}

All the uncompressed samples were compared, as shown in Figure 6.2 and Figure 6.3.

The overall trend observed was that the denser the material, the more stable the data. The fiberglass sample (the least dense material among those tested) experienced a lot of noise 
and unpredictability. The 4" uncompressed samples are plotted together as a comparison between materials in Figure 6.2.

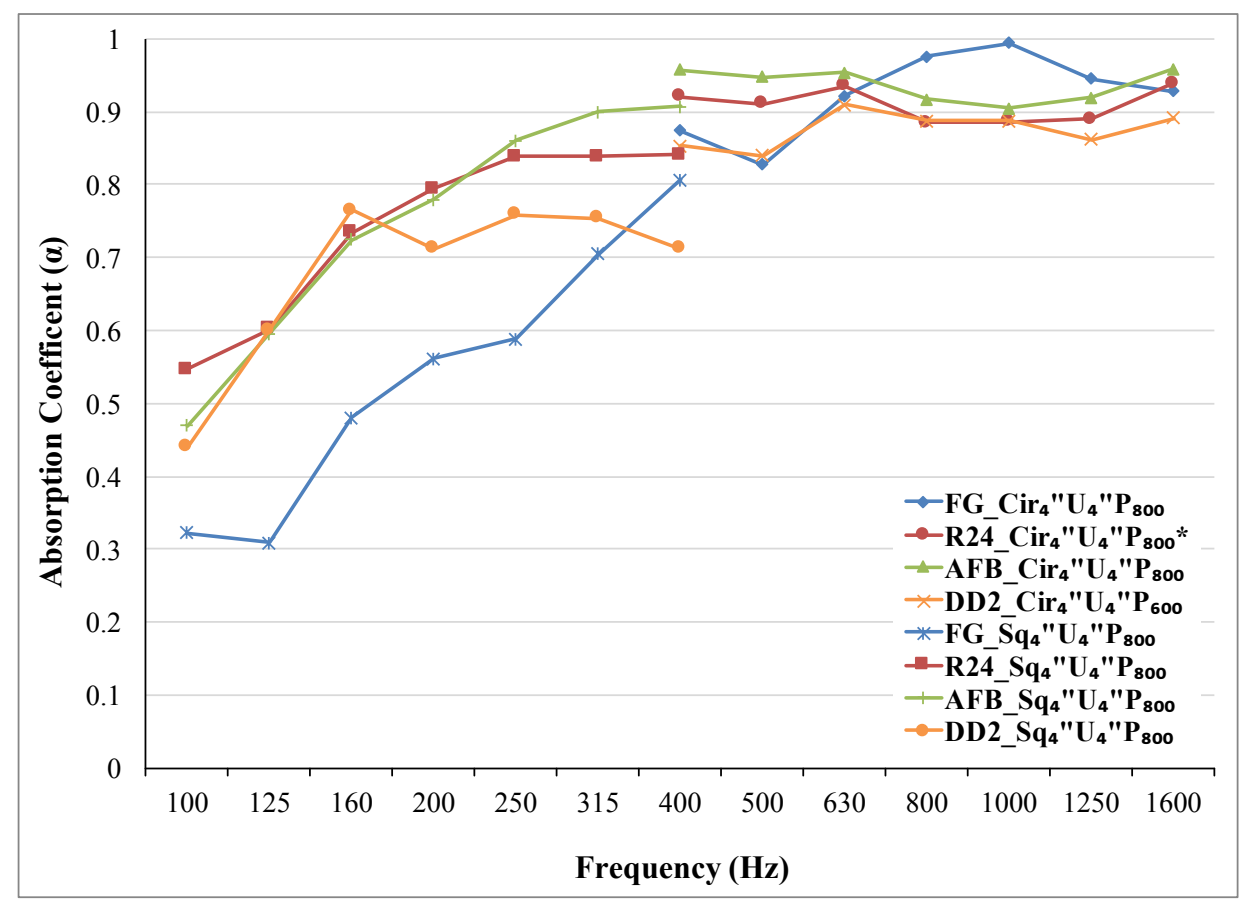

Figure 6.2 - Absorption coefficient for various uncompressed 4" samples

The fiberglass 4" square sample had the lowest absorption coefficient, but the corresponding circular sample approached an absorption coefficient of 1 around $800-1100 \mathrm{~Hz}$, before plateauing. R24 and AFB displayed very similar behaviour. AFB did surpass R24 around $200 \mathrm{~Hz}$ and had a slightly higher absorption performance. Being the densest sample, DD2 performed below the R24 and AFB samples.

Figure 6.3 shows how the various uncompressed 2" samples compare to each other. Comparing Figure 6.2 (4") to Figure 6.3 (2"), it is more evident that the thicker the sample, the more stable the results, especially evident in the fiberglass sample. 


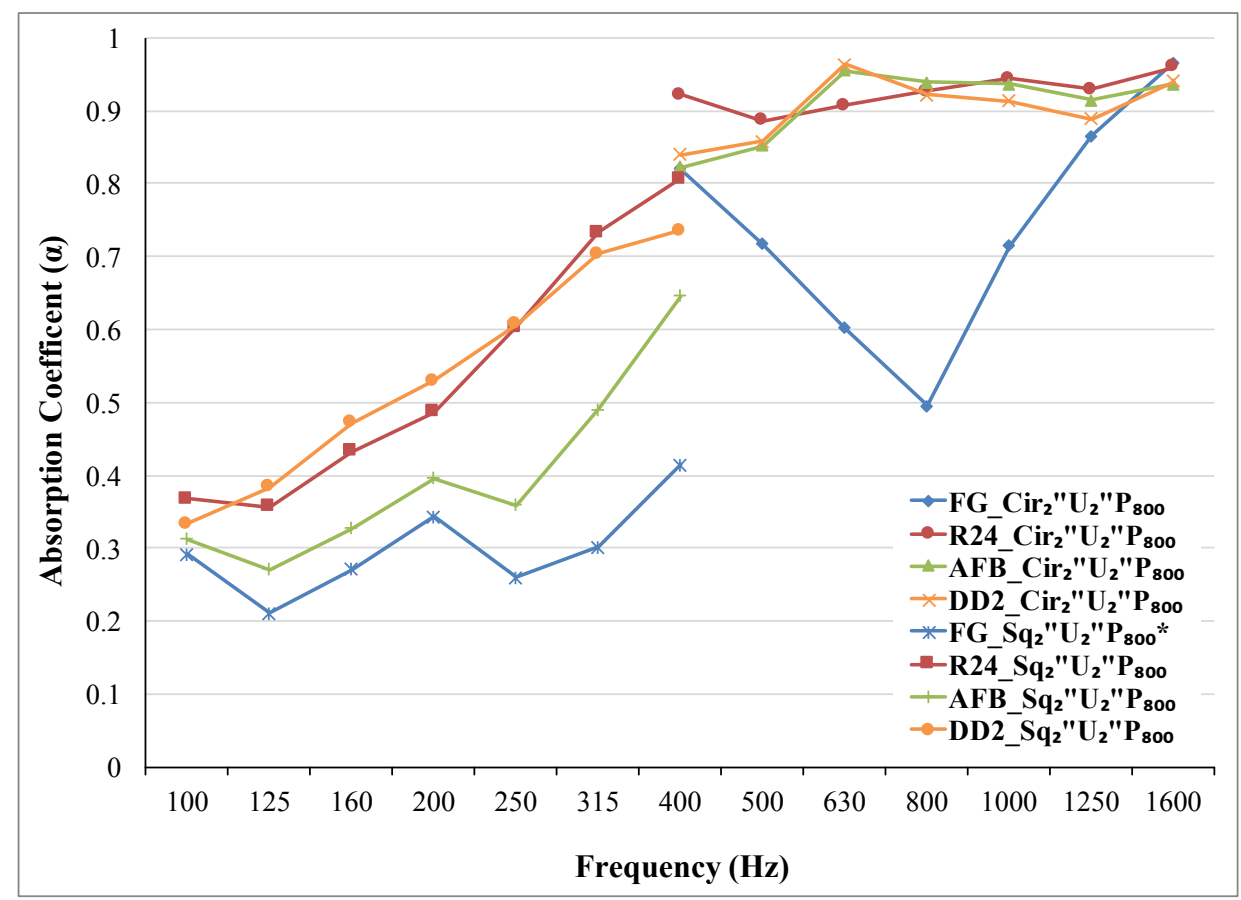

Figure 6.3 - Absorption coefficient for various uncompressed 2" samples

With the exception of fiberglass, all the $2 "$ circular samples in the higher frequency range behaved similarly to the 4" circular samples. On the other hand, in the lower frequency range, R24 and DD2 were more alike, while AFB had a lower absorption coefficient followed by the fiberglass sample.

\subsubsection{Fiberglass}

Of all the different samples, the fiberglass presented the most leakages, especially in the circular samples. Preparing and mounting the fiberglass was very difficult, especially the 2" sample.

Results from eight different tests of fiberglass were plotted together in Figure 6.4. 


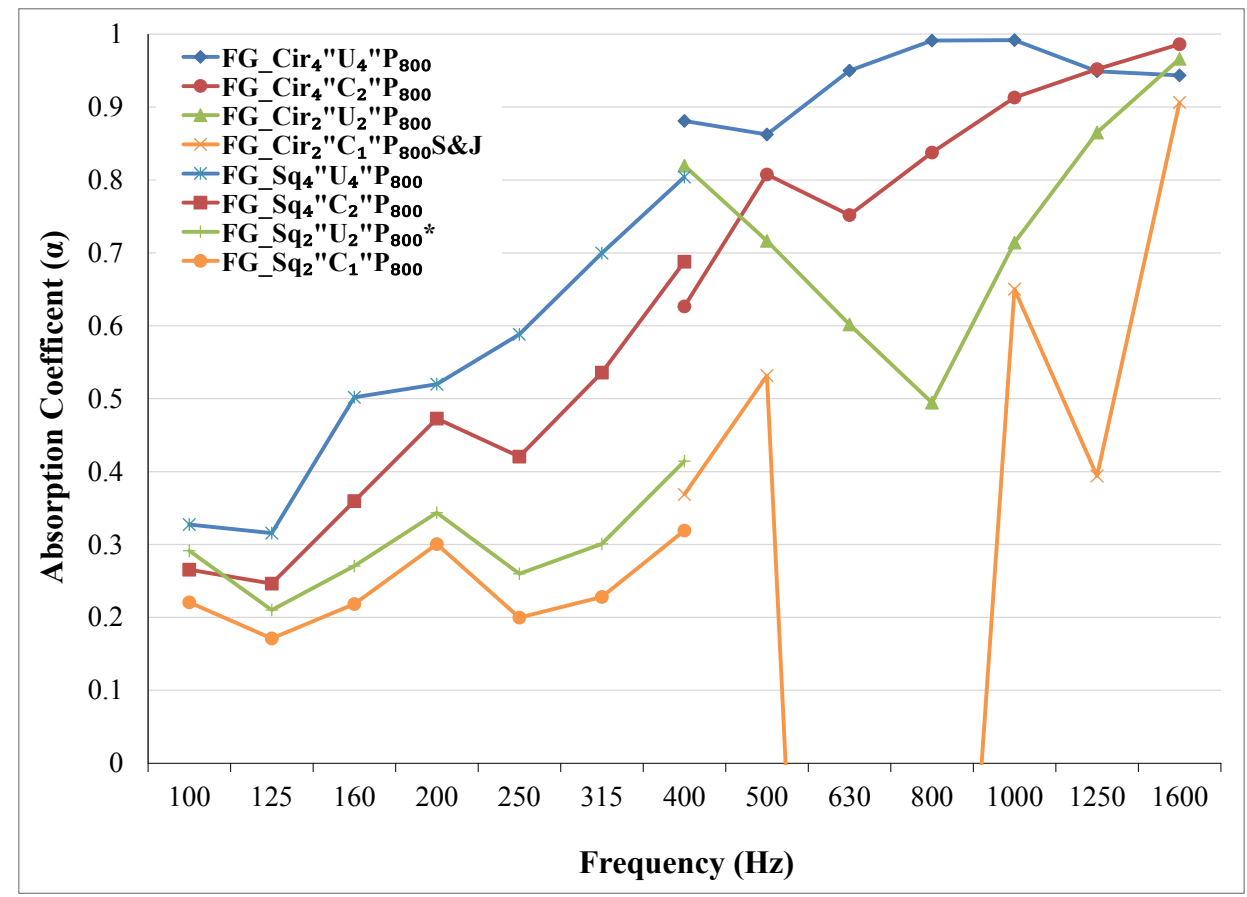

Figure 6.4 - Absorption coefficient results for fiberglass 2" and 4" samples

There was a strong relationship between the thickness of the sample and the decrease in the absorption coefficient. Starting from top to bottom, the 4" uncompressed sample had the highest absorption performance, followed by the 4" compressed to 2", then the 2 " uncompressed and lastly the 2" sample compressed to 1". Figure 6.4 also revealed that for both uncompressed and compressed circular 2" thick samples there were a lot of leakages and fluctuations. The 2" circular uncompressed sample showed a gradual dip to $800 \mathrm{~Hz}$ before rising again. For the 2" compressed sample, the absorption coefficient dipped below 0 between $630 \mathrm{~Hz}$ and $800 \mathrm{~Hz}$.

Several alternative configurations that included compression with a stocking, no stocking, adding a ring, or applying petroleum jelly were used as attempts to improve the testing results. Unfortunately, there was no clear improvement, as discussed in Chapter 7.0 Experimental Errors/Limitations.

\section{$6.1 .3 R 24$}

The R24 sample had similar behaviour to the fiberglass, with many leakages. The 1" compressed material experienced much more fluctuations than the uncompressed 2" counterpart. A clear degraded performance (less absorption) was displayed in lower 
frequencies for compressed samples. The compressed R 24 results did not experience the same extent of fluctuations or noise as the compressed 2" fiberglass.

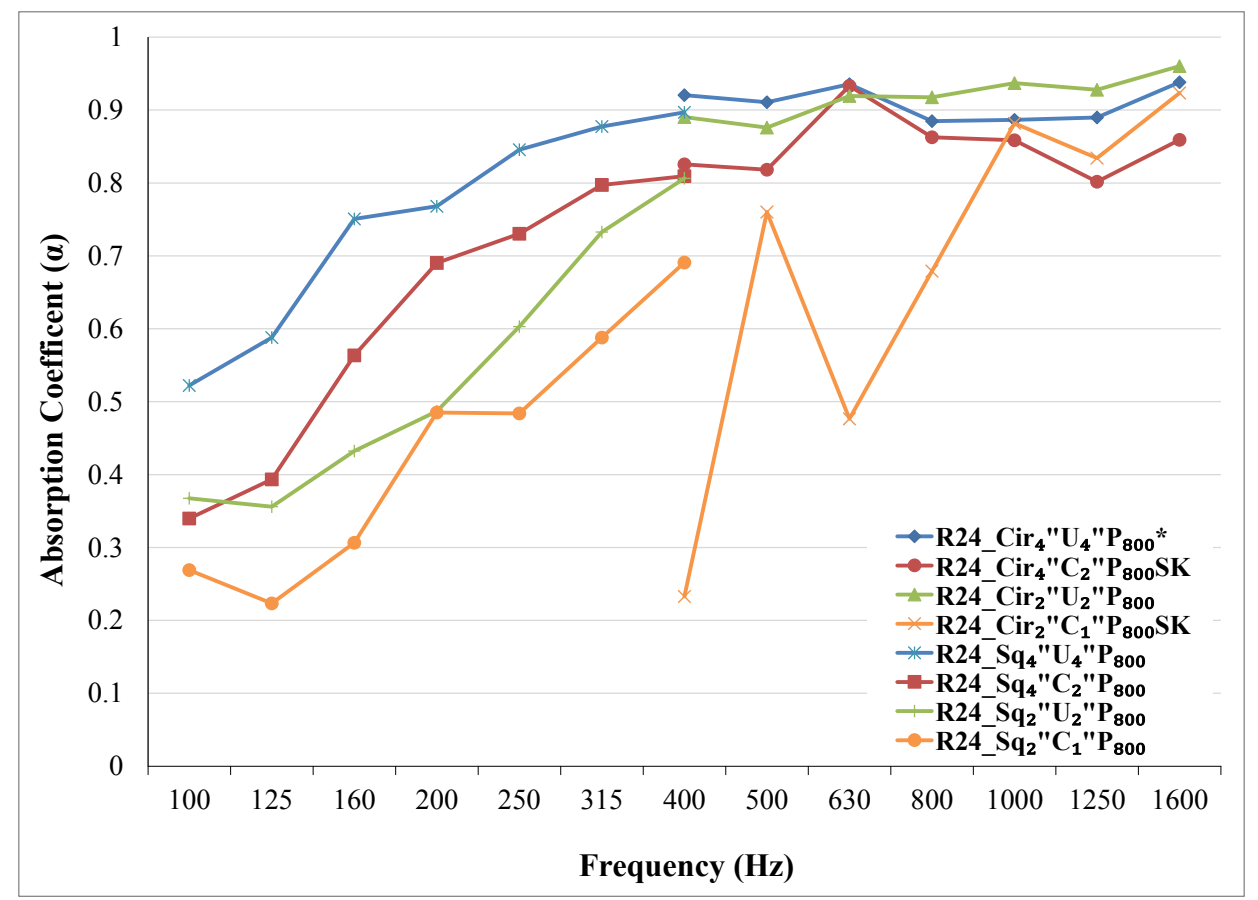

Figure 6.5 - Absorption coefficient results for R24 2" and 4" samples

Similarly to Iannace et al.'s results, shown in Figure 2.9, the reduction in absorption coefficient due to the thickness effect was most evident in the lower frequency ranges. The data seemed to be less sensitive to the thickness difference. Especially past $630 \mathrm{~Hz}$, the 2" uncompressed sample surpassed the 4 " uncompressed sample. There was an average decrease of $6 \%$ and $15 \%$ when the R24 sample was compressed from 4" to 2", for the circular and square samples, respectively.

Alternative methods for compressing the circular sample using a stocking and a ring added, did not improve the quality of the data. There was a strong resonance at $630 \mathrm{~Hz}$ and a minor one at $1200 \mathrm{~Hz}$ when the sample was compressed.

\subsubsection{AFB}

As the AFB sample was compressed, the absorption coefficient slightly lowered. Due to the high density of the sample, neither the 4" square sample or the 2" circular sample could achieve the compression rate of 2 ; a maximum compression of 1.3 was achieved. 


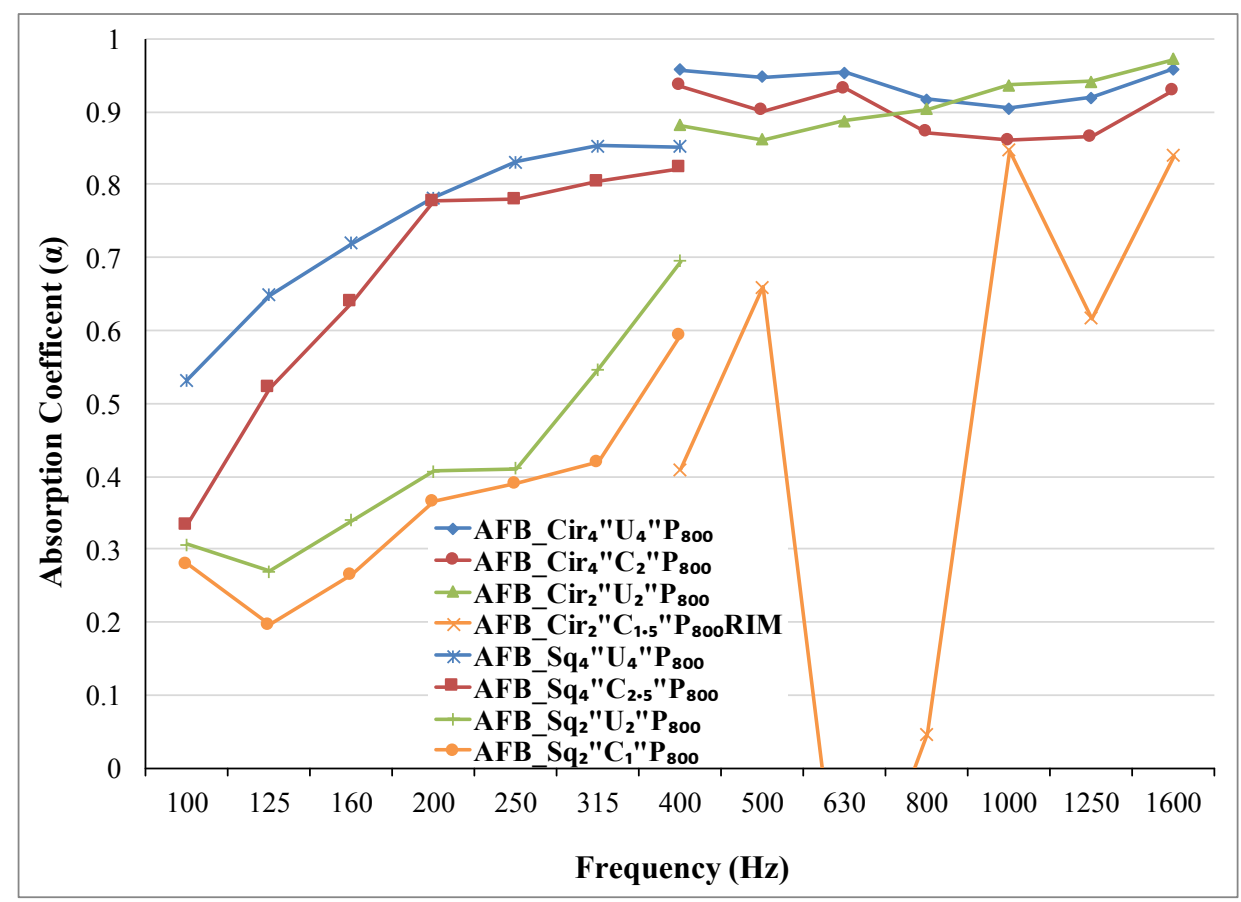

Figure 6.6 - Absorption coefficient for AFB 2" and 4" samples

Figure 6.6 shows a similar pattern to Figure 6.5 for the R24 samples. As the AFB circular sample was compressed from 4" to 2 " there was an average $4 \%$ decrease in absorption coefficient, while in the square sample compressed from 4 " to 2.5 " the average decrease was $6 \%$. The compressed samples exhibited more instability in the results. The 2 " uncompressed sample surpassed the 4" uncompressed sample above $800 \mathrm{~Hz}$. Similarly to the fiberglass and R24 samples, the 2" circular sample compressed to 1" was not stable.

\subsubsection{DD2}

Figure 6.7 shows various uncompressed thicknesses and dimensions for the DD2 specimens along with the manufacturer's data from $100 \mathrm{~Hz}$ to $2000 \mathrm{~Hz}$. Overall, both sets (circular or square) of DD2 samples could not be compressed with the use of the nylon stocking or the bricks. However, using a custom circular ring as a holder, a 4" sample was compressed to 3 " by pushing the rigid backend into the sample. Results for this test showed that the 4" compressed sample decreased in absorption coefficient; however, more noise was present in the data. 


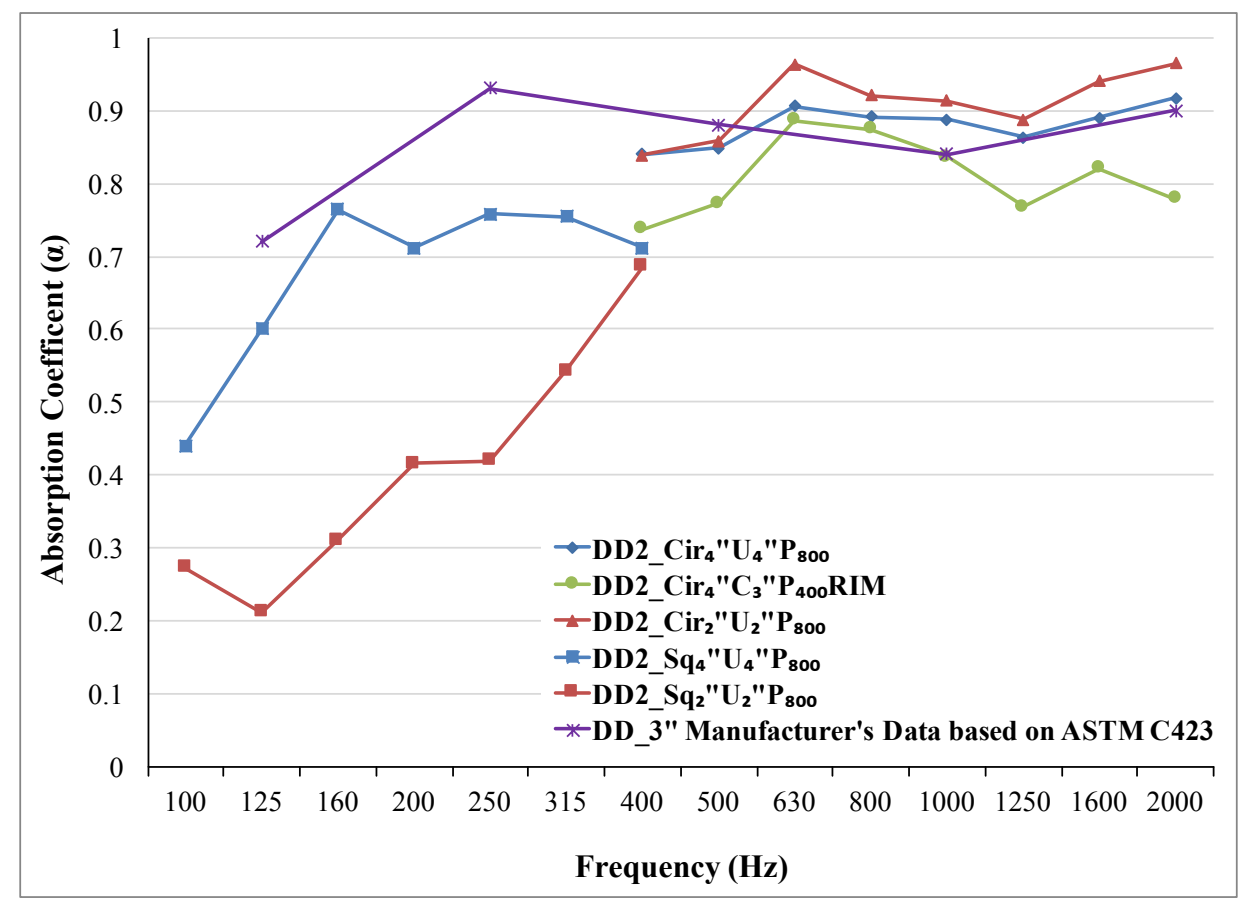

Figure 6.7 - Absorption coefficient results for DD2 samples

As can be seen in Figure 6.7, the DD2 samples were not as sensitive to thickness as other material. Unlike other samples, the DD2 2" circular sample had a higher absorption performance than the 4" sample. Even though the manufacturer's testing methods were different from Tao et al.'s method, the comparison highlights the difference in results in the lower frequency range and the similarity past $500 \mathrm{~Hz}$.

During testing of a 2" thick DD2 circular sample, there was an external noise disturbance outside the lab. As a result, that sample was retested (without any external disturbance) to investigate the reliability of the data. The data were compared in Figure 6.8 from $100 \mathrm{~Hz}$ to $2000 \mathrm{~Hz}$. 


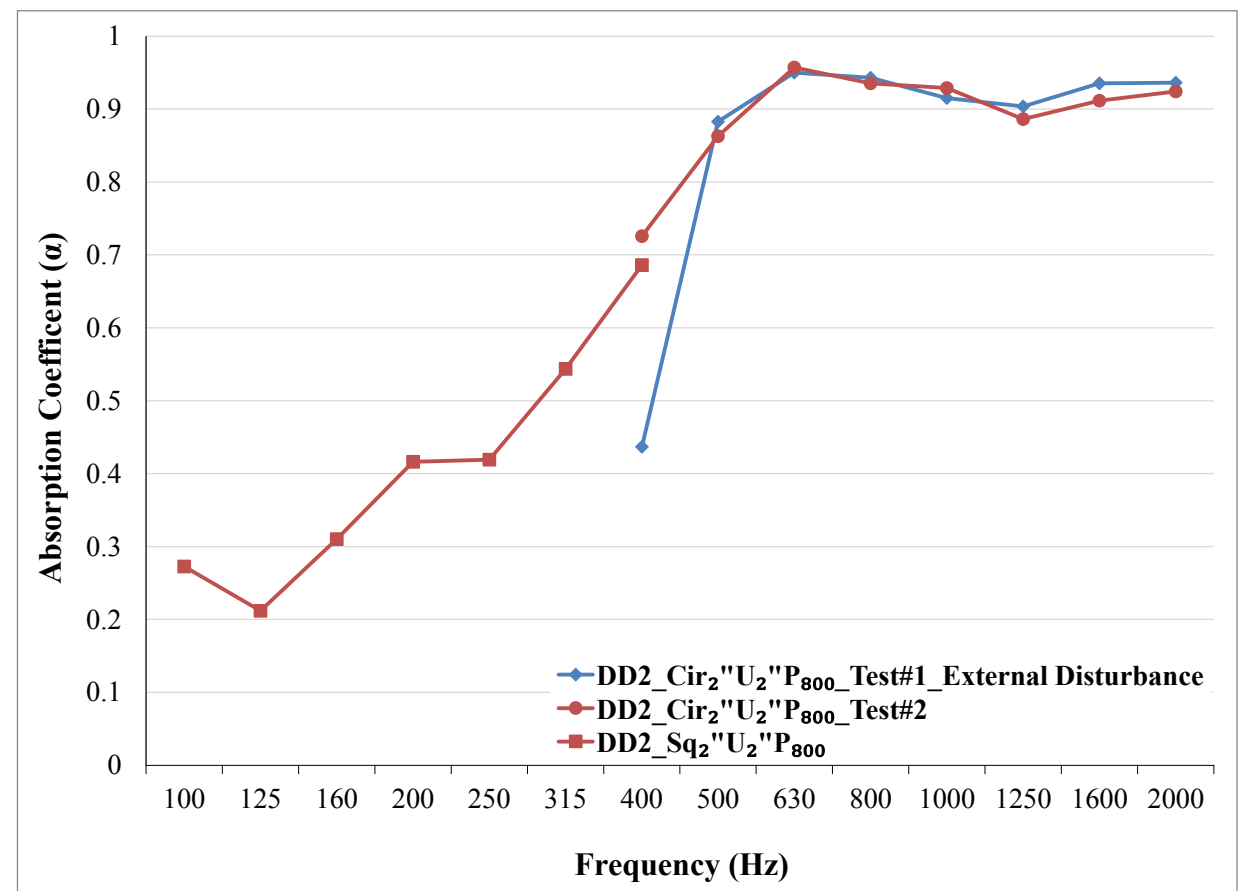

Figure 6.8 - Absorption coefficient results for DD2 with external noise disturbance

In Figure 6.8, the tests results with a external disturbance are plotted along with a 2" square sample. A clear continuity can be seen with the red lines, whereas the disruption appears to have caused a dip in the absorption performance at $400 \mathrm{~Hz}$.

\subsubsection{Absorption Coefficient Results Summary}

Overall, the absorption performance decreased as the samples were compressed. All the samples demonstrated a high absorption coefficient (0.8) within the frequency ranges of 400 - 1600 Hz. Fiberglass and R24 showed more fluctuations, while all 2" compressed samples had lots of leakages. A clear general relationship presented in Figure 6.9 was observed across all four sample types, and most evident in the lower frequency range. 


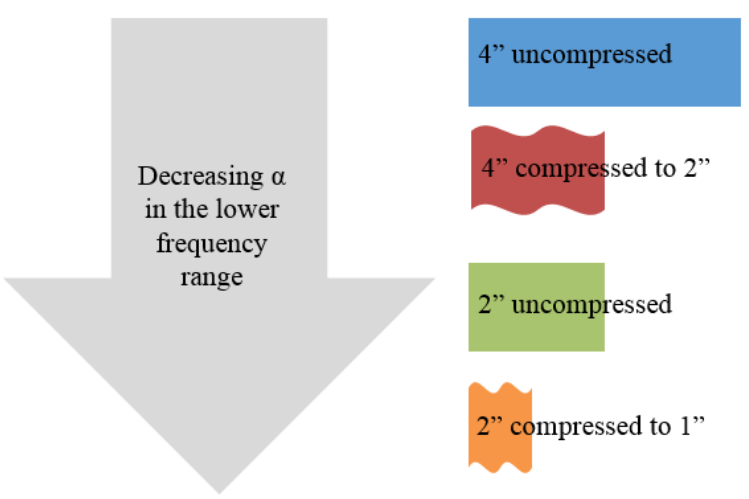

Figure 6.9 - Graphical representation of the decrease in absorption coefficient

A summary of the observations is detailed under the following headings.

\section{- Influence of Thickness}

The thickness of the materials was found to influence the absorption coefficient. There was a clear distinction between the quality of the data as the sample decreased in thickness. The thinner 2" samples had more fluctuations. Specifically, the circular 2" thick samples for both the R24 and AFB performed better (higher absorption) than the 4" samples.

- Influence of Compression

Compression was found to affect the absorption coefficient. R24 and fiberglass experienced the most amount of leakages. In general, as the sample was compressed, the absorption coefficient decreased. In addition, the compressed results fluctuated more than the uncompressed results, especially for the 2" samples.

- Influence of Frequency Range (circular vs square samples)

Overall, the test results for the circular samples appeared to have more fluctuations, particularly for the R24 and fiberglass samples or the 2" compressed to 1" samples. The influence of the thickness or the compression, affected the lower frequency ranges the most. 


\subsection{Flow Resistivity}

\subsubsection{Pre-testing Assessment}

In order to compare the experimental results, an estimate of the flow resistivity of uncompressed material values were compiled in Table 6.1. Estimated values between $250 \mathrm{~Hz}$ and $400 \mathrm{~Hz}$ were taken from the previous report using the three-microphone technique [39]. Additional AFB and fiberglass values (from unknown measurement techniques) were taken from the manufacturer's data brochure [32]. Although these values were not likely obtained using Tao et al.'s technique, a general trend can be analyzed. As expected, it can be seen in Table 6.1 that the denser the material the higher the flow resistivity. It is unclear why the flow resistivity values reported in the manufacturer's data vary with thickness.

Table 6.1 - Estimated Flow Resistivity

\begin{tabular}{|c|c|c|}
\hline Material Type & $\begin{array}{c}\text { Thickness } \\
\text { (Inches) }\end{array}$ & $\begin{array}{c}\text { Estimated Flow Resistivity } \\
\text { (MKS rayls/m) }\end{array}$ \\
\hline R24 & $4 ”$ & $12,000[39]$ \\
\hline \multirow{3}{*}{ AFB } & $4 ”$ & $12,300[39]$ \\
& $3 ”$ & $16,600[32]$ \\
\hline DD2 & $1.5 ”$ & $15,000[32]$ \\
\hline \multirow{3}{*}{ Fiberglass } & $4 ”$ & $18,000[39]$ \\
& $3.5 ”$ & $2,800[39]$ \\
& $2.5 ”$ & $4,800[32]$ \\
\hline
\end{tabular}

It is expected that compression will result in a smaller (denser) sample that, therefore, experiences a higher flow resistivity [36].

Dr. Ramakrishnan previously tested several samples for their flow resistivity and transmission loss using Doutres et al.'s three-microphone method [39]. The following chapter compares the current results to the three-microphone results. Several graphs have been extracted from the report for an easier comparison. 


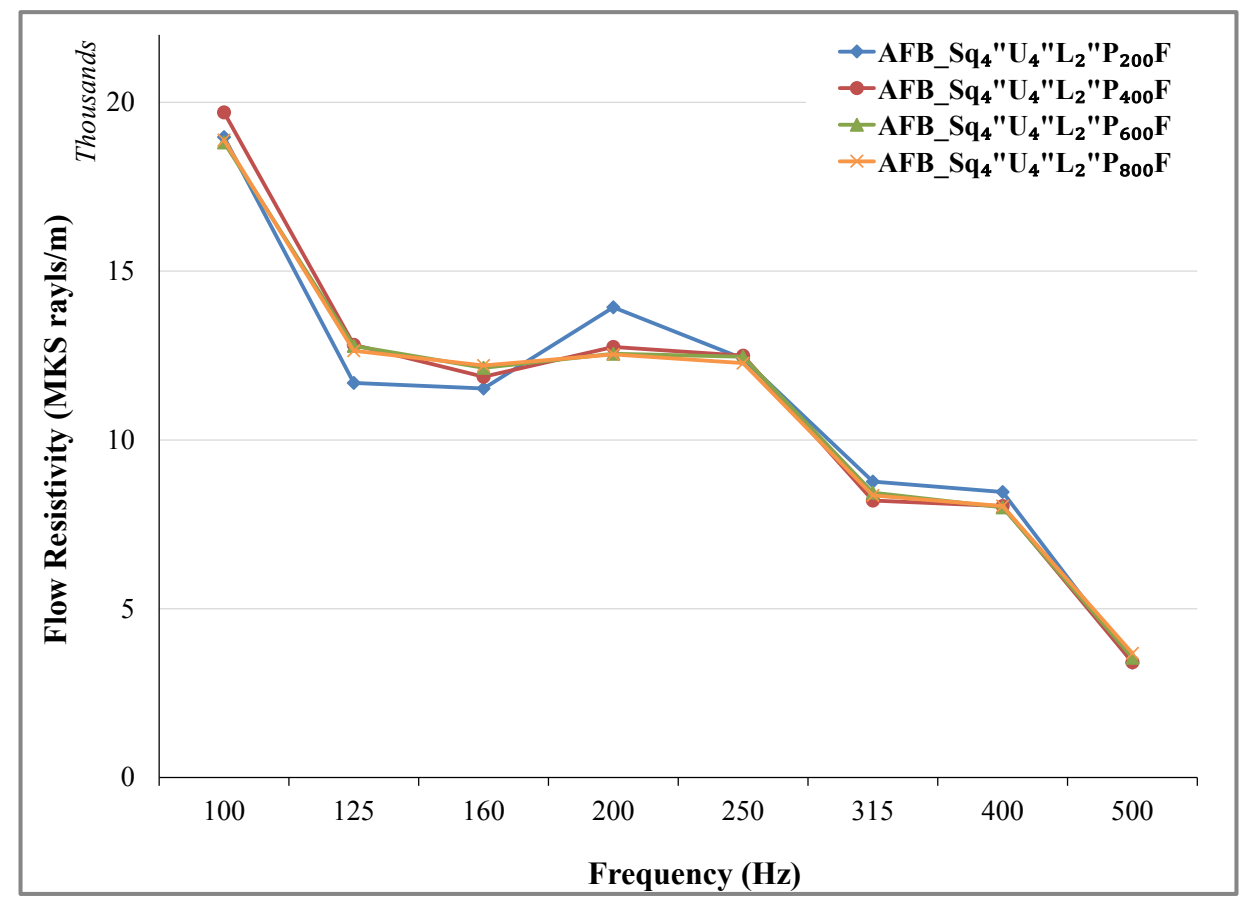

Figure 6.10 - Flow resistivity of AFB 4" samples for different white noise durations

Unlike the absorption coefficient results reported in Figure 5.1, flow resistivity did not show much sensitivity to white noise duration, as shown in Figure 6.10 for an AFB 4" sample. Similarities in the results from all four tested durations were evident, with the exception of the 200 points line varying slightly more. It is possible that the flow resistivity results are not as sensitive to the averaging time, since they are based on the initial absorption coefficient testing, which is all 800 points. Due to limited time, most of the air gap tests for the flow resistivity were conducted using 400 points, since this graph indicates there is negligible difference.

Only the flow resistivity results for the square samples are presented in the current paper. The reasoning behind this restriction is twofold. First, Tao et al.'s paper experimental results were limited to the ranges of $80-500 \mathrm{~Hz}$. Thus, the same limitation was applied herein. Secondly, a circular frame (for the air gap) was not fabricated in time for testing. Therefore, the measurement accuracy of the air gap behind the circular sample was deemed unreliable. To account for the adjustment, the data cut-off was altered to $500 \mathrm{~Hz}$ for the square samples. 


\subsubsection{Fiberglass}

In Dr. Ramakrishnan's previous study, the flow resistivity results for an 8 " thick fiberglass sample and its compressed 4" results are shown in Figure 6.11. The results were quite steady and indicated a gradual flow resistivity increase as the frequency increased. Resonance at $190 \mathrm{~Hz}$ and $480 \mathrm{~Hz}$ in the uncompressed results was magnified in the compressed samples.

Eight different flow resistivity fiberglass results from the current study have been plotted together in Figure 6.12. Two groupings were identified: stable uncompressed (2"and 4") samples, and fluctuating compressed (2" and 4") samples. The 2" uncompressed sample showed only a slightly higher flow resistivity than the 4" uncompressed sample. As the sample was compressed from 4 " to 2 " the flow resistivity more than doubled and peaked at $200 \mathrm{~Hz}$.

In comparison, the current uncompressed samples results were within range of the threemicrophone method results. However, the compressed in comparison fluctuated more and doubled in the flow resistivity results.

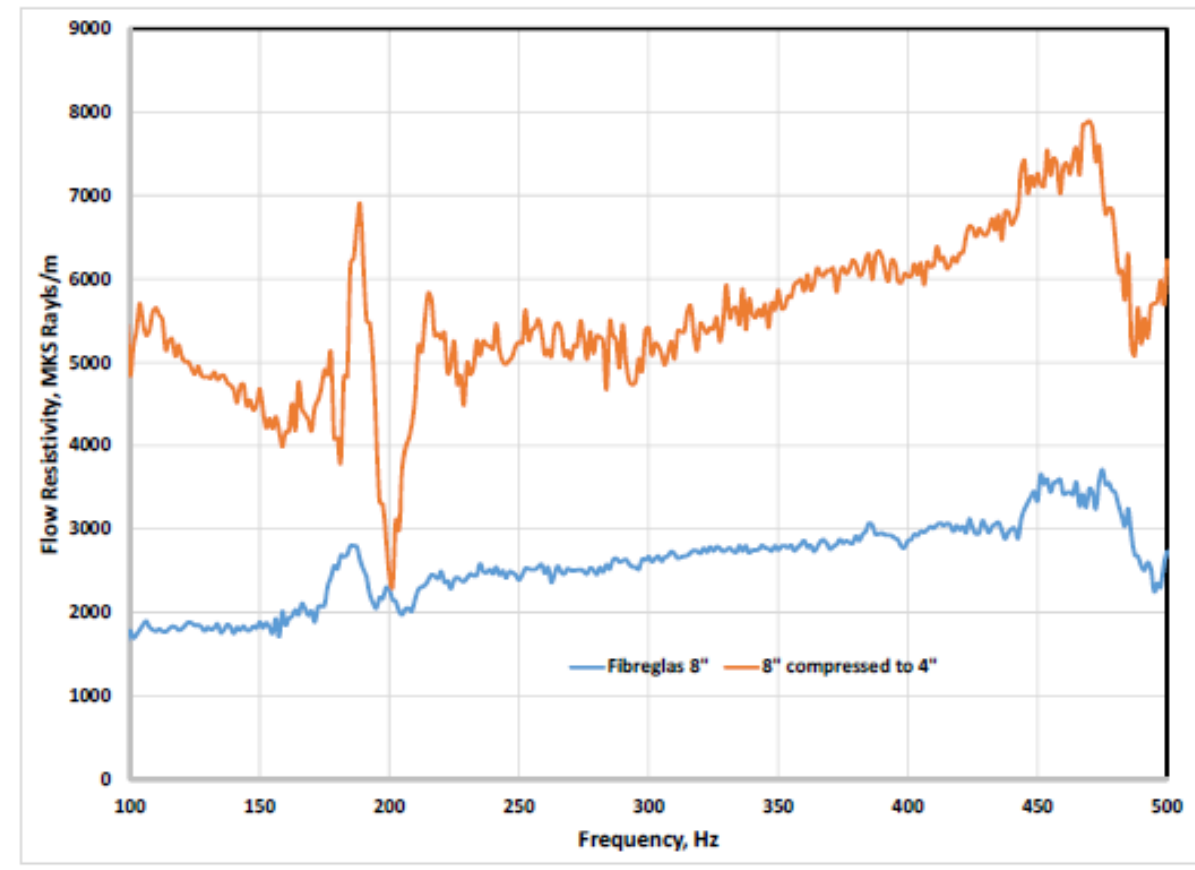

Figure 6.11 - Three-microphone method: Flow resistivity of fiberglass 8" sample [39] 


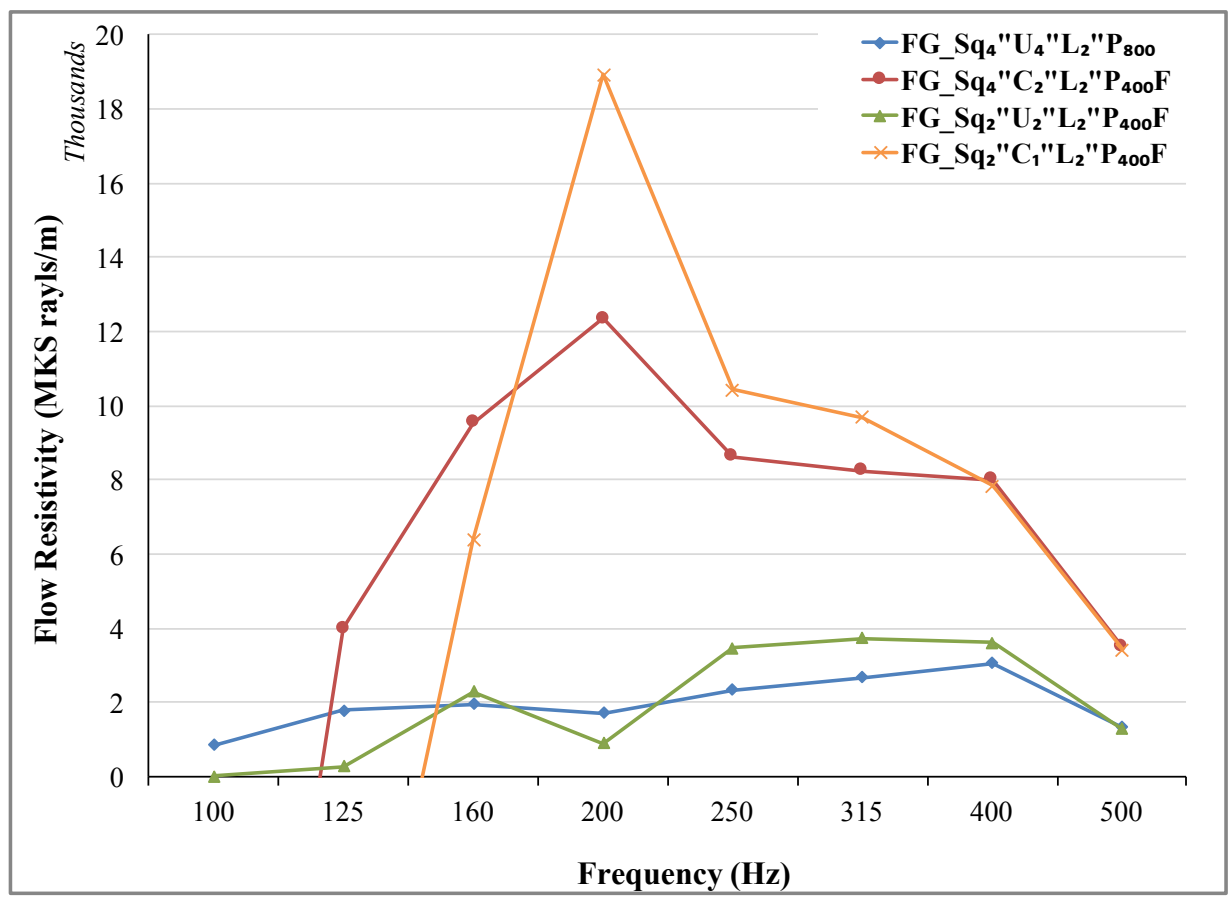

Figure 6.12 - Flow resistivity of fiberglass square samples

\section{$6.2 .3 R 24$}

The three-microphone study flow resistivity results are presented in Figure 6.13 for a 4" thick R24 sample compressed to 3". The uncompressed (blue line) sample results were steady with a couple of peaks near $190 \mathrm{~Hz}$ and $480 \mathrm{~Hz}$. The compressed sample progressively peaked near $225 \mathrm{~Hz}$ to $45,000 \mathrm{MKS}$ rayls/m before gradually decreasing to level off at 25,000 MKS rayls/m.

Current study results in Figure 6.14 did not show two distinct groups, since the 4" compressed (red line) results merged with the 2" uncompressed (green line) results near $350 \mathrm{~Hz}$. Despite the crisscrossing of lines, compression did double the flow resistivity, with a clear offset between the uncompressed and compressed samples.

In comparison, the current study's flow resistivity ranges were similar to the threemicrophone results between 100-250 Hz. Both data sets were around 12,000 MKS rayls $/ \mathrm{m}$ for the uncompressed samples, while the 4 " compressed samples were both approximately 25,000 MKS rayls/m.

Similar results were obtained using air gaps of 2", 4" and 6" for the R24 uncompressed 4" samples (not shown). However, the 6" gap seemed to have fewer fluctuations. 


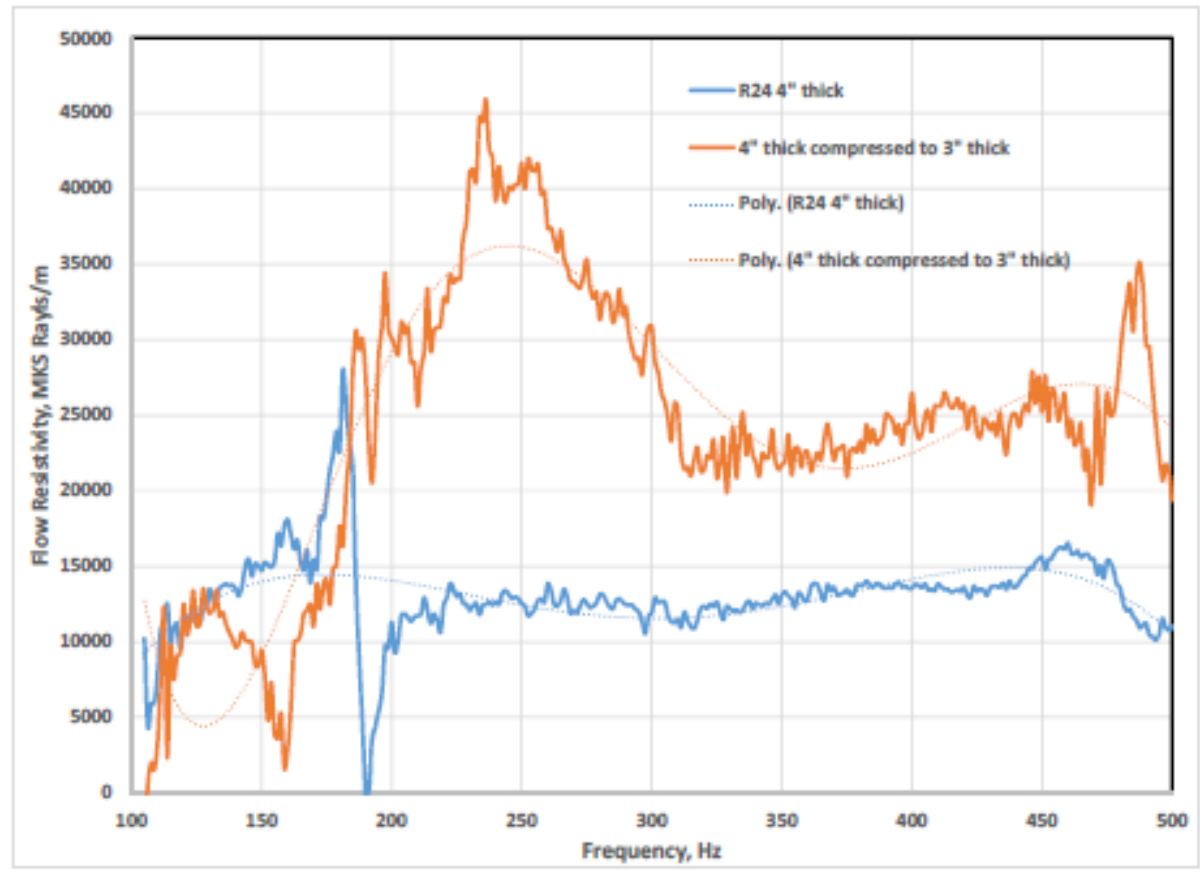

Figure 6.13 - Three microphone method: Flow resistivity of R24 4" sample [39]

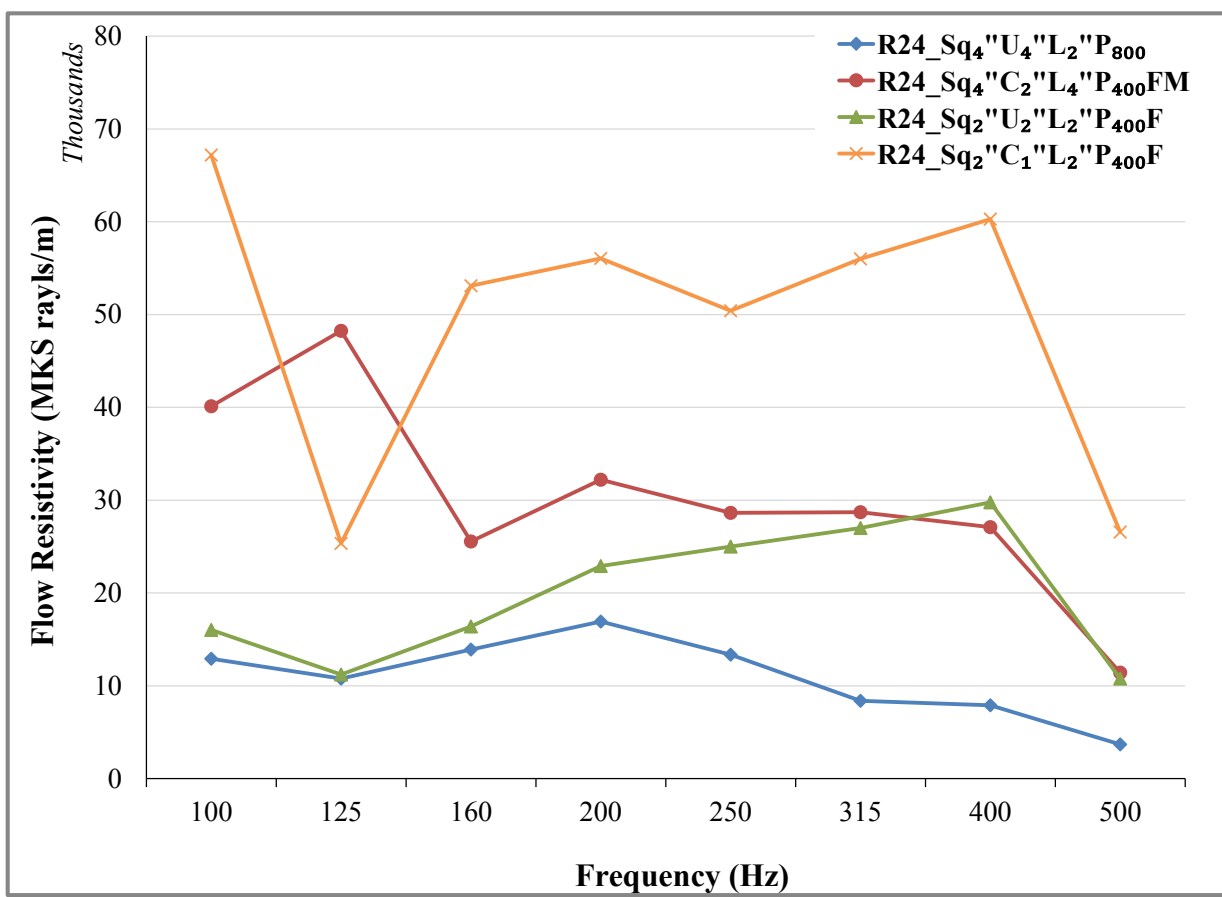

Figure 6.14 - Flow Resistivity for R24 square samples 


\subsection{4 $A F B$}

In the previous study, a 4" thick AFB sample was compressed (Figure 6.15) with rather stable results past $250 \mathrm{~Hz}$. Resonance was present in both samples near $200 \mathrm{~Hz}$ and $480 \mathrm{~Hz}$. As expected, the flow resistivity increased as the samples were compressed; however, unlike the other samples, the compressed result did not double in value, instead reaching only 1.5 times greater than the uncompressed value.

Two groups (uncompressed and compressed results) are illustrated in the current paper's data (Figure 6.16). The 2" uncompressed sample resulted in only a slightly higher flow resistivity than the 4" uncompressed sample. Compression did double the flow resistivity results. All the data lines had a common decline after $400 \mathrm{~Hz}$.

In contrast to the three-microphone results, the current results were less stable; however, for the 4" uncompressed sample, the current study shared similar values, hovering around 12,000 MKS rayls/m between $125-250 \mathrm{~Hz}$ before declining.

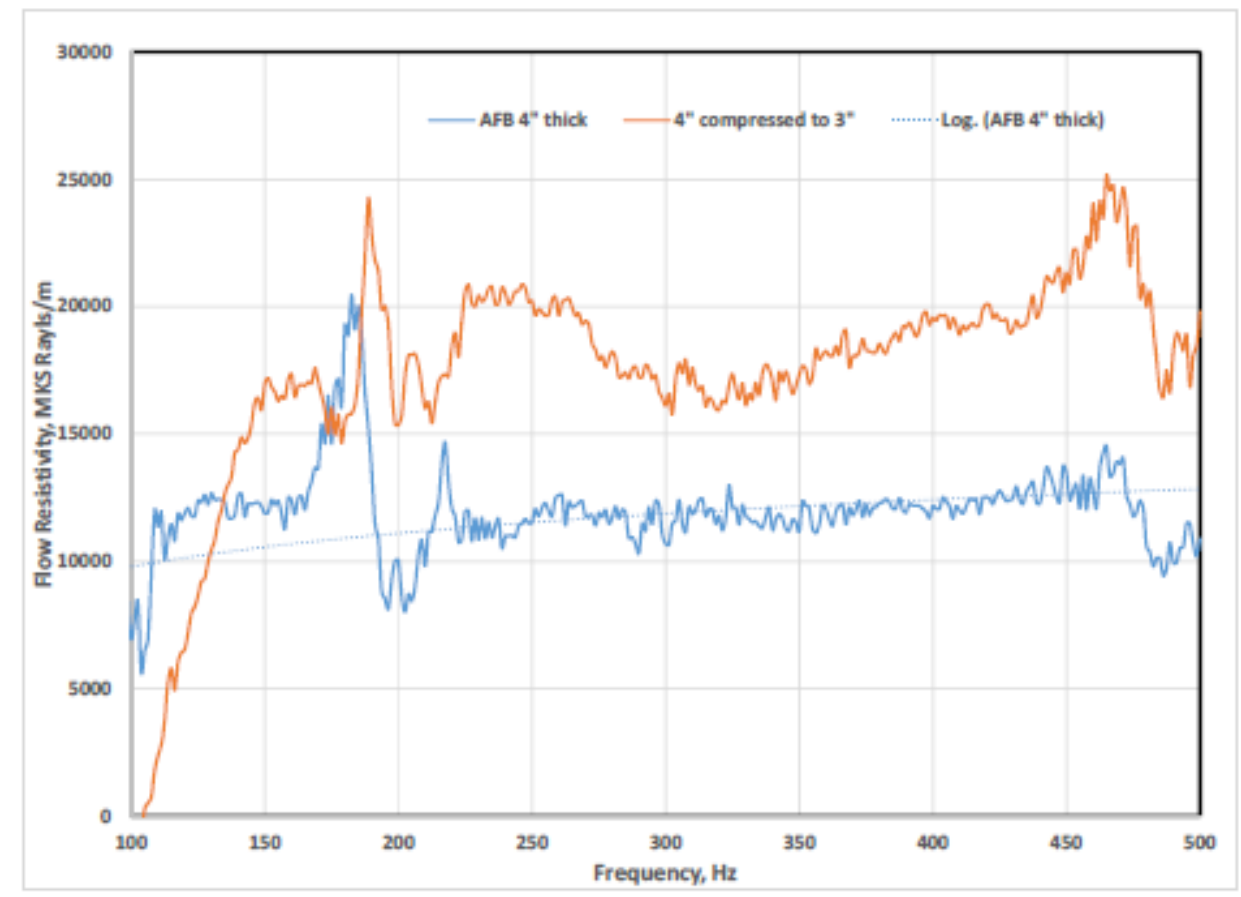

Figure 6.15 - Three microphone method: Flow resistivity of AFB 4" sample [39] 


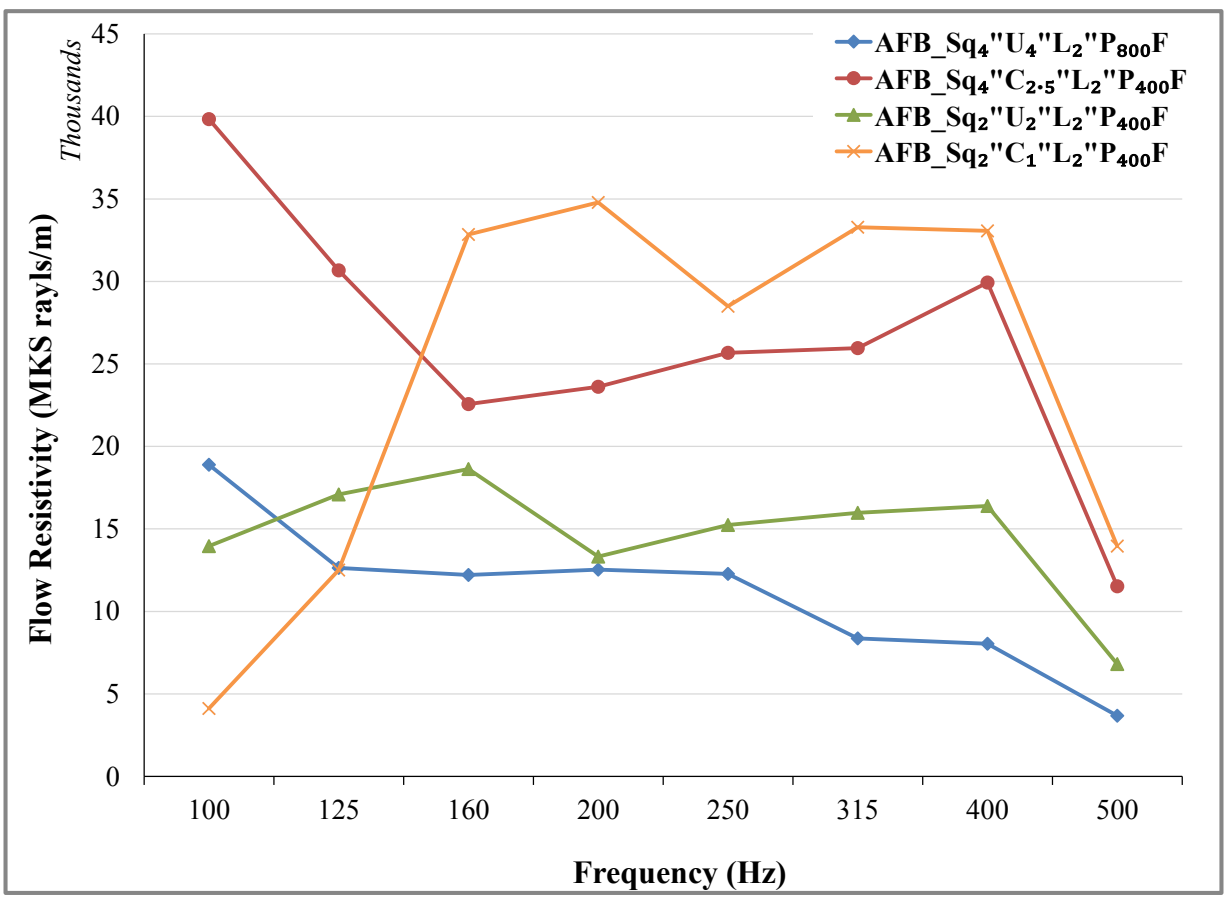

Figure 6.16 - Flow resistivity of AFB square samples

\subsubsection{DD2}

Due to the high density of the DD2 samples, only the uncompressed state was tested. Figure 6.17 shows the three-microphone results for 2" and 4" thick DD2 samples. The results demonstrated resonance near $200 \mathrm{~Hz}$, and the 2" data was seen to have flow resistivity ranges close to the 4", but with more noise.

The results from the current study comparing the different air gaps of 2" and 4" for both uncompressed samples are shown in Figure 6.18. Two separate groups were observed, with the 2" samples nearly $10,000 \mathrm{MKS}$ raysl/m higher than the 4" samples. The 4" frame lowered the absorption performance slightly.

Unlike the three-microphone results, the flow resistivity for the 2" was more stable and had a higher flow resistivity than that for the 4" sample. In general, the 2" sample shown in Figure 6.18 approached closest to 22,000 MKS rayls/m, while the previous study for both 2" and 4" samples plateaued around 18,000 MKS rayls/m. 


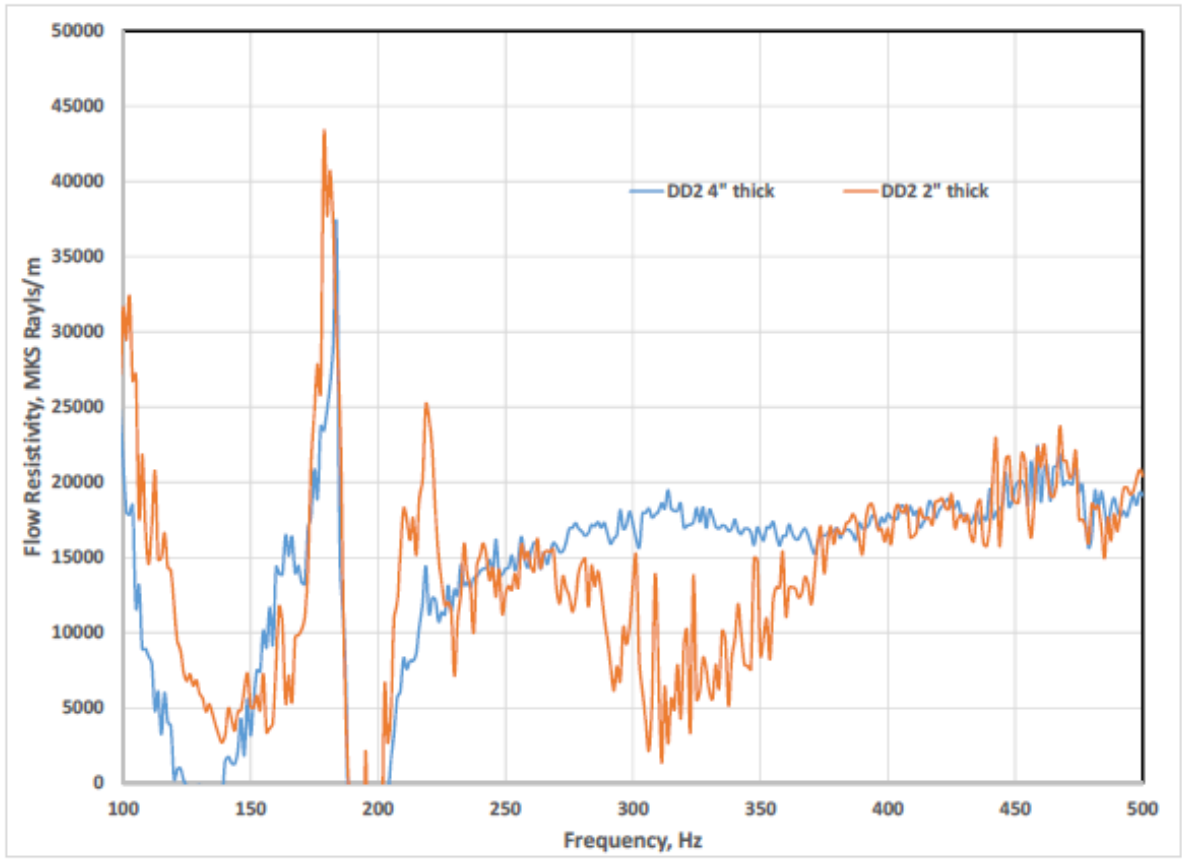

Figure 6.17- Three microphone method: Flow resistivity of DD2 4" sample [39]

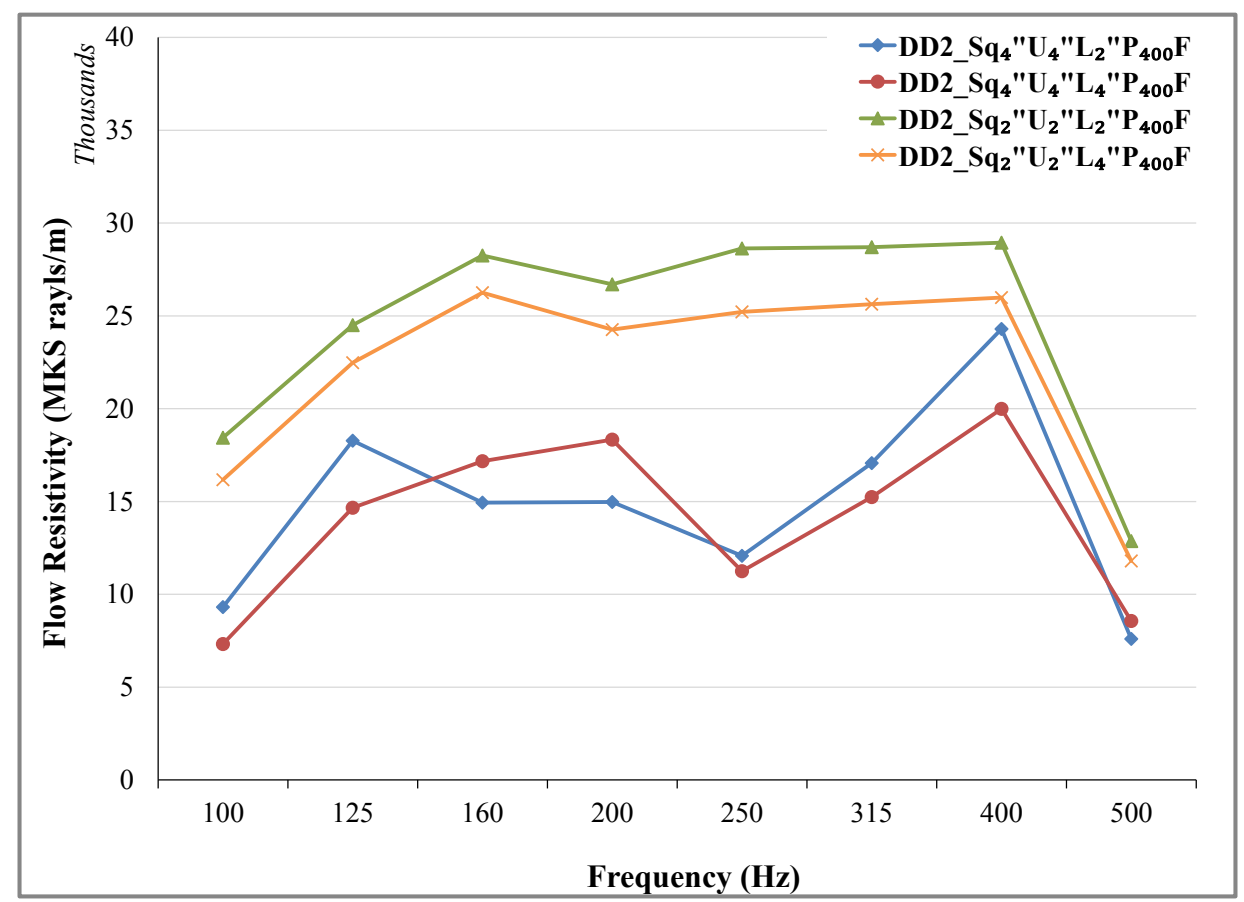

Figure 6.18 - Flow resistivity of DD2 square samples 


\subsubsection{Flow Resistivity Results Summary}

Overall, the flow resistivity results showed an increase as the samples were compressed. Limited to the square samples, a general relationship presented in Figure 6.19 was observed across all four sample types, with the exception of DD2. A dip at $250 \mathrm{~Hz}$ was observed in the 2" compressed samples as well.

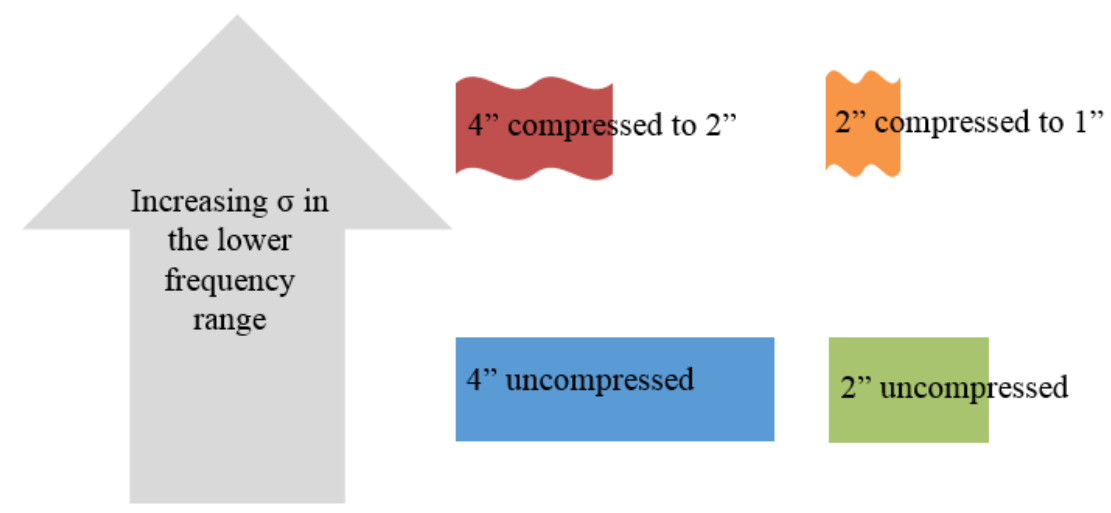

Figure 6.19 - Graphical representation of increasing flow resistivity

A summary of the observations are detailed under the following headings.

- Influence of L (Air Gap)

According to Tao et al., a 4" gap resulted in better accuracy over the 2".

Comparing the various air gaps 2 "and 4" gap, the 4" lowered the flow resistivity results slightly.

- Influence of Thickness

Most of the flow resistivity results for all the samples were independent of thickness with the exception of DD2. The 2" DD2 samples appeared to be more stable than the 4" samples. However, all 4" samples were within ranges listed in Table 6.1.

- Influence of Compression

In general, the flow resistivity increased as the samples were compressed and was independent of the thickness of the sample. Any slight resonance is exaggerated in the compressed results.

- Influence of Frequency Range (circular vs square samples)

Tao et al.'s results are limited to the range from $80-500 \mathrm{~Hz}$. Overall, the test 
results for the circular samples in this part of the experiment were very widespread making it inconclusive and were not presented a part of the current report. It is possible that a circular frame is required to help maintain the air gap behind the specimen. 


\subsection{Experimental Errors/Limitations}

During the setup and testing, there were several factors that might have contributed to the experimental errors associated with the use of impedance tubes. The chapter analyzes these factors and are subdivided into three categories; general, absorption coefficient and flow resistivity.

\subsection{General}

\subsubsection{Sample Preparation}

Stanley outlined with the agreement with Hua that samples should be prepared with the same sheet of material $[25,26]$. Manufacturing variability from different sheets will increase the variability of the results. It is likely that the samples used in the current study were from different batches.

Fiberglass is very porous, and shaping the samples to the desired dimensions were more difficult than with the denser samples. The cutting process likely caused slight deformation in the sample that directly affects the leakages. Due to the light structure, it appeared that the fiberglass sample was also sensitive to how it was handled when placed into the tube. The effects of handling will be discussed in Sections 7.1.3 and 7.1.4.

Based on the equipment availability, the blade saw and compass cutter were used to prepare the samples. However, specific cutting techniques summarized in Table 7.1 were suggested by Stanley to help reduce sample variations.

Table 7.1 - Test Specimen Cutting Techniques based on Stanley [26]

\begin{tabular}{|l|l|}
\hline \multicolumn{1}{|c|}{ Cutting systems } & \multicolumn{1}{c|}{ Material Suitability, Pros and Cons } \\
\hline 1) Rotating circular steel blades & +most cost effective between the 3 systems \\
mounted in a drill press or & -labour intensive \\
milling machine & -not suitable for fibrous or flimsy materials \\
\hline 2) High pressure water jet & -requires time for specimens to dry \\
stream with computer numeric & -may have ragged edges for thicknesses over 1 inch \\
control of cutting & --not suitable for fibrous or flimsy materials \\
\hline 3) Circular die blades used with & +consider if systems 1 and 2 are not suitable \\
a stamping press & -may form concave edges inadvertently \\
\hline
\end{tabular}


Specifically for the fiberglass specimens, it may be worth considering using the water cutting system. Oliva et al. also used water cutting to prepare their mineral wool samples [24].

\subsubsection{Compression Technique}

Overall, as the sample is compressed, additional edge constraint will occur and affect the results. However, some samples may also have experienced lateral gaps.

For the circular samples, uniaxial compression may not have been properly achieved due to the difficulty of uniformly compressing the samples. The simple action of knotting the end of the stocking may have inadvertently caused bi-axial compression. Possible lateral deformation and consequent air gaps might have skewed the results. After compression, some of the samples could not hold themselves up vertically. A custom circular ring was installed in order to hold the material upright.

An alternative compression technique that may reduce the possibility of bi-axial compression was found employed by Li. Li used a custom ring and mesh to compress a 1" thick foam to analyse the effect of compression as shown in Figure 7.1 [37]. She demonstrated that the mesh had minimal effect on the absorption coefficient.
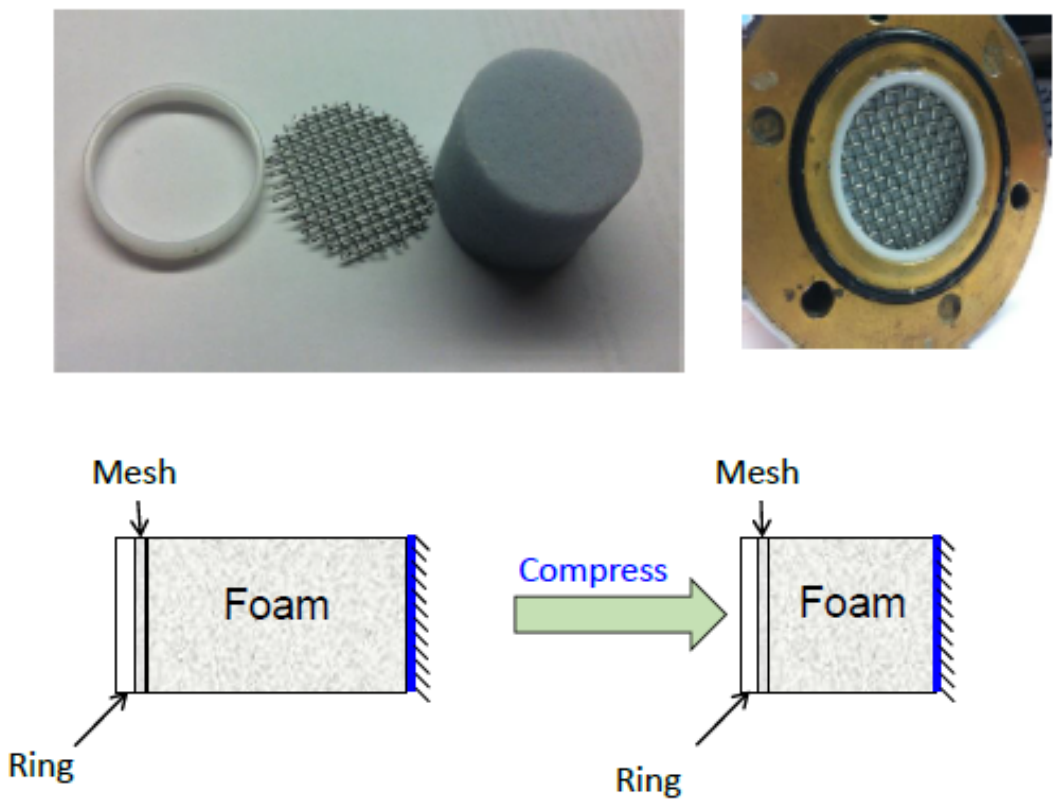

Figure 7.1- Components and schematic of Li's compression method [37] 
Without a sample holder. in one instance in the circular tube, a sample was found to be offset by $5 \mathrm{~mm}$ towards the backend. The offset might have been caused by the force of pulling the rigid backend, causing suction. The offset is an experimental error. It is important to open the tube to check for any movement of the sample.

A possible experimental inconsistency in the square tube was how the samples were compressed as compared to the circular samples as illustrated in Figure 7.3. The square tube had a 1" foam inner perimeter edge that was used to hold the sample in place. The rigid backing was then used to compress the sample. It is possible that the compression on one end caused bulging on the inner face. Consequently, the inner face could not be aligned from the instrumental face. In comparison, the circular samples were compressed at both ends.

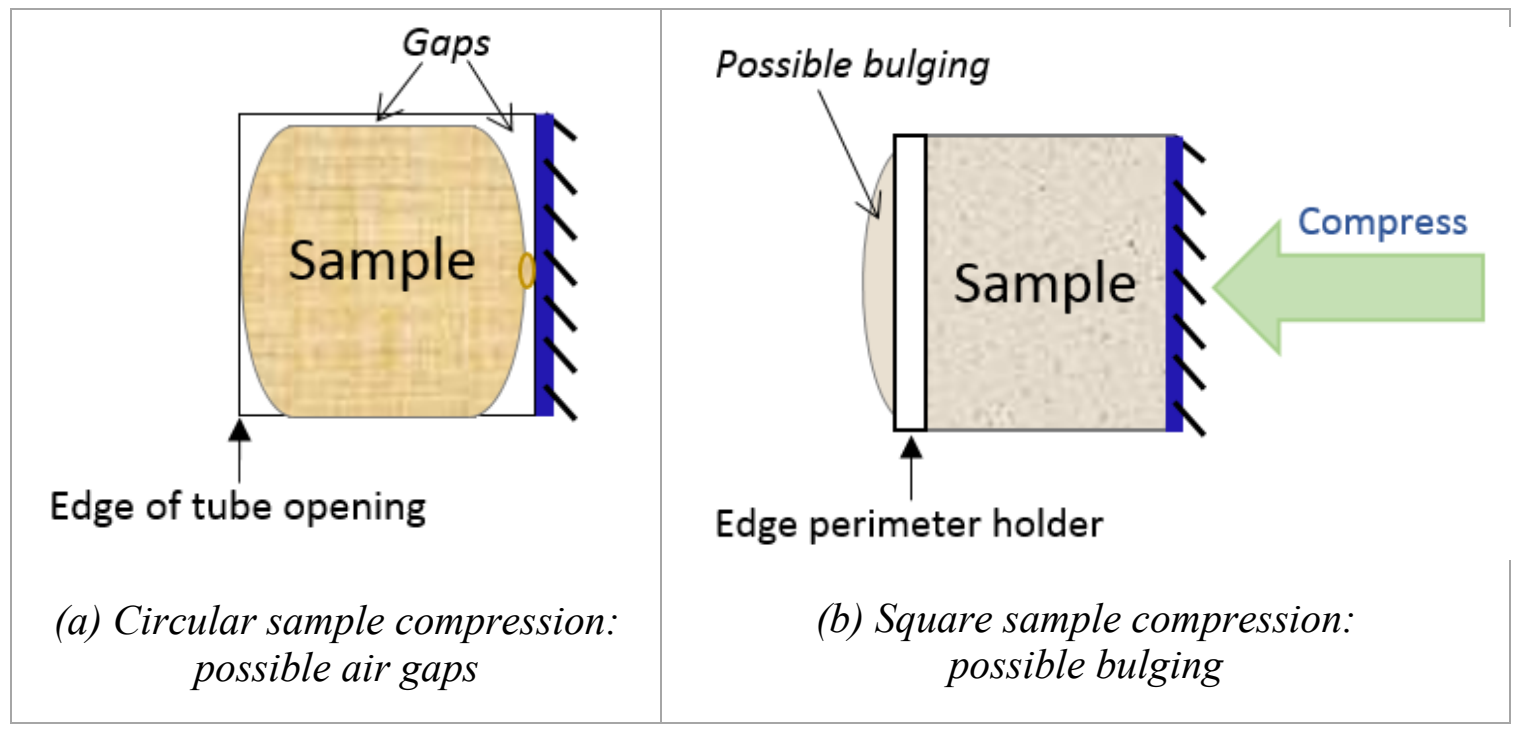

Figure 7.2- Possible issues for the circular and square compression setup

The flow resistivity test required an air gap behind the sample. Therefore, the compression formerly completed with a rigid end was now being done only around the edges. A perforated square mesh was used to act as a rigid backing and was found to have minimal effect on the results.

\subsubsection{Leakages}

In general, there was evidence of leakages in the sample around the $100 \mathrm{~Hz}$ range. The following graph, Figure 7.3, shows three samples of fiberglass. The 2" square 
compressed sample is shown to be more stable than the 2" circular compressed samples. The 2 " compressed to 0.5 " results were so unstable that the most of the data cannot be plotted with the exception at $2000 \mathrm{~Hz}$.

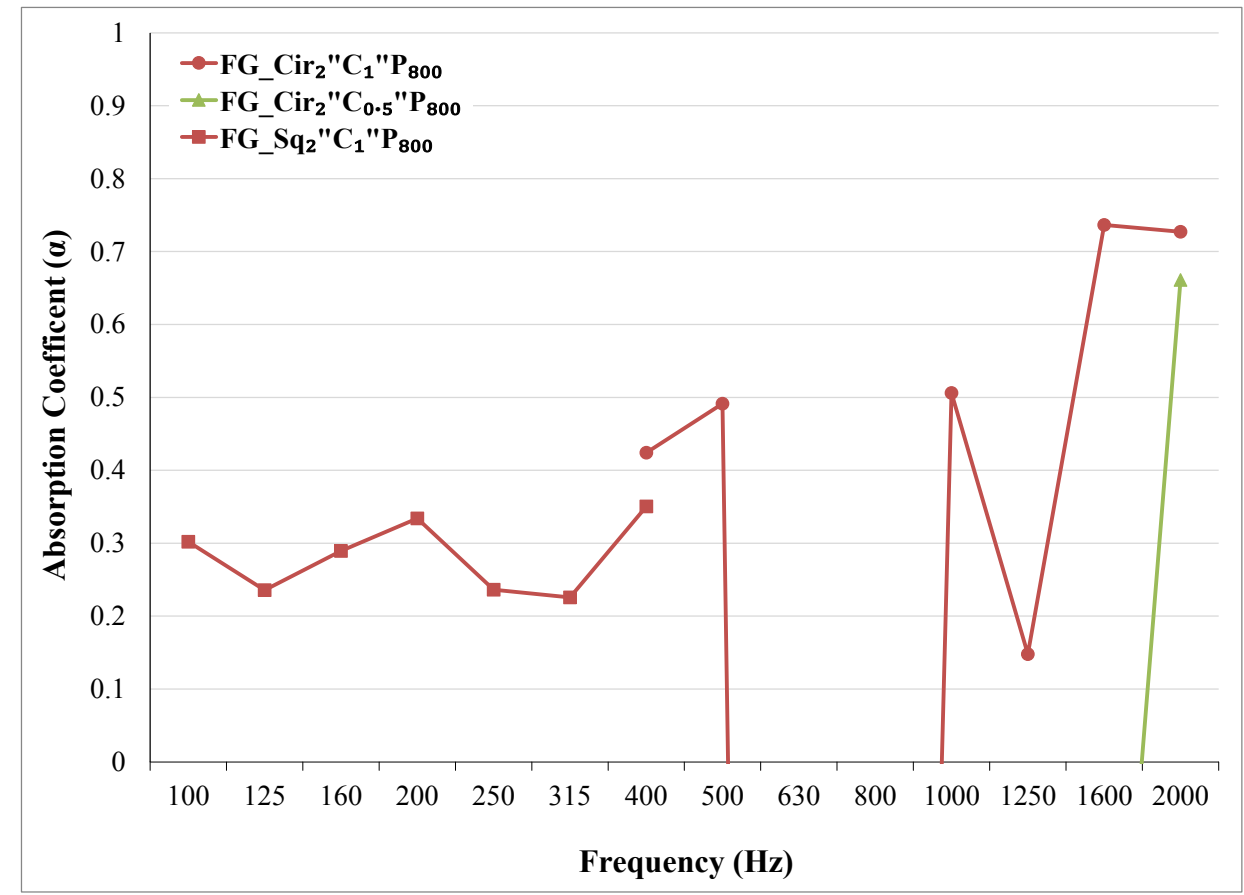

Figure 7.3 - Absorption coefficient: Fiberglass 2" compressed sample

Kino and Ueno found that diameters $0.5 \mathrm{~mm}-1 \mathrm{~mm}$ less than the tube size helped to avoid air leakages effects [40]. Compression of the sample causes slight deformation. It is suggested that petroleum jelly be placed to cover the gaps around the sample and the tube inner surface. To test whether the results could be improved, a custom ring installed for a better fit or petroleum jelly was applied to the sample edges for the compressed fiberglass sample are shown in Photograph 7.1. 


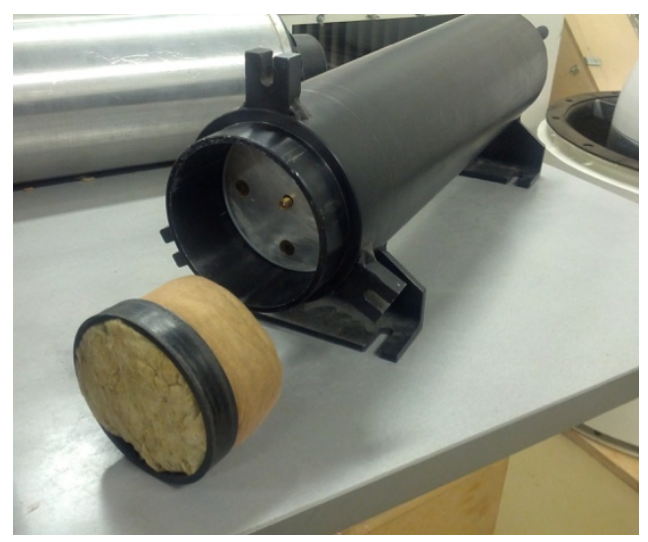

(a) Custom Ring Used to Fit Samples

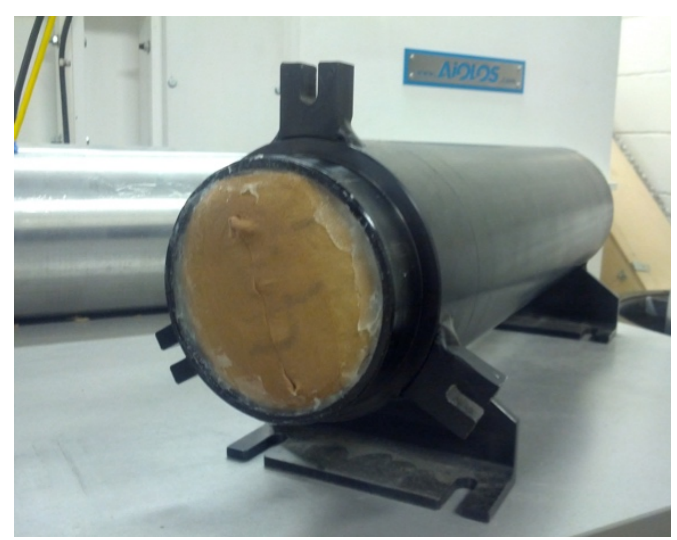

(b) Application of Petroleum Jelly

Photograph 7.1 - Different setup configurations

Contrary to the suggestion from several authors, the petroleum jelly applied to two samples did not improve the results as shown in Figure 7.4 and Figure 7.5.

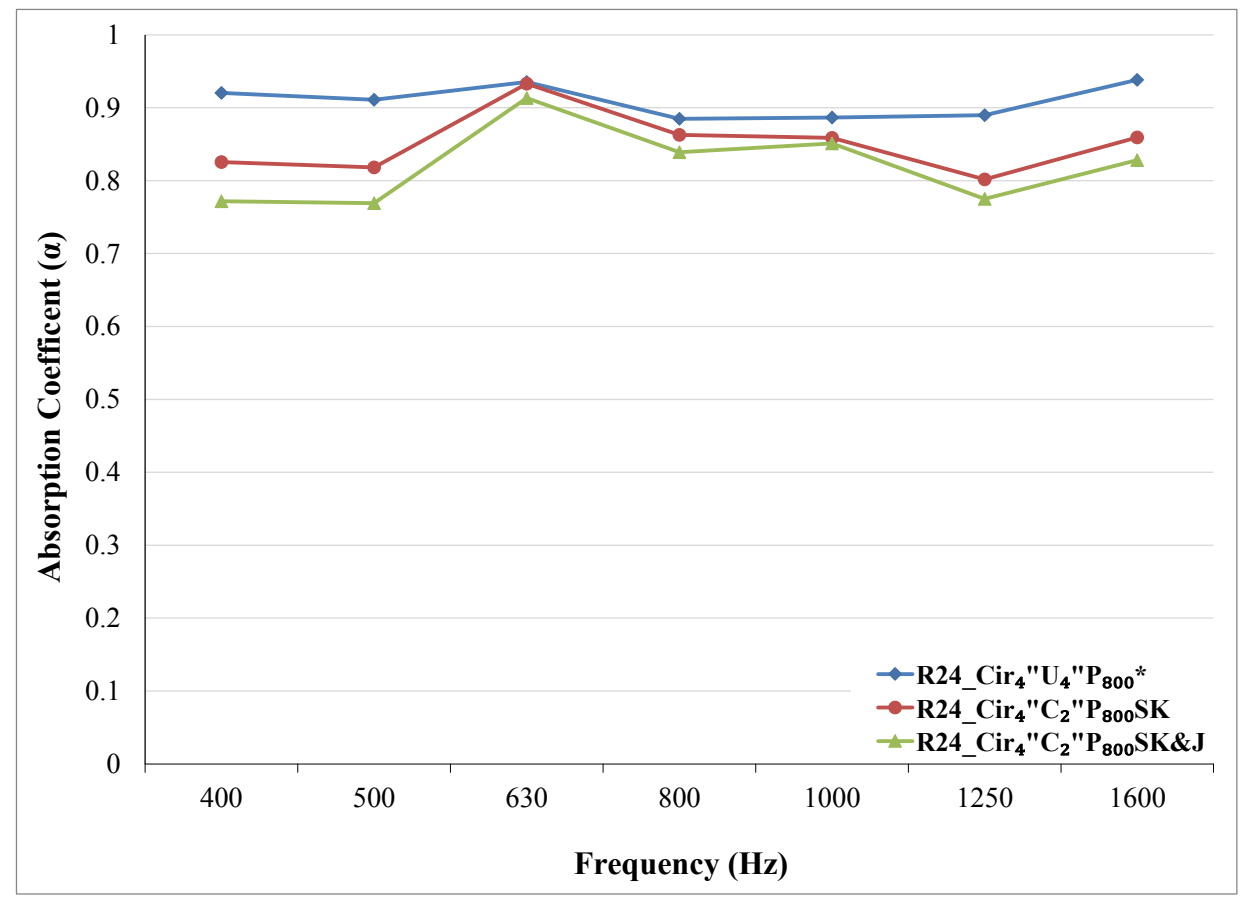

Figure 7.4 - Absorption coefficient for R24 varying 4" samples

Figure 7.4 of a R24 circular sample that was compressed from 4" to 2". The sample was first tested compressed with a knotted stocking, and then retested with a knotted stocking with jelly to seal the edges as shown in Photograph 7.1(b). The data resulted in a slightly lowered absorption with an identical pattern shown. 


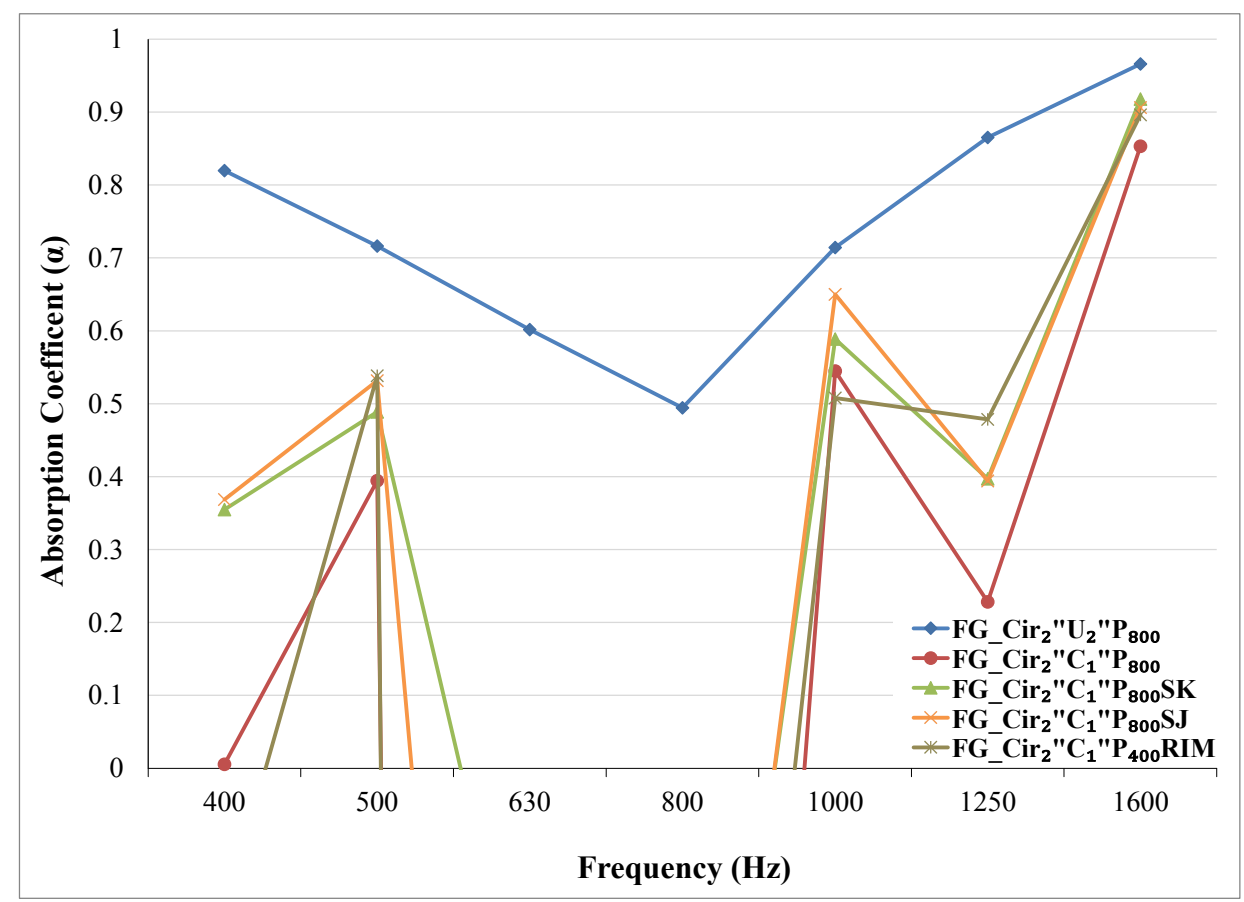

Figure 7.5 - Absorption coefficient of fiberglass varying 2" samples

Different configurations were attempted to help improve the fiberglass 2" compressed circular sample results as presented in Figure 7.5. The configurations included; manual compression (red line), knotted stocking compression (green line), with petroleum jelly (orange line) or the use of the ring (grey line). No improvement was seen, as all of the compressed samples in Figure 7.5 followed a similar pattern and appeared to have a resonance at $630 \mathrm{~Hz} / 800 \mathrm{~Hz}$, which magnified substantially from the uncompressed sample.

According to Cummings noted that there are issues with air gap behind the sample [41]. The current compression technique makes an air gap difficult to avoid in compressed samples because the knot behind the sample prevents full contact between the sample and rigid backing. An alternative method was to test the sample without a knot and that did not improve the results either for the 2" fiberglass sample as seen in Figure 7.5.

Cummings also pointed out that the effect of air gaps around the specimen is more evident in lower frequencies and higher flow resistivity [41]. He also stated that samples with higher flow resistivity compared to low flow resistivity are more prone to measurement errors. That would indicate that the DD2 samples experienced more errors 
than the fiberglass samples, which was not what the current study found. However, an experimental error most likely occurred in the flow resistivity results that indicated a great difference between the 2" and 4" DD2 samples.

\subsubsection{Varying Back End Depths (Circular tube)}

Song and Bolton found that both the absorption coefficient and transmission loss are affected by the boundary constraints of the sample [42]. During the setup of the impedance tube, it was possible that the fiberglass sample was inadvertently compressed as the rigid backing was adjusted to its proper place. Figure 7.6 illustrates that varying the depths behind 4" fiberglass uncompressed circular samples changed how the sample behaves. It was evident that for the same sample, the depth behind the fiberglass altered the absorption performance.

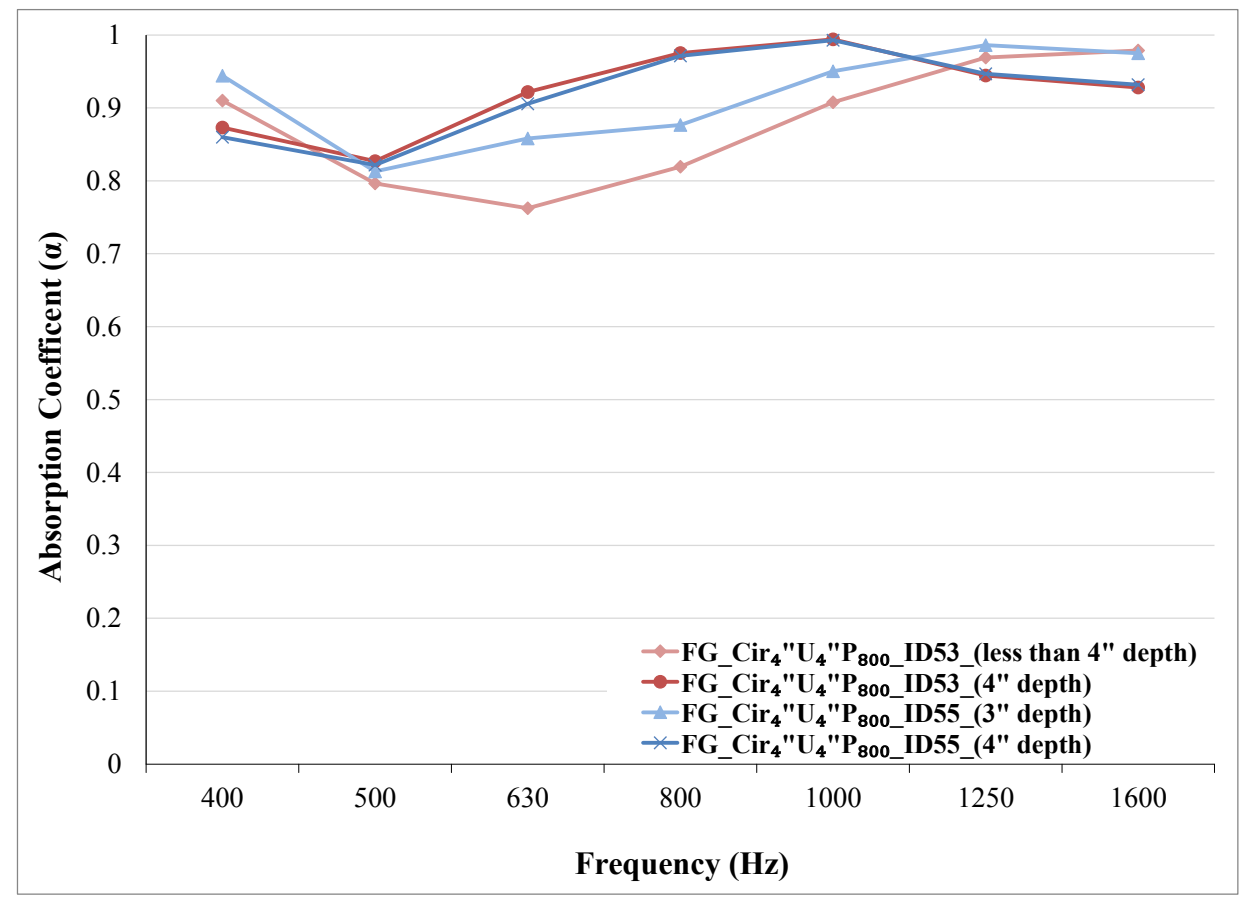

Figure 7.6 - Absorption coefficient for fiberglass 4" samples of varying depths

The two samples with an exact 4" depth (darker lines) experienced a shift in the maxima closer to the lower frequency range as compared to those with a shorter backend depth (lighter line). A comparable relationship can be drawn from Figure 7.7. Muhammad et al. studied the effect of air gap distances $(0,5,10,15,20$ and $25 \mathrm{~mm})$ behind a $25 \mathrm{~mm}$ thick polyurethane foam on the absorption coefficient as shown in Figure 7.7 [43]. 


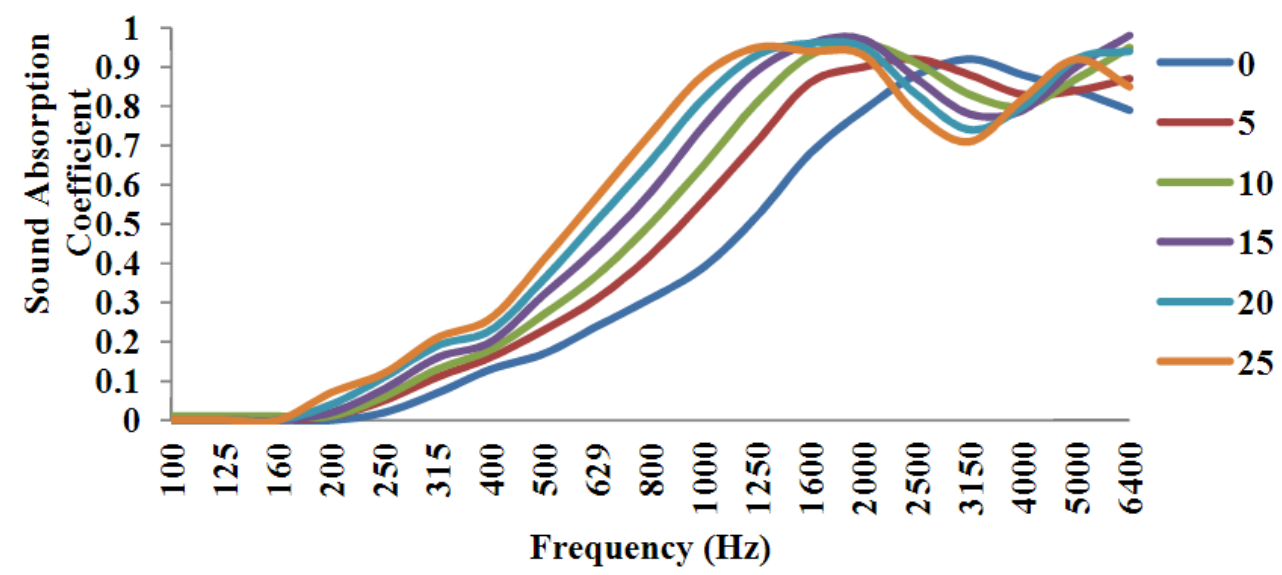

Figure 7.7 - Absorption coefficient of polyurethane with different air gaps [43]

The authors found that as the air gap increased the maxima shifts towards the lower frequency similar to the shift found in Figure 7.6 when the depth was measured to be precisely 4". The similarity might suggest that the fiberglass samples were compressed during mounting and by measuring out exactly 4" before mounting may only be giving a perception of accuracy. However, in reality the 4" may be permitting an air gap in a compressed sample when mounted.

Due to the fiberglass' soft skeleton, it was not possible to identify whether the uncompressed fiberglass sample was inadvertently compressed during mounting unless it is tested in a transparent tube. Although a custom circular ring was made for the current study, it is recommended that a thinner ring be made for future work. The ring was an attempt to control the leakages by acting as a sleeve within the tube to ensure an improved fit around the sample.

\subsection{Absorption Coefficient}

\subsubsection{Data Uncertainty}

Hua and Herrin listed three variabilities that can occur that are the resonance, low frequency and high frequency variability. In the methodology section, the low and high frequency limits were previously determined and cut off accordingly. However, the authors pointed out that the material properties and material thickness determine the resonance frequencies and occurs when $\operatorname{Im}(\mathrm{Z} / \rho \mathrm{c})=0$ as plotted in Figure 7.8(b). 


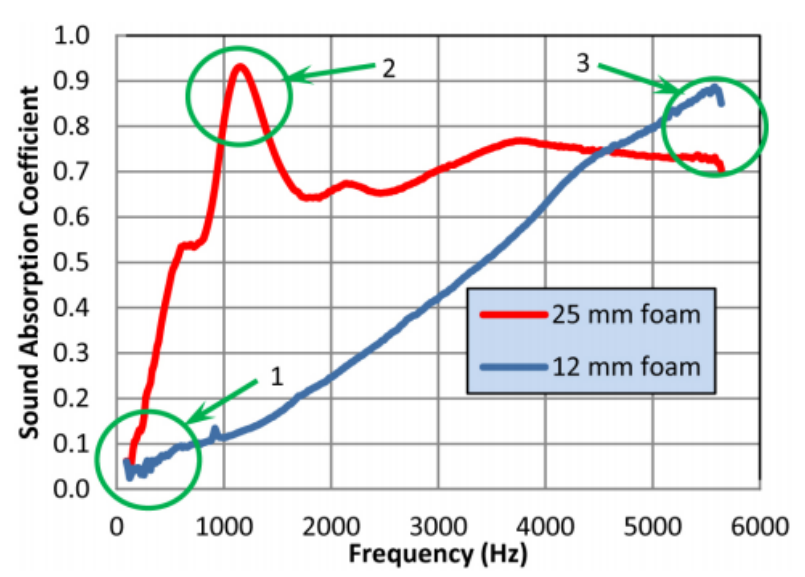

(a) Three common regions of measurement uncertainty

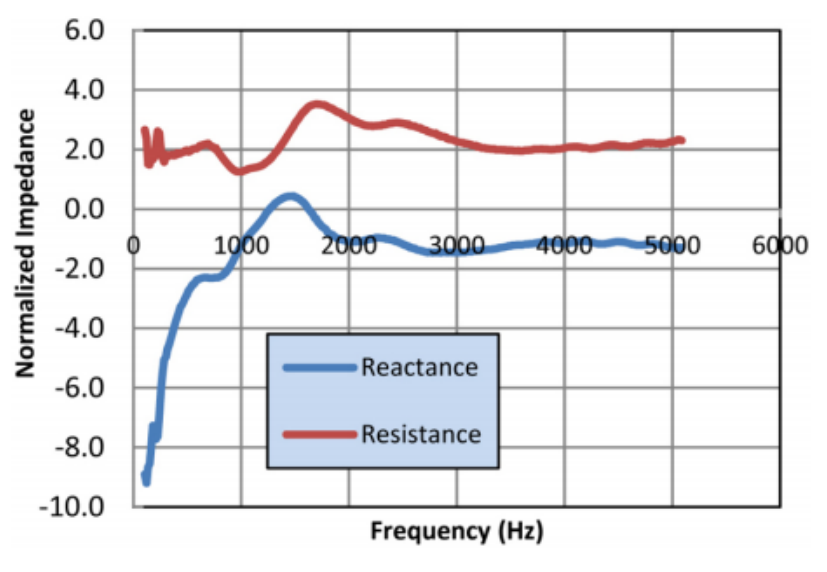

(b) Acoustical impedance of a $25 \mathrm{~mm}$ foam sample

Figure 7.8 - Resonance regions matching [25]

The authors plotted the acoustical impedance vs frequency of a $25 \mathrm{~mm}$ foam and found that resonance on that graph matches, in location, the one shown in the absorption coefficient in Figure 7.8(a). These resonances are also sensitive to the sample preparation $[25]$.

\subsection{Flow Resistivity}

\subsubsection{Methodology Testing Order}

The flow resistivity was also measured using the same sample as those used for the absorption coefficient. Due to the delay of the custom frames, used to act as the air gap behind the sample, the order in which the experiments were conducted was affected. To test for the flow resistivity, specimens were retested for the uncompressed state and compressed with an additional air gap. Unfortunately, the flow resistivity testing was conducted after the absorption coefficient. Table 7.2 lists a comparison between the order of the current study with what is proposed. 
Table 7.2 - Current vs. proposed testing order

\begin{tabular}{|c|c|c|}
\hline$\#$ & Testing order in current paper & Proposed testing order in future paper \\
\hline 1. & uncompressed sample for $\alpha$ & uncompressed sample for $\alpha$ \\
\hline 2. & compressed sample for $\alpha$ & uncompressed sample for $\sigma$ \\
\hline 3. & uncompressed sample for $\sigma$ & compressed sample for $\alpha$ \\
\hline 4. & compressed sample for $\sigma$ & compressed sample for $\sigma$ \\
\hline
\end{tabular}

The current order resulted in testing samples that had already been compressed previously and unintended cyclical compression was applied. The compression would have changed the physical strand orientation and density. There is some elasticity within the denser samples; however, the specimen would not have reverted back to its original uncompressed form. Another possible concern is that the white noise duration for the flow resistivity tests was shorter than the initial absorption coefficient tests.

In order to overcome these issues, the uncompressed samples should have been tested for both absorption coefficient and flow resistivity before compression, and a matching white noise duration been used.

\subsubsection{Initial Data Errors}

Another factor that needs to be considered is that the flow resistivity calculation was based on the underlying absorption coefficient data. It is difficult to know if any issues in the initial data could potentially negatively affect and were inadvertently carried over to flow resistivity results. A sharp dip at $630 \mathrm{~Hz}$ was found across all the flow resistivity data for the 2" compressed samples. A less pronounced dip at $630 \mathrm{~Hz}$ was also present in the absorption coefficient data. It is possible any resonance in the absorption coefficient data could have been magnified in the flow resistivity data. 


\subsection{Conclusion}

This paper experimentally studied the effects of compression on the absorption coefficient, flow resistivity and its experimental errors for porous fibrous material. The samples of fiberglass and three varying densities of rockwool that were 2" and 4" thick were tested using two different impedance tube sizes. Three compression rates of $1,1.3$ and 2 for these samples were also analysed. Using a standard impedance tube, a novel approach by Tao et al. was implemented to find the flow resistivity. Although there are some experimental errors, this study demonstrates that there is potential in finding flow resistivity using a standard impedance tube.

\subsection{Absorption Coefficient}

In brief, as porous material is compressed, the porosity decreases and thus lowers the sound absorption coefficient. The test results showed that for all the sample types the absorption coefficient is decreased and this was most evident in the lower frequency ranges. The 4" thick samples were more stable than the 2" thick samples. The compressed results from 2" to 1" for all the samples fluctuated, especially the fiberglass sample.

\subsection{Flow Resistivity}

Compression appears to increase the flow resistivity. As compared to the threemicrophone previous results, Tao et al.'s method result shows the flow resistivity is within the range of the estimated values; however, the calculated values are frequency dependent widely varied. The air gap of 2" seems to be more stable in the results. Tao et al.'s results were within $80-500 \mathrm{~Hz}$, and the results in the current paper demonstrated more stability in the lower frequency ranges as opposed to the circular samples (higher frequency ranges).

\subsection{Experimental Errors}

There are various factors that can contribute to the experimental errors. Sample preparation and variation may have affected the results. The compression technique may have caused unintended leakages due to bi-axial compression. The testing order meant the samples were retested when they had already been previously compressed, and 
undoubtedly affected the results. The flow resistivity data builds on the initial absorption coefficient results and any errors may have carried over to the final numbers.

\subsection{Future Work}

It is recommended that further study be conducted using Tao et al.'s novel technique especially for the higher frequency range. Suggestions outlined in Chapter 7.0 regarding sample preparation, mounting and compression techniques should be further implemented. A 2" circular ring to enforce the air gap behind the sample for the circular tube should be investigated for further testing. In addition, following Li's technique, a ring and mesh should be built for the circular tube as an alternate means of compressing the sample.

A number of papers used a numerical finite element analysis FEA model to help validate the experimental data, and it is also recommended that validation with a FEA model be conducted. 


\subsection{References}

[1] R. Ramakrishnan, J. Jung, S. Kim, J. A. Smith, R. Roos, and M. Hodgson, "Effect of compression on acoustic performance of fibrous materials," in Proceedings of the Acoustic Week in Canada, 2014, pp. 5-6.

[2] H. Seddeq, "Factors influencing acoustic performance of sound absorptive materials," Aust. J. Basic Appl. Sci., vol. 3, no. 4, pp. 4610-4617, 2009.

[3] J. P. Arenas and M. J. Crocker, "Recent Trends in Porous Sound-Absorbing Materials," Noise Vib. Control Mag., vol. 44, no. 7, pp. 12-17, 2010.

[4] California Energy Commisision, "California Energy Star Homes Program: High Quality Insulation Installation and Thermal Bypass Checklist Procedures,” 2006. [Online]. Available: http://www.consol.ws/builder-resources/files/CA-ThermalBypass.pdf. [Accessed: 16-Feb-2016].

[5] Oak Ridge National Laboratory, "Insulation Fact Sheet," DOE/CE-0180, 2008. [Online]. Available: http://web.ornl.gov/sci/roofs+walls/facts/Insulation Fact Sheet 2008.pdf. [Accessed: 08-Feb-2016].

[6] J. Valiulis and S. Phillips, "Twelve Common Deficiencies Found during Firestopping," J. ASTM Int., vol. 3, no. 4, 2006.

[7] B. Garner and M. Furbish, "Mineral Wool In Green Roofs," Furbish, Baltimore, USA, 2015.

[8] B. Stein, Building Technology: Mechanical and Electrical Systems. New York, USA: J. Wiley and Sons, 1997.

[9] HB Lanarc Consultants Ltd, "Pipes need jackets too. Improving Performance of BC Buildings through Mechanical Insulation Practice and Standards - A White Paper," International Association of Heat and Frost Insulators and Allied Workers (IAHFIAW) - Local 118, BC, Canada, 2010. 
[10] K. Collier, "Understanding long-term insulation efficiency," Plant Engineering, 2006. [Online]. Available: http://www.plantengineering.com/industry-news/topstories/single-article/understanding-long-term-insulationefficiency/d8b9ef50f2.html. [Accessed: 09-Feb-2016].

[11] Pittsburgh Corning Europe, Foamglas Industrial Insulation Handbook. Waterloo, Belgium: Pittsburgh Corning, 1992.

[12] Canada Mortgage and Housing Corporation, "Insulating Your House," 2016. [Online]. Available: http://www.cmhc-schl.gc.ca/en/co/grho/grho_010.cfm. [Accessed: 12-Feb-2016].

[13] Oak Ridge National Laboratory, "Technology Fact Sheet: Ceiling and Attics," 2000 .

[14] R. Aldrich and S. Puttagunta, "Measure Guideline : Sealing and Insulating Ducts in Existing Homes," 2011. [Online]. Available: http://www.nrel.gov/docs/fy12osti/53494.pdf. [Accessed: 15-Feb-2016].

[15] Owens Corning, "Technical Bulletin: Building Insulation Compressed R-value Chart," 2012. [Online]. Available: http://www2.owenscorning.com/literature/pdfs/10017857 Building Insul Compressed R-Value Chart Tech Bulletin.pdf. [Accessed: 08-Feb-2016].

[16] M. A. Kuczmarski and J. C. Johnston, "Acoustic Absorption in Porous Materials," NASA/TM-2011-216995, 2011. [Online]. Available: http://ntrs.nasa.gov/archive/nasa/casi.ntrs.nasa.gov/20110011143.pdf. [Accessed: 15-Jan-2016].

[17] M. E. Delany and E. N. Bazley, "Acoustical properties of fibrous absorbant materials," Appl. Acoust., vol. 3, no. 2, pp. 105-116, 1970.

[18] Y. Miki, "Acoustical properties of porous materials-Modifications of DelanyBazley models," J. Acoust. Soc. Jpn.(E), vol. 11, no. 1, pp. 19-24, 1990. 
[19] J. Y. Chung and D. A. Blaser, "Transfer function method of measuring in-duct acoustic properties. II. Experiment," J. Acoust. Soc. Am., vol. 68, no. 3, pp. 907921, 1980.

[20] J. Y. Chung and D. A. Blaser, "Transfer function method of measuring in-duct acoustic properties. I. Theory," J. Acoust. Soc. Am., vol. 68, no. 3, pp. 907-913, 1980.

[21] O. Doutres, Y. Salissou, N. Atalla, and R. Panneton, "Evaluation of the acoustic and non-acoustic properties of sound absorbing materials using a threemicrophone impedance tube," Appl. Acoust., vol. 71, no. 6, pp. 506-509, 2010.

[22] International Organization for Standardization, "ISO 10534-2:1998 (E): acoustics - determination of sound absorption coefficient and impedance in impedance tubes - Part 2: transfer-function method," 1998.

[23] ASTM International, "ASTM E1050, Standard Test Method for Impedance and Absorption of Acoustical Materials Using a Tube, Two Microphones and a Digital Frequency Analysis," pp. 1-12, 2015.

[24] D. Oliva and V. Hongisto, "Sound absorption of porous materials - Accuracy of prediction methods," Appl. Acoust., vol. 74, no. 12, pp. 1473-1479, 2013.

[25] X. Hua and D. W. Herrin, "Reducing the Uncertainty of Sound Absorption Measurements Using the Impedance Tube Method," SAE Int., vol. 1965, no. 2, pp. $2-7,2013$.

[26] D. Stanley, "Impedance Tube Specimen Preparation And Mounting Issues," in Internoise in New Yock City, USA, 2012, p. 7.

[27] M. Wolkesson, "Evaluation of impedance tube methods - A two microphone insitu method for road surfaces and the three microphone transfer function method for porous materials," Master's Thesis, Chalmers University of Technology, Sweden, 2013. 
[28] J. Tao, P. Wang, X. Qiu, and J. Pan, "Static flow resistivity measurements based on the ISO 10534.2 standard impedance tube," Build. Environ., pp. 6-11, 2015.

[29] Roxul, "ComfortbBatt - Technical Product Information," 2013. [Online]. Available: http://www.roxul.com/files/RX-NA_EN/pdf/Technical Data Sheetsupdated/COMFORTBATT_CDAwithSS.pdf. [Accessed: 07-Nov-2015].

[30] Roxul, “AFB - Techical Product Information.” [Online]. Available: http://www.roxul.com/files/RX-NA_EN/pdf/Technical Data Sheetsupdated/Building Envelope/AFB.pdf. [Accessed: 07-Nov-2015].

[31] Roxul, "CavityRock DD - Technical Product Information.” [Online]. Available: http://www.roxul.com/files/RX-NA_EN/pdf/Technical Data Sheetsupdated/TOPROCK_DD.pdf. [Accessed: 07-Nov-2015].

[32] Roxul, "Roxul AFB.” [Online]. Available: http://www.roxul.com/files/RXNA_EN/pdf/Brochures and Sell Sheets/Residential/AFB Sell Sheet.pdf. [Accessed: 07-Nov-2015].

[33] R. Sauro and M. Vargas, "Absorption coefficients-part 2: is 'edge-effect' more important than expected?," Inter-Noise 2009 Ottawa, Canada, 2009.

[34] B. Castagnède, A. Aknine, B. Brouard, and V. Tarnow, "Effects of compression on the sound absorption of fibrous materials," Appl. Acoust., vol. 61, pp. 3-7, 2000.

[35] G. Iannace, E. Ianniello, and S. Basturk, "An experimental study of effects of concentrated compressions on sound absorption of polyester fibre panels," in Euronoise 2009 in Edinburgh, Scotland, 2009.

[36] C. N. Wang, Y. M. Kuo, and S. K. Chen, "Effects of compression on the sound absorption of porous materials with an elastic frame," Appl. Acoust., vol. 69, pp. 31-39, 2008.

[37] W. Li, "Experimental studies on the determination of acoustic bulk material properties and transfer impedance," Master's Thesis, University of Kentucky, USA, 2014. 
[38] A. Farina and A. Torelli, "Measurement of the sound absorption coefficient of materials with a new sound intensity technique," in Proceedings of the AES in Munich, Germany, 1997.

[39] R. Ramakrishnan and J. A. Smith, "Acoustic Performance of Fibrous Materials Report 2," Ryerson University, Toronto, Canada, 2015.

[40] N. Kino and T. Ueno, "Investigation of sample size effects in impedance tube measurements," Appl. Acoust., vol. 68, no. 11-12, pp. 1485-1493, 2007.

[41] A. Cummings, "Impedance tube measurements on porous media: The effects of air-gaps around the sample," J. Sound Vib., vol. 151, no. 1, pp. 63-75, 1991.

[42] B. H. Song, J. S. Bolton, and Y. J. Kang, "Effect of circumferential edge constraint on the acoustical properties of glass fiber materials," J. Acoust. Soc. Am., vol. 110, no. 6, p. 2902, 2001.

[43] M. Muhammad, N. Sa'at, H. Naim, M. Isa, H. Yussof, and M. Yati, "The Effect of Air Gap Thickness on Sound Absorption Coefficient of Polyurethane Foam," Def. S T Tech. Bull., vol. 5(2), pp. 176-187, 2012. 


\section{Appendix A}

Testing Records 


\section{Absorption Coefficient Testing Records}

\begin{tabular}{|c|c|c|c|c|c|c|c|c|c|c|c|c|c|c|}
\hline & & \multicolumn{13}{|c|}{ Frequency } \\
\hline$\#$ & Samples & 100 & 125 & 160 & 200 & 250 & 315 & 400 & 500 & 630 & 800 & 1000 & 1250 & 1600 \\
\hline 1 & AFB_Cir 2 "C 1.5 "P 400 RIM_93_1236-37 & & & & & & & 0.526 & 0.710 & 0 & 0.051 & 0.844 & 0.590 & 0.846 \\
\hline 2 & AFB $\mathrm{Cir}_{2} " \mathrm{C}_{1.5} " \mathrm{P}_{800} 93 \quad 1097-98$ & & & & & & & 0 & 0.354 & 0 & 0 & 0.762 & 0.691 & 0.899 \\
\hline 3 & AFB_Cir 2 "C $1.5 " P_{800} 95 \_1099-00$ & & & & & & & 0 & 0.475 & 0 & 0 & 0.764 & 0.739 & 0.934 \\
\hline 4 & AFB $\mathrm{Cir}_{2} " \mathrm{C}_{1.5} \mathrm{P}_{800} \mathrm{RIM} 93$ 1238-39 & & & & & & & 0.409 & 0.660 & 0 & 0.046 & 0.846 & 0.616 & 0.840 \\
\hline 5 & AFB_Cir ${ }_{2} " \mathrm{U}_{2} \mathrm{P}_{800}$ 49_1049-50 & & & & & & & 0.763 & 0.878 & 0.931 & 0.930 & 0.926 & 0.929 & 0.952 \\
\hline 6 & AFB $\mathrm{Cir}_{2} " \mathrm{U}_{2} " \mathrm{P}_{800} 491270-71$ & & & & & & & 0.822 & 0.852 & 0.955 & 0.939 & 0.936 & 0.915 & 0.937 \\
\hline 7 & AFB_Cir 2 "U $U_{2} " \mathrm{P}_{800}$ 51_1051-52 & & & & & & & 0.942 & 0.848 & 0.896 & 0.898 & 0.944 & 0.953 & 0.971 \\
\hline 8 & AFB $\mathrm{Cir}_{2} " \mathrm{U}_{2} " \mathrm{P}_{800} 93 \quad 1093-94$ & & & & & & & 0.881 & 0.861 & 0.887 & 0.903 & 0.936 & 0.941 & 0.972 \\
\hline 9 & AFB $\mathrm{Cir}_{2}{ }^{\prime \prime} \mathrm{U}_{2} " \mathrm{P}_{800} 95$ 1095-96 & & & & & & & 0.824 & 0.844 & 0.874 & 0.887 & 0.934 & 0.948 & 0.973 \\
\hline 10 & AFB_Cir 4 "C $C_{2} " \mathrm{P}_{800}$ 101_1104-03 & & & & & & & 0.916 & 0.889 & 0.968 & 0.903 & 0.882 & 0.853 & 0.905 \\
\hline 11 & $\mathrm{AFB} \mathrm{Cir}_{4}{ }^{\prime \prime} \mathrm{C}_{2}{ } \mathrm{P}_{800} \quad 105 \quad 1107-08$ & & & & & & & 0.935 & 0.900 & 0.932 & 0.871 & 0.860 & 0.865 & 0.929 \\
\hline 12 & AFB_Cir 4 "U U"P800_101_1102-01 & & & & & & & 0.957 & 0.947 & 0.954 & 0.917 & 0.904 & 0.919 & 0.958 \\
\hline 13 & AFB $\mathrm{Cir}_{4} " \mathrm{U}_{4} " \mathrm{P}_{800} 105 \quad 1105-06$ & & & & & & & 0.935 & 0.936 & 0.948 & 0.899 & 0.897 & 0.921 & 0.961 \\
\hline 14 & AFB_Cir 4 "U $U_{4} " P_{800} 65 \_1065-66$ & & & & & & & 0.908 & 0.880 & 0.936 & 0.868 & 0.873 & 0.863 & 0.925 \\
\hline 15 & AFB $\mathrm{Cir}_{4} " \mathrm{U}_{4} " \mathrm{P}_{800} 67 \quad 1067-68$ & & & & & & & 0.938 & 0.944 & 0.950 & 0.904 & 0.902 & 0.917 & 0.959 \\
\hline 16 & AFB_Sq ${ }_{2} " \mathrm{C}_{1} " \mathrm{P}_{800}$ 113_1167-68 & 0.279 & 0.195 & 0.265 & 0.365 & 0.390 & 0.419 & 0.593 & 0.320 & & & & & \\
\hline 17 & AFB $\mathrm{Sq}_{2} " \mathrm{C}_{1.5} " \mathrm{P}_{800} \quad 129 \quad 1131-32$ & 0.253 & 0.193 & 0.286 & 0.375 & 0.405 & 0.418 & 0.579 & 0.317 & & & & & \\
\hline 18 & AFB $\quad \mathrm{Sq}_{2} " \mathrm{U}_{2} " \mathrm{P}_{800} \quad 113 \quad 1113-14$ & 0.306 & 0.269 & 0.340 & 0.407 & 0.411 & 0.547 & 0.695 & 0.361 & & & & & \\
\hline 19 & AFB_Sq ${ }_{2} " \mathrm{U}_{2} " \mathrm{P}_{800} 113$ 1165-66 & 0.297 & 0.247 & 0.352 & 0.400 & 0.395 & 0.555 & 0.707 & 0.362 & & & & & \\
\hline 20 & AFB $\mathrm{Sq}_{2} " \mathrm{U}_{2} " \mathrm{P}_{800} \quad 129 \quad 1129-30$ & 0.312 & 0.271 & 0.327 & 0.396 & 0.359 & 0.490 & 0.645 & 0.358 & & & & & \\
\hline 21 & AFB_Sq Sq $_{4} C_{2.5} " \mathrm{P}_{800} 115 \_1119-20$ & 0.306 & 0.467 & 0.624 & 0.758 & 0.796 & 0.832 & 0.850 & 0.403 & & & & & \\
\hline 22 & AFB Sq4 ${ }^{\prime \prime} C_{2.5} " P_{800} 127 \quad 1135-36$ & 0.333 & 0.521 & 0.638 & 0.776 & 0.779 & 0.803 & 0.822 & 0.405 & & & & & \\
\hline 23 & AFB_Sq 4 "C $C_{3} " \mathrm{P}_{800} 115 \_1117-18$ & 0.344 & 0.513 & 0.650 & 0.780 & 0.797 & 0.852 & 0.862 & 0.408 & & & & & \\
\hline 24 & AFB $\mathrm{Sq}_{4} " \mathrm{C}_{3} " \mathrm{P}_{800} 127 \quad 1133-34$ & 0.365 & 0.569 & 0.668 & 0.774 & 0.787 & 0.823 & 0.836 & 0.411 & & & & & \\
\hline 25 & AFB_Sq Sq $_{4} \mathrm{U}_{4} " \mathrm{P}_{800} 115$ 1115-16 & 0.469 & 0.595 & 0.724 & 0.779 & 0.860 & 0.899 & 0.907 & 0.427 & & & & & \\
\hline 26 & $\mathrm{AFB} \mathrm{Sq}_{4} " \mathrm{U}_{4} \mathrm{P}_{800} 115 \quad 1222-23$ & 0 & 0 & 0 & 0.108 & 0.170 & 0.293 & 0.260 & 0.093 & & & & & \\
\hline 27 & AFB Sq $4 " U_{4} " P_{800} \quad 127 \quad 1127-28$ & 0.532 & 0.648 & 0.720 & 0.782 & 0.831 & 0.853 & 0.852 & 0.406 & & & & & \\
\hline 28 & DD2_Cir 2 "U $U_{2} " \mathrm{P}_{800} 37$ 1037-38 & & & & & & & 0.437 & 0.883 & 0.950 & 0.943 & 0.915 & 0.904 & 0.935 \\
\hline 29 & DD2 $\mathrm{Cir}_{2} " \mathrm{U}_{2} " \mathrm{P}_{800} 37 \quad 1258-59$ & & & & & & & 0.726 & 0.863 & 0.957 & 0.935 & 0.929 & 0.886 & 0.911 \\
\hline 30 & DD2_Cir 2 "U ${ }_{2} " \mathrm{P}_{800} 39 \_1039-40$ & & & & & & & 0.839 & 0.858 & 0.963 & 0.921 & 0.913 & 0.888 & 0.940 \\
\hline 31 & DD2 $\mathrm{Cir}_{4}{ }^{\prime \prime} \mathrm{C}_{3}{ }^{\prime \prime} \mathrm{P}_{400} \mathrm{RIM} 31 \quad 1228-29$ & & & & & & & 0.738 & 0.773 & 0.886 & 0.874 & 0.836 & 0.768 & 0.820 \\
\hline 32 & DD2_Cir 4 "U $U_{4} " \mathrm{P}_{200}$ 31_1 $1200-99$ & & & & & & & 0.903 & 0.872 & 0.892 & 0.840 & 0.842 & 0.848 & 0.918 \\
\hline 33 & DD2 $\mathrm{Cir}_{4} " \mathrm{U}_{4} " \mathrm{P}_{200} \mathrm{RIM} 31 \quad 1202-03$ & & & & & & & 0.820 & 0.835 & 0.906 & 0.822 & 0.814 & 0.788 & 0.876 \\
\hline 34 & DD2_Cir 4 "U $U_{4} " \mathrm{P}_{400} 31 \_1204-05$ & & & & & & & 0.861 & 0.840 & 0.919 & 0.885 & 0.884 & 0.861 & 0.889 \\
\hline 35 & $\mathrm{DD} 2 \mathrm{Cir}_{4} \mathrm{U}_{4} \mathrm{P}_{400} 31 \quad 1232-33$ & & & & & & & 0.844 & 0.837 & 0.918 & 0.881 & 0.884 & 0.854 & 0.881 \\
\hline 36 & DD2 $\mathrm{Cir}_{4} " \mathrm{U}_{4} " \mathrm{P}_{400} \mathrm{RIM} 31 \quad 1226-27$ & & & & & & & 0.715 & 0.761 & 0.882 & 0.853 & 0.836 & 0.776 & 0.824 \\
\hline 37 & 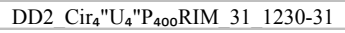 & & & & & & & 0.750 & 0.751 & 0.902 & 0.833 & 0.823 & 0.766 & 0.827 \\
\hline 38 & DD2 $\mathrm{Cir}_{4} " \mathrm{U}_{4} " \mathrm{P}_{600} 31 \quad \overline{1206-07}$ & & & & & & & 0.853 & 0.840 & 0.909 & 0.887 & 0.887 & 0.861 & 0.890 \\
\hline 39 & DD2_Cir 4 "U $U_{4} " \mathrm{P}_{800}$ 31_1031-32 & & & & & & & 0.914 & 0.878 & 0.914 & 0.870 & 0.872 & 0.876 & 0.920 \\
\hline 40 & DD2 $\mathrm{Cir}_{4} " \mathrm{U}_{4} " \mathrm{P}_{800} 31 \quad 1033-34$ & & & & & & & 0.910 & 0.878 & 0.910 & 0.868 & 0.873 & 0.879 & 0.920 \\
\hline 41 & DD2_Cir 4 "U $U_{4} \mathrm{P}_{800} 31$ 31_208-09 & & & & & & & 0.840 & 0.848 & 0.906 & 0.891 & 0.888 & 0.863 & 0.890 \\
\hline 42 & $\mathrm{DD} 2 \mathrm{Cir}_{4}{ }^{\prime \prime} \mathrm{U}_{4} " \mathrm{P}_{800} 35 \quad 1035-36$ & & & & & & & 0.909 & 0.874 & 0.923 & 0.874 & 0.881 & 0.865 & 0.909 \\
\hline 43 & DD2_Sq $\mathrm{Sq}_{2} \mathrm{U}_{2}{ }^{\prime} \mathrm{P}_{800}$ 109_1109-10 & 0.273 & 0.212 & 0.310 & 0.416 & 0.419 & 0.544 & 0.686 & 0.357 & & & & & \\
\hline 44 & DD2 $\mathrm{Sq}_{2} " \mathrm{U}_{2} " \mathrm{P}_{800} \quad 125 \quad 1125-26$ & 0.334 & 0.384 & 0.472 & 0.530 & 0.606 & 0.703 & 0.735 & 0.358 & & & & & \\
\hline 45 & DD2 $\mathrm{Sq}_{4} " \mathrm{U}_{4} " \mathrm{P}_{800} \quad 169 \quad 1169-70$ & 0.420 & 0.548 & 0.773 & 0.699 & 0.749 & 0.724 & 0.698 & 0.339 & & & & & \\
\hline 46 & DD2_Sq $\mathrm{Sq}_{4} \mathrm{U}_{4}{ } \mathrm{P}_{800}$ 171_1171-72 & 0.440 & 0.600 & 0.765 & 0.711 & 0.759 & 0.754 & 0.712 & 0.341 & & & & & \\
\hline 47 & FG $\mathrm{Cir}_{2} \mathrm{C}_{0.5} " \mathrm{P}_{800} 81 \quad 1084-83$ & & & & & & & 0 & 0 & 0 & 0 & 0 & 0 & 0 \\
\hline 48 & FG_Cir ${ }_{2} " \mathrm{C}_{1} \mathrm{P}_{400} \mathrm{RIM}$ 61_1214-15 & & & & & & & 0 & 0.538 & 0 & 0 & 0.508 & 0.479 & 0.896 \\
\hline 49 & $\mathrm{FG} \mathrm{Cir}_{2}{ }^{\prime \prime} \mathrm{C}_{1}{ } \mathrm{P}_{400} \mathrm{~S} \& \mathrm{~J} \quad 85 \quad 1266-67$ & & & & & & & 0.290 & 0.452 & 0 & 0 & 0.607 & 0.332 & 0.879 \\
\hline 50 & FG_Cir 2 "C $C_{1} " \mathrm{P}_{800} 81$ 81_1262-63 & & & & & & & 0.424 & 0.491 & 0 & 0 & 0.506 & 0.148 & 0.737 \\
\hline 51 & $\mathrm{FG} \mathrm{Cir}_{2} " \mathrm{C}_{1} " \mathrm{P}_{800} 85 \quad 1254-55$ & & & & & & & 0.005 & 0.394 & 0 & 0 & 0.545 & 0.228 & 0.853 \\
\hline 52 & FG_Cir ${ }_{2}{ }^{2} C_{1} " P_{800} R I M \_81 \_1256-57$ & & & & & & & 0 & 0 & 0 & 0 & 0.284 & 0 & 0.649 \\
\hline 53 & FG $\mathrm{Cir}_{2}{ }^{\prime \prime} \mathrm{C}_{1}{ } \mathrm{P}_{800} \mathrm{~S} \& \mathrm{~J} \quad 85 \quad 1264-65$ & & & & & & & 0.369 & 0.532 & 0 & 0 & 0.650 & 0.394 & 0.906 \\
\hline 54 & FG $\mathrm{Cir}_{2} " \mathrm{C}_{1} " \mathrm{P}_{800} \mathrm{SK} \quad 85 \quad 1087-88$ & & & & & & & 0.355 & 0.489 & 0 & 0 & 0.589 & 0.397 & 0.918 \\
\hline 55 & 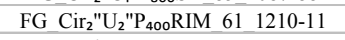 & & & & & & & 0.067 & 0.701 & 0 & 0.727 & 0.834 & 0.952 & 0.970 \\
\hline 56 & FG $\mathrm{Cir}_{2}{ } \mathrm{U}_{2}{ } \mathrm{P}_{800} 61 \quad \overline{1061-62}$ & & & & & & & 0 & 0.671 & 0.190 & 0.626 & 0.732 & 0.868 & 0.956 \\
\hline 57 & FG_Cir ${ }_{2} " \mathrm{U}_{2} " \mathrm{P}_{800}$ 63_1063-64 & & & & & & & 0 & 0.591 & 0.012 & 0.581 & 0.679 & 0.848 & 0.941 \\
\hline 58 & $\mathrm{FG} \mathrm{Cir}{ }_{2} " \mathrm{U}_{2} " \mathrm{P}_{800} 81 \quad 1081-82$ & & & & & & & 0 & 0.510 & 0 & 0 & 0.629 & 0.725 & 0.894 \\
\hline 59 & FG_Cir ${ }_{2} " \mathrm{U}_{2} " \mathrm{P}_{800}{ }_{85} 85 \_1085-86$ & & & & & & & 0.820 & 0.716 & 0.602 & 0.494 & 0.714 & 0.865 & 0.966 \\
\hline 60 & $\mathrm{FG} \mathrm{Cir}_{4} " \mathrm{C}_{2} " \mathrm{P}_{400} \quad 53 \quad 1298-99$ & & & & & & & 0.758 & 0.803 & 0.739 & 0.831 & 0.901 & 0.950 & 0.987 \\
\hline 61 & FG_Cir 4 "C $C_{2} " P_{800}$ 77_1079-80 & & & & & & & 0.626 & 0.808 & 0.752 & 0.838 & 0.913 & 0.952 & 0.986 \\
\hline 62 & $\mathrm{FG} \mathrm{Cir}_{4} " \mathrm{C}_{2} " \mathrm{P}_{800} \quad 89 \quad 1091-92$ & & & & & & & 0.848 & 0.801 & 0.784 & 0.840 & 0.918 & 0.956 & 0.980 \\
\hline 63 & FG $\mathrm{Cir}_{4} " \mathrm{U}_{4} " \mathrm{P}_{800} 53$ 1053-54 & & & & & & & 0.910 & 0.796 & 0.763 & 0.819 & 0.908 & 0.969 & 0.979 \\
\hline 64 & FG_Cir 4 "U $\mathrm{U}_{4} " \mathrm{P}_{800}$ 53_1057-58 & & & & & & & 0.873 & 0.827 & 0.922 & 0.975 & 0.994 & 0.944 & 0.928 \\
\hline 65 & $\mathrm{FG} \mathrm{Cir}_{4} " \mathrm{U}_{4} " \mathrm{P}_{800} 55 \quad 1055-56$ & & & & & & & 0.944 & 0.813 & 0.858 & 0.877 & 0.950 & 0.986 & 0.975 \\
\hline 66 & FG_Cir 4 "U $\mathrm{U}_{4} " \mathrm{P}_{800}$ 55_1059-60 & & & & & & & 0.860 & 0.822 & 0.906 & 0.971 & 0.993 & 0.947 & 0.932 \\
\hline 67 & $\mathrm{FG} \mathrm{Cir}_{4} " \mathrm{U}_{4} " \mathrm{P}_{800} 77 \quad 1078-77$ & & & & & & & 0.881 & 0.862 & 0.950 & 0.991 & 0.992 & 0.949 & 0.944 \\
\hline 68 & FG_Cir 4 "U $U_{4} " P_{800} 89 \_1089-90$ & & & & & & & 0.889 & 0.850 & 0.946 & 0.986 & 0.987 & 0.919 & 0.899 \\
\hline 69 & FG Sq $\mathrm{Sq}_{2} \mathrm{C}_{1} \mathrm{P}_{800} \quad 173 \quad 1175-76$ & 0.302 & 0.236 & 0.289 & 0.334 & 0.236 & 0.226 & 0.351 & 0.207 & & & & & \\
\hline 70 & FG Sq Sq $_{2} \mathrm{C}_{1} " \mathrm{P}_{800} \quad 177 \quad 1179-80$ & 0.221 & 0.171 & 0.218 & 0.300 & 0.200 & 0.228 & 0.319 & 0.178 & & & & & \\
\hline 71 & FG $\mathrm{Sq}_{2} " \mathrm{U}_{2} " \mathrm{P}_{800} * \quad 173 \quad 1173-74$ & 0.292 & 0.210 & 0.270 & 0.344 & 0.260 & 0.301 & 0.414 & 0.235 & & & & & \\
\hline
\end{tabular}




\begin{tabular}{|c|c|c|c|c|c|c|c|c|c|c|c|c|c|c|}
\hline 72 & FG $\mathrm{Sq}_{2} " \mathrm{U}_{2} " \mathrm{P}_{800} 177 \quad 1177-78$ & 0.275 & 0.196 & 0.252 & 0.323 & 0.255 & 0.270 & 0.395 & 0.224 & & & & & \\
\hline 73 & $\mathrm{FG} \mathrm{Sq} \mathrm{Sq}_{4} \mathrm{C}_{1} " \mathrm{P}_{800} \quad 111 \quad 1123-24$ & 0.666 & 0.193 & 0.262 & 0.358 & 0.355 & 0.377 & 0.502 & 0.265 & & & & & \\
\hline 74 & FG_Sq Sq $_{4} \mathrm{C}_{1}$ "P ${ }_{800}$ 137_1141-42 & 0.247 & 0.185 & 0.274 & 0.402 & 0.353 & 0.417 & 0.574 & 0.308 & & & & & \\
\hline 75 & FG $\mathrm{Sq}_{4} \mathrm{C}_{2}{ }^{\prime \prime} \mathrm{P}_{800} \quad 111 \quad 1121-22$ & 0.265 & 0.246 & 0.360 & 0.473 & 0.421 & 0.536 & 0.688 & 0.359 & & & & & \\
\hline 76 & FG_Sq" ${ }_{4} \mathrm{C}_{2} " \mathrm{P}_{800}$ 137_1139-40 & 0.292 & 0.236 & 0.354 & 0.502 & 0.429 & 0.580 & 0.715 & 0.356 & & & & & \\
\hline 77 & FG Sq $4 " \mathrm{~S}_{4} " \mathrm{P}_{800} \quad 111 \quad 1111-12$ & 0.327 & 0.316 & 0.502 & 0.520 & 0.588 & 0.700 & 0.804 & 0.363 & & & & & \\
\hline 78 & FG Sq4"U $\mathrm{Sq}_{4} \mathrm{P}_{800} \quad 137 \quad 1137-38$ & 0.322 & 0.309 & 0.481 & 0.561 & 0.589 & 0.704 & 0.806 & 0.353 & & & & & \\
\hline 79 & $\mathrm{R} 24 \mathrm{Cir}_{2} " \mathrm{C}_{1} " \mathrm{P}_{800} 73$ 1260-61 & & & & & & & 0.420 & 0.659 & 0.171 & 0.721 & 0.873 & 0.817 & 0.917 \\
\hline 80 & R24 $\mathrm{Cir}_{2} " \mathrm{C}_{1} " \mathrm{P}_{800} \mathrm{SK} 69 \quad 1072-71$ & & & & & & & 0.769 & 0.858 & 0.735 & 0.758 & 0.897 & 0.768 & 0.881 \\
\hline 81 & R24 $\mathrm{Cir}_{2} " \mathrm{C}_{1} " \mathrm{P}_{800} \mathrm{SK} 73 \quad 1075-76$ & & & & & & & 0.233 & 0.760 & 0.477 & 0.679 & 0.882 & 0.834 & 0.923 \\
\hline 82 & $\mathrm{R} 24 \mathrm{Cir}_{2}{ }^{\prime} \mathrm{U}_{2}{ } \mathrm{P}_{800} 41 \quad 1041-42$ & & & & & & & 0.922 & 0.886 & 0.906 & 0.926 & 0.943 & 0.929 & 0.959 \\
\hline 83 & R24_Cir 2 "U ${ }_{2}$ "P $800 \_43 \_1043-44$ & & & & & & & 0.847 & 0.908 & 0.889 & 0.926 & 0.918 & 0.886 & 0.929 \\
\hline 84 & $\mathrm{R} 24 \mathrm{Cir}_{2}{ }^{\prime \prime} \mathrm{U}_{2} " \mathrm{P}_{800} 69 \quad 1069-70$ & & & & & & & 0.918 & 0.883 & 0.899 & 0.860 & 0.879 & 0.812 & 0.903 \\
\hline 85 & R24_Cir ${ }_{2} \mathrm{U}_{2}$ "P $\mathrm{P}_{800}$ 73_1073-74 & & & & & & & 0.890 & 0.876 & 0.919 & 0.918 & 0.937 & 0.928 & 0.960 \\
\hline 86 & $\mathrm{R} 24 \mathrm{Cir}_{4}{ }^{\prime \prime} \mathrm{C}_{2} " \mathrm{P}_{400} \mathrm{~S} \quad 45 \quad 1242-43$ & & & & & & & 0.773 & 0.791 & 0.933 & 0.859 & 0.860 & 0.781 & 0.846 \\
\hline 87 & R24 $\mathrm{Cir}_{4} " \mathrm{C}_{2} " \mathrm{P}_{800} \mathrm{~S} \& \mathrm{RIM} 45 \quad 1246-47$ & & & & & & & 0.692 & 0.732 & 0.911 & 0.849 & 0.816 & 0.723 & 0.794 \\
\hline 88 & R24_Cir 4 "C ${ }_{2} " \mathrm{P}_{800}$ S\&RIM_45_1248-49 & & & & & & & 0.729 & 0.737 & 0.924 & 0.858 & 0.819 & 0.711 & 0.805 \\
\hline 89 & $\mathrm{R} 24 \mathrm{Cir}_{4}{ }^{\prime \prime} \mathrm{C}_{2} " \mathrm{P}_{800} \mathrm{~S} \quad 45 \quad 1244-45$ & & & & & & & 0.752 & 0.784 & 0.927 & 0.851 & 0.856 & 0.792 & 0.839 \\
\hline 90 & $\mathrm{R} 24 \_\mathrm{Cir}_{4}{ }^{\prime \prime} \mathrm{C}_{2} " \mathrm{P}_{800} \mathrm{SK} \& \mathrm{~J} \_47 \_1253-52$ & & & & & & & 0.772 & 0.769 & 0.913 & 0.839 & 0.851 & 0.775 & 0.828 \\
\hline 91 & $\mathrm{R} 24 \mathrm{Cir}_{4}{ }^{11} \mathrm{C}_{2}{ } \mathrm{P}_{800} \mathrm{SK} 47 \quad 1250-51$ & & & & & & & 0.826 & 0.818 & 0.933 & 0.863 & 0.859 & 0.802 & 0.859 \\
\hline 92 & $\mathrm{R} 24 \mathrm{Cir}_{4}{ } \mathrm{C}_{3}{ } \mathrm{P}_{400} 45 \_1240-41$ & & & & & & & 0.876 & 0.878 & 0.941 & 0.903 & 0.901 & 0.872 & 0.906 \\
\hline 93 & $\mathrm{R} 24 \mathrm{Cir}_{4}{ }^{\prime \prime} \mathrm{U}_{4} " \mathrm{P}_{800} * 45 \quad 1045-46$ & & & & & & & 0.915 & 0.899 & 0.917 & 0.869 & 0.872 & 0.853 & 0.902 \\
\hline 94 & $\mathrm{R} 24 \mathrm{Cir}_{4}{ }^{\prime \prime} \mathrm{U}_{4} " \mathrm{P}_{800} * 47 \quad 1047-48$ & & & & & & & 0.920 & 0.911 & 0.935 & 0.885 & 0.886 & 0.890 & 0.938 \\
\hline 95 & $\mathrm{R} 24 \mathrm{Sq}_{2} " \mathrm{C}_{1} " \mathrm{P}_{800} \quad 155 \quad 1157-58$ & 0.270 & 0.188 & 0.321 & 0.379 & 0.490 & 0.537 & 0.701 & 0.354 & & & & & \\
\hline 96 & $\mathrm{R} 24 \quad \mathrm{Sq}_{2} " \mathrm{C}_{1} " \mathrm{P}_{800} \quad 159 \quad 1161-62$ & 0.269 & 0.223 & 0.307 & 0.485 & 0.484 & 0.588 & 0.691 & 0.339 & & & & & \\
\hline 97 & $\mathrm{R} 24 \_\mathrm{Sq}_{2} " \mathrm{C}_{1} " \mathrm{P}_{800}$ 159_1163-64 & 0.267 & 0.229 & 0.317 & 0.487 & 0.491 & 0.590 & 0.692 & 0.339 & & & & & \\
\hline 98 & $\mathrm{R} 24 \mathrm{Sq}_{2} " \mathrm{U}_{2} " \mathrm{P}_{800} \quad 155 \quad 1155-56$ & 0.311 & 0.263 & 0.397 & 0.516 & 0.466 & 0.667 & 0.792 & 0.396 & & & & & \\
\hline 99 & $\mathrm{R} 24 \mathrm{Sq}_{2} " \mathrm{U}_{2} " \mathrm{P}_{800} \quad 159 \quad 1159-60$ & 0.368 & 0.356 & 0.432 & 0.487 & 0.603 & 0.733 & 0.806 & 0.390 & & & & & \\
\hline 100 & $\mathrm{R} 24 \mathrm{Sq}_{4} " \mathrm{C}_{2} " \mathrm{P}_{800} \quad 143 \quad 1145-46$ & 0.340 & 0.393 & 0.564 & 0.690 & 0.730 & 0.797 & 0.809 & 0.381 & & & & & \\
\hline 101 & $\mathrm{R} 24 \_\mathrm{Sq}_{4} " \mathrm{C}_{2} " \mathrm{P}_{800} 147 \_1151-52$ & 0.316 & 0.419 & 0.583 & 0.688 & 0.730 & 0.758 & 0.757 & 0.347 & & & & & \\
\hline 102 & $\mathrm{R} 24 \mathrm{Sq}_{4} " \mathrm{C}_{3} " \mathrm{P}_{800} \quad 147 \quad 1149-50$ & 0.459 & 0.554 & 0.665 & 0.724 & 0.789 & 0.796 & 0.796 & 0.376 & & & & & \\
\hline 103 & $\mathrm{R} 24 \_\mathrm{Sq}_{4} " \mathrm{U}_{4} " \mathrm{P}_{800}$ 143_1143-44 & 0.522 & 0.588 & 0.751 & 0.768 & 0.846 & 0.877 & 0.897 & 0.429 & & & & & \\
\hline 104 & $\mathrm{R} 24 \mathrm{Sq}_{4} " \mathrm{U}_{4} " \mathrm{P}_{800} \quad 147 \quad 1147-48$ & 0.526 & 0.597 & 0.736 & 0.784 & 0.846 & 0.851 & 0.856 & 0.407 & & & & & \\
\hline 105 & R24_Squ"U ${ }_{4} " P_{800} 147 \_1153-54$ & 0.546 & 0.602 & 0.733 & 0.794 & 0.838 & 0.838 & 0.840 & 0.400 & & & & & \\
\hline
\end{tabular}




\section{Flow Resistivity Testing Records}

\begin{tabular}{|c|c|c|c|c|c|c|c|c|c|c|c|c|c|c|}
\hline & & \multicolumn{13}{|c|}{ Frequency } \\
\hline \# & Samples & 100 & 125 & 160 & 200 & 250 & 315 & 400 & 500 & 630 & 800 & 1000 & 1250 & 1600 \\
\hline 106 & AFB_Cir ${ }_{2} \mathrm{U}_{2} " \mathrm{~L}_{6} " \mathrm{P}_{800}$ 49_1049-50_1272-73 & & & & & & & & 18369 & 8745 & 12867 & 7918 & 6885 & 10702 \\
\hline 107 & AFB_Cir ${ }_{2} \mathrm{U}_{2}{ }^{\prime \prime} \mathrm{L}_{2} " \mathrm{P}_{400} 49-1270-71 \_1360-61$ & & & & & & & & 18123 & 386 & 10148 & 12697 & 12731 & 12857 \\
\hline 108 & AFB_Cira" $\mathrm{U}_{4} " \mathrm{~L}_{2} " \mathrm{P}_{400} 65$ 65 $1065-66 \_1312-13$ & & & & & & & & 9565 & 7417 & 11029 & 10457 & 12257 & 11591 \\
\hline 109 & AFB_Cir ${ }_{4} " \mathrm{U}_{4} " \mathrm{~L}_{4} " \mathrm{P}_{400} 65$ 65_1065-66_1314-15 & & & & & & & & 10841 & 8187 & 11066 & 10979 & 12556 & 5708 \\
\hline 110 & AFB_Cir ${ }_{4} " \mathrm{U}_{4} " \mathrm{~L}_{6} " \mathrm{P}_{400} 65$ 65_1065-66_1316-17 & & & & & & & & 10606 & 8195 & 10982 & 8368 & 6132 & 11506 \\
\hline 111 & AFB_Cir ${ }_{2}{ }^{\prime C} C_{1.5} " L_{2} " P_{400}=95 \_1099-00 \_1290-91$ & & & & & & & & 14191 & 4996 & 17113 & 23815 & 26387 & 15903 \\
\hline 112 & AFB_Cir ${ }^{\prime \prime} C_{2}{ }^{2} L_{2} " \mathrm{P}_{400} \mathrm{~F}$ _101_1104-03_1292-93 & & & & & & & & 22131 & 8689 & 13757 & 16380 & 18684 & 19411 \\
\hline 113 & 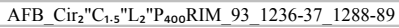 & & & & & & & & 30001 & 0 & 17064 & 20195 & 37218 & 30993 \\
\hline 114 & AFB_Cir $2 " \mathrm{U}_{2} " \mathrm{~L}_{2} " \mathrm{P}_{400} 49$-1270-71_1360-61 & & & & & & & & 18839 & 1350 & 8114 & 8950 & 14633 & 15108 \\
\hline 115 & DD2_Cir 4 "U $\mathrm{U}_{4} " \mathrm{~L}_{2} " \mathrm{P}_{200}$ 31_1031-32_1185-86 & & & & & & & & 8512 & 10479 & 12683 & 12832 & 13236 & 12887 \\
\hline 116 & $\mathrm{DD} 2 \mathrm{Cir}_{4} " \mathrm{U}_{4}$ "L $\mathrm{L}_{4} " \mathrm{P}_{200} 31$ 31031-32_1187-88 & & & & & & & & 10427 & 11260 & 13588 & 12797 & 14038 & 8713 \\
\hline 117 & DD2_Cir ${ }_{4} \mathrm{U}_{4} " \mathrm{~L}_{6} " \mathrm{P}_{200} 31$ 31031-32_1189-90 & & & & & & & & 11344 & 10965 & 13858 & 8544 & 6867 & 13043 \\
\hline 118 & DD2_Cir ${ }_{4} \mathrm{U}_{4}{ }^{\prime \prime} \mathrm{L}_{4}{ } \mathrm{P}_{400} \mathrm{RIM}$ 31_1031-32_1224-25 & & & & & & & & 10241 & 9363 & 12466 & 8906 & 10784 & 381 \\
\hline 119 & 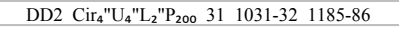 & & & & & & & & 8517 & 10280 & 12495 & 12689 & 12932 & 12253 \\
\hline 120 & $\mathrm{DD} 2 \mathrm{Cir}_{4} " \mathrm{U}_{4} " \mathrm{~L}_{4} " \mathrm{P}_{200} 31 \quad 1031-32 \quad 1187-88$ & & & & & & & & 10311 & 11081 & 13216 & 12616 & 13931 & 7991 \\
\hline 121 & DD2_Cir ${ }_{4} \mathrm{UU}_{4} " \mathrm{~L}_{6}{ } \mathrm{P}_{200}$ 31_1031-32_1189-90 & & & & & & & & 11137 & 11278 & 13315 & 8739 & 7082 & 12601 \\
\hline 122 & $\mathrm{DD} 2 \mathrm{Cir}_{2} \mathrm{U}_{2} " \mathrm{~L}_{2}{ } \mathrm{P}_{400}{ }_{3} 37$ 1258-59_1356-57 & & & & & & & & 20229 & 0 & 4238 & 4417 & 13882 & 17749 \\
\hline 123 & DD2_Cir ${ }^{\prime \prime} \mathrm{U}_{2}{ }^{2} \mathrm{~L}_{4} " \mathrm{P}_{400}$ 37_1258-59_1358-59 & & & & & & & & 20574 & 4268 & 11764 & 9168 & 15993 & 8148 \\
\hline 124 & FG_Cir ${ }^{\prime \prime} \mathrm{U}_{4} " \mathrm{~L}_{2} " \mathrm{P}_{400}$ 53_1057-58_1294-95 & & & & & & & & 4650 & 2933 & 1411 & 1648 & 2934 & 3678 \\
\hline 125 & FG_Cir ${ }_{2} \mathrm{U}_{2}{ } \mathrm{~L}_{2}{ } \mathrm{P}_{400} \mathrm{RIM}-61 \_1061-62 \_1212-13$ & & & & & & & & 5264 & 3036 & 7493 & 8705 & 11027 & 7661 \\
\hline 126 & 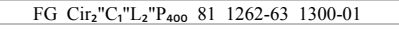 & & & & & & & & 0 & 9439 & 16264 & 14859 & 17652 & 15199 \\
\hline 127 & $\mathrm{FG} \mathrm{Cir}_{4} " \mathrm{C}_{2}{ } \mathrm{~L}_{2}$ "P $\mathrm{P}_{400}$-53_1298-99_1296-97 & & & & & & & & 8815 & 3261 & 11677 & 13260 & 11769 & 6868 \\
\hline 128 & R24_Cir ${ }_{2} " \mathrm{U}_{2}{ }^{\prime \prime} \mathrm{L}_{2} \mathrm{P}_{400} 411$ 1041-42_1304-05 & & & & & & & & 0 & 0 & 0 & 0 & 0 & 0 \\
\hline 129 & R24_Cir ${ }_{2} " \mathrm{U}_{2}$ "L $\mathrm{L}_{2} " \mathrm{P}_{800} 41$ 41_1041-42_1306-07 & & & & & & & & 15571 & 0 & 13986 & 7781 & 9550 & 10517 \\
\hline 130 & R24_Cir 2 "U ${ }_{2} " \mathrm{~L}_{4} " \mathrm{P}_{400} 41$ 41_1041-42_1308-09 & & & & & & & & 15931 & 2821 & 13740 & 5173 & 7786 & 3964 \\
\hline 131 & R24_Cir ${ }_{2} " \mathrm{U}_{2}$ "L $\mathrm{L}_{6} " \mathrm{P}_{400} 41$ 41_1041-42_1310-11 & & & & & & & & 14851 & 6020 & 12545 & 6938 & 12022 & 10190 \\
\hline 132 & R24_Cir ${ }_{4} " \mathrm{U}_{4} " \mathrm{~L}_{2} " \mathrm{P}_{800} 45+1045-46$ 1191-92 & & & & & & & & 7067 & 7724 & 7644 & 8584 & 9748 & 8985 \\
\hline 133 & R24_Cir ${ }^{\prime \prime} \mathrm{C}_{2}$ "L $\mathrm{L}_{2} \mathrm{P}_{400}$ 45_1045-46_1302-03 & & & & & & & & 15075 & 15304 & 14375 & 11668 & 16293 & 22081 \\
\hline 134 & R24_Cir ${ }^{2} \mathrm{C}_{1} " \mathrm{~L}_{2} " \mathrm{P}_{400}$ 73_1260-61_1362-63 & & & & & & & & 29791 & 0 & 18066 & 32583 & 46143 & 38254 \\
\hline 135 & R24_Cir ${ }_{2}{ }^{2} \mathrm{C}_{1} " \mathrm{~L}_{4}$ "P $\mathrm{P}_{400}$ 73_1260-61_1364-65 & & & & & & & & 37358 & 7240 & 25416 & 35729 & 40184 & 6436 \\
\hline 136 & AFB_Sq${ }^{\prime} \mathrm{U}_{4} " \mathrm{~L}_{2} " \mathrm{P}_{200} \mathrm{~F}$-115_1115-16_1181-82_2 & 18972 & 11688 & 11525 & 13930 & 12408 & 8770 & 8457 & 3404 & & & & & \\
\hline 137 & AFB_Squ"U ${ }_{4} " \mathrm{~L}_{2} " \mathrm{P}_{400} \overline{\mathrm{F}} 11 \overline{15} \_1115-1 \overline{6} \_1216-1 \overline{7}$ & 19706 & 12819 & 11873 & 12757 & 12500 & 8208 & 8043 & 3415 & & & & & \\
\hline 138 & AFB_Sq Sq $_{4} \mathrm{U}_{4} " \mathrm{~L}_{2}{ } \mathrm{P}_{600} \mathrm{~F}$ F $115 \_1115-16 \_1218-19$ & 18813 & 12789 & 12135 & 12555 & 12466 & 8441 & 8000 & 3548 & & & & & \\
\hline 139 & AFB_Sq Sq $_{4} " \mathrm{U}_{4} " \mathrm{~L}_{2} " \mathrm{P}_{800} \mathrm{~F} \_115 \_1115-16 \_1220-21$ & 18883 & 12639 & 12208 & 12536 & 12275 & 8359 & 8040 & 3679 & & & & & \\
\hline 140 & 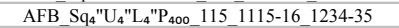 & 13324 & 11049 & 11980 & 13494 & 12565 & 5789 & 6794 & 2692 & & & & & \\
\hline 141 & AFB_Sq ${ }_{4} " \mathrm{C}_{3} " \mathrm{~L}_{2} " \mathrm{P}_{400} \mathrm{~F} \_115 \_1117-18 \_1274-75$ & 31565 & 21449 & 15885 & 17889 & 18579 & 21251 & 23255 & 8035 & & & & & \\
\hline 142 & AFB_Sq Sq $_{4} \mathrm{C}_{2 \cdot 5} " \mathrm{~L}_{2} " \mathrm{P}_{400} \mathrm{~F} \_115 \_1119-20 \_1276-77$ & 39831 & 30668 & 22563 & 23621 & 25667 & 25965 & 29929 & 11525 & & & & & \\
\hline 143 & AFB_Sq ${ }_{4} " \mathrm{U}_{4} " \mathrm{~L}_{2} " \mathrm{P}_{800} \mathrm{~F} \_127 \_1127-28 \_1366-67$ & 15728 & 20569 & 7621 & 9061 & 6833 & 8033 & 11562 & 3685 & & & & & \\
\hline 144 & AFB_Sq $\mathrm{Sq}_{4} " \mathrm{U}_{4} " \mathrm{~L}_{2} " \mathrm{P}_{800 \mathrm{~F}} \mathrm{~F} 127 \_1127-28 \_1368-69$ & 15512 & 18789 & 11088 & 16049 & 15238 & 8912 & 14109 & 4967 & & & & & \\
\hline 145 & AFB_Sq $\mathrm{Sq}_{4} " \mathrm{U}_{4} " \mathrm{~L}_{2} " \mathrm{P}_{800 \mathrm{~F}} \mathrm{~F} 127 \_1127-28 \_1370-71$ & 15497 & 18709 & 11169 & 16192 & 14021 & 8876 & 14146 & 4921 & & & & & \\
\hline 146 & AFB Sq $\mathrm{Sq}_{2} \mathrm{U}_{2} " \mathrm{~L}_{2} " \mathrm{P}_{400} \mathrm{~F} 113 \quad 1165-66 \quad 1346-47$ & 13961 & 17093 & 18631 & 13320 & 15243 & 15970 & 16397 & 6816 & & & & & \\
\hline 147 & AFB_Sq $q_{2} " \mathrm{C}_{1} " \mathrm{~L}_{2} " \mathrm{P}_{400} \mathrm{~F}$ F $113 \_1167-68 \_1284-85$ & 4116 & 12509 & 32851 & 34783 & 28500 & 33292 & 33061 & 13951 & & & & & \\
\hline 148 & DD2_Sq ${ }_{2} " \mathrm{U}_{2} " \mathrm{~L}_{2}{ } \mathrm{P}_{400} \mathrm{~F} \_109 \_1109-10 \_1348-49$ & 18437 & 24496 & 28254 & 26695 & 28630 & 28699 & 28941 & 12863 & & & & & \\
\hline 149 & DD2_Sq ${ }_{2} " \mathrm{U}_{2} " \mathrm{~L}_{4} " \mathrm{P}_{400} \mathrm{~F}$ 109_1109-10_1350-51 & 16167 & 22470 & 26250 & 24258 & 25220 & 25628 & 25989 & 11798 & & & & & \\
\hline 150 & DD2_Sq $\mathrm{Sq}_{4} " \mathrm{U}_{4} " \mathrm{~L}_{2} " \mathrm{P}_{400} \mathrm{~F} 169+1169-70 \_1352-53$ & 9310 & 18272 & 14941 & 14967 & 12070 & 17069 & 24296 & 7592 & & & & & \\
\hline 151 & DD2_Sq $\mathrm{Sq}_{4} \mathrm{U}_{4} " \mathrm{~L}_{4} " \mathrm{P}_{400} \mathrm{~F}$ F_169_1169-70_1354-55 & 7316 & 14665 & 17166 & 18327 & 11240 & 15235 & 19985 & 8560 & & & & & \\
\hline 152 & 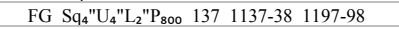 & 859 & 1800 & 1972 & 1714 & 2349 & 2684 & 3056 & 1328 & & & & & \\
\hline 153 & 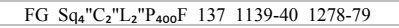 & 0 & 4006 & 9553 & 12353 & 8625 & 8247 & 7998 & 3508 & & & & & \\
\hline 154 & FG_Sq $\mathrm{Sq}_{4} \mathrm{C}_{1}{ }^{\prime} \mathrm{L}_{2}{ } \mathrm{P}_{400} \mathrm{~F}-137 \_1141-42 \_1280-81$ & 0 & 9141 & 21081 & 22660 & 15777 & 17374 & 16621 & 7200 & & & & & \\
\hline 155 & FG_Sq ${ }^{\prime \prime} \mathrm{U}_{2} " \mathrm{~L}_{2} " \mathrm{P}_{400} \mathrm{~F}$-177_1177-78_1322-23 & 9 & 279 & 2309 & 911 & 3483 & 3739 & 3614 & 1284 & & & & & \\
\hline 156 & FG_Sq $=" \mathrm{U}_{2} " \mathrm{~L}_{4} " \mathrm{P}_{400} \mathrm{~F}-177-1177-78 \_1324-25$ & 581 & 1276 & 2533 & 2378 & 3351 & 3491 & 3715 & 1419 & & & & & \\
\hline 157 & FG_Sq ${ }^{\prime \prime} \mathrm{U}_{2} " \mathrm{~L}_{6} " \mathrm{P}_{400} \mathrm{~F}-177 \_1177-78 \_1328-29$ & 2664 & 2736 & 3519 & 3091 & 3531 & 3640 & 3838 & 1673 & & & & & \\
\hline 158 & FG_Sq $\mathrm{Sq}_{2} \mathrm{C}_{1} " \mathrm{~L}_{2} " \mathrm{P}_{400} \mathrm{~F}-177$ 1179-80_1282-83 & 0 & 0 & 6402 & 18933 & 10438 & 9693 & 7844 & 3436 & & & & & \\
\hline 159 & $\mathrm{R} 24 \_\mathrm{Sq}_{4} " \mathrm{U}_{4} " \mathrm{~L}_{2} " \mathrm{P}_{800}{ }_{147} 14147-48 \_1193-94$ & 12919 & 10762 & 13908 & 16926 & 13348 & 8375 & 7887 & 3680 & & & & & \\
\hline 160 & R24_Sq" $" \mathrm{U}_{4} " \mathrm{~L}_{4} " \mathrm{P}_{400}$ 147_1147-48_1195-96 & 12031 & 11461 & 14217 & 15738 & 15367 & 8985 & 8284 & 4896 & & & & & \\
\hline 161 & 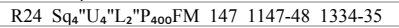 & 12948 & 11785 & 14320 & 15840 & 6289 & 7741 & 8512 & 4013 & & & & & \\
\hline 162 & R24_Sq $\mathrm{Sq}_{4} " \mathrm{U}_{4} " \mathrm{~L}_{4} " \mathrm{P}_{400} \mathrm{FM}{ }_{1} 147 \_1147-48 \_1336-37$ & 9838 & 10995 & 13869 & 16007 & 7173 & 8198 & 9020 & 4001 & & & & & \\
\hline 163 & R24_Sq $\mathrm{Sq}_{4} " \mathrm{U}_{4} " \mathrm{~L}_{6} " \mathrm{P}_{400} \mathrm{FM} \_147 \_1147-48 \_1338-39$ & 11128 & 11879 & 14785 & 16826 & 7098 & 7460 & 8470 & 4178 & & & & & \\
\hline 164 & $\mathrm{R} 24 \_\mathrm{Sq}_{4} " \mathrm{C}_{2} " \mathrm{~L}_{6} " \mathrm{P}_{400} \mathrm{FM}-147 \_1147-48+1340-41$ & 0 & 0 & 0 & 0 & 0 & 0 & 0 & 0 & & & & & \\
\hline 165 & $\mathrm{R} 24 \_\mathrm{Sq}_{4} " \mathrm{C}_{2}$ "L4"P $\mathrm{L}_{400} \mathrm{FM} \_147 \_1147-48 \_1342-43$ & 40123 & 48234 & 25543 & 32207 & 28643 & 28708 & 27083 & 11425 & & & & & \\
\hline 166 & $\mathrm{R} 24 \_\mathrm{Sq}_{4} " \mathrm{C}_{2} \mathrm{LL}_{2} " \mathrm{P}_{400} \mathrm{FM}-147 \_1147-48 \_1344-45$ & 53068 & 0 & 0 & 34325 & 21750 & 20840 & 28283 & 11238 & & & & & \\
\hline 167 & $\mathrm{R} 24 \_\mathrm{Sq}_{2} " \mathrm{U}_{2} " \mathrm{~L}_{4} " \mathrm{P}_{400} \mathrm{~F} \_159-1159-60 \_1318-19$ & 14053 & 15958 & 19819 & 22781 & 24168 & 26091 & 30443 & 11311 & & & & & \\
\hline 168 & R24_Sq $\mathrm{Sq}_{2} " \mathrm{U}_{2}{ }^{\prime \prime} \mathrm{L}_{4} " \mathrm{P}_{400} \mathrm{FM} \_159$ & 13433 & 13416 & 18740 & 21522 & 23497 & 25637 & 30319 & 11299 & & & & & \\
\hline 169 & R24_Sq2"U ${ }_{2} " \mathrm{~L}_{2} " \mathrm{P}_{400} \mathrm{~F}$ F_159_1159-60_1332-33 & 16010 & 11216 & 16380 & 22892 & 24999 & 27007 & 29757 & 10771 & & & & & \\
\hline 170 & $\mathrm{R} 24-\mathrm{Sq}_{2} " \mathrm{C}_{1} " \mathrm{~L}_{2}{ } \mathrm{P}_{400} \mathrm{~F}$-159_1163-64_1286-87 & 67192 & 25335 & 53093 & 56053 & 50407 & 55992 & 60276 & 26565 & & & & & \\
\hline
\end{tabular}




\section{Appendix B}

Fortran and Matlab Scripts 


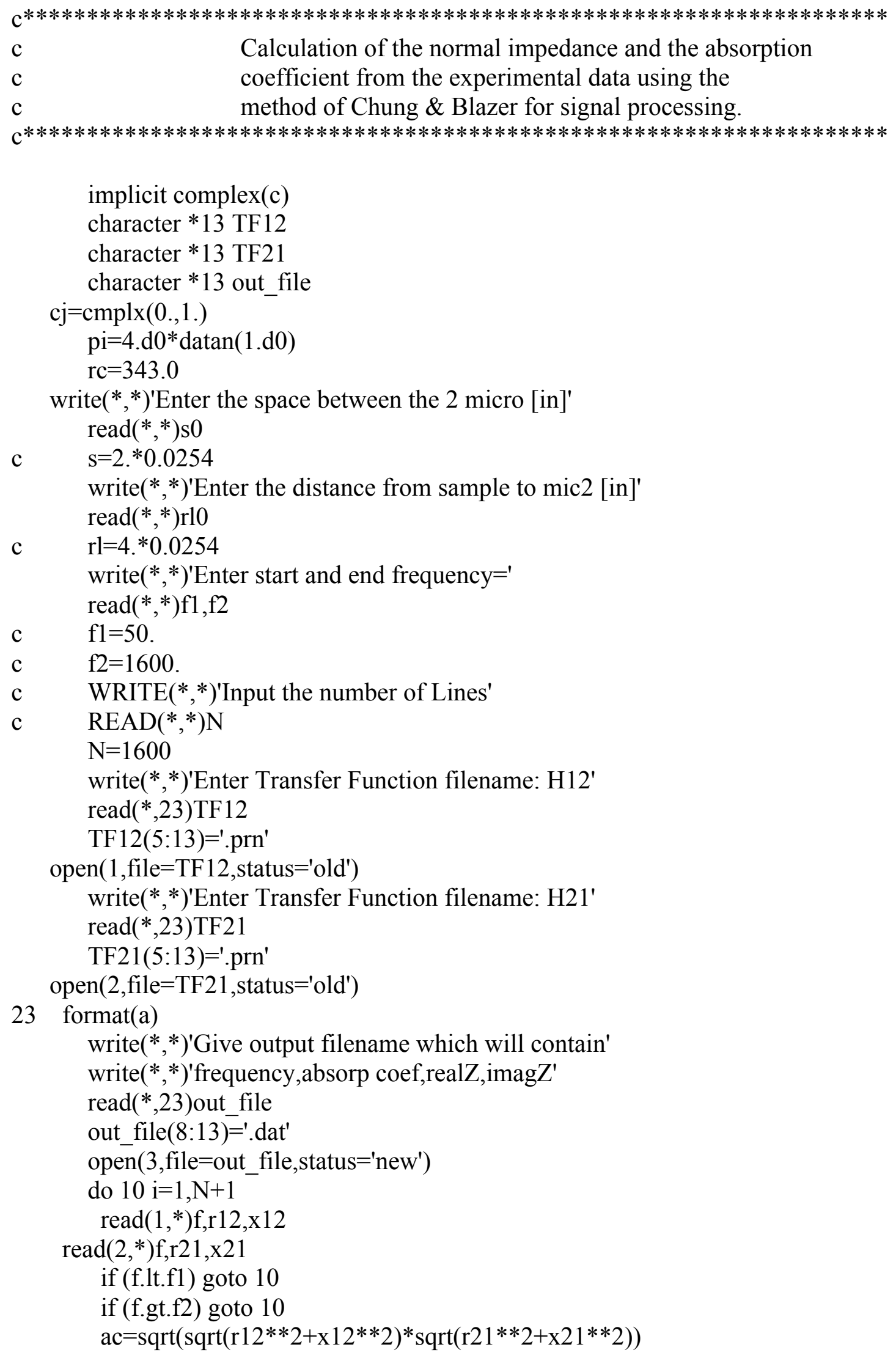




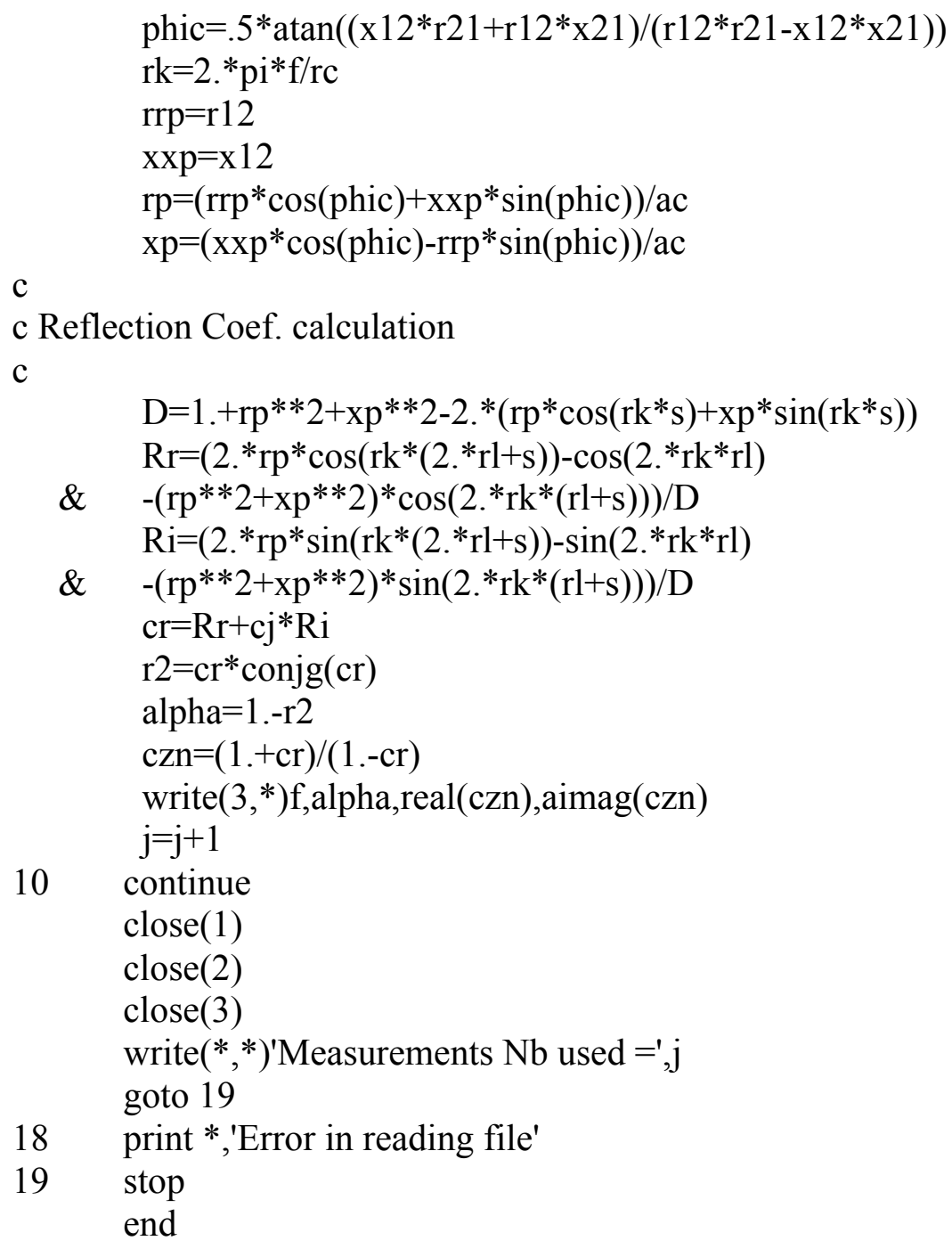

18 print *,'Error in reading file'

19 stop

end 


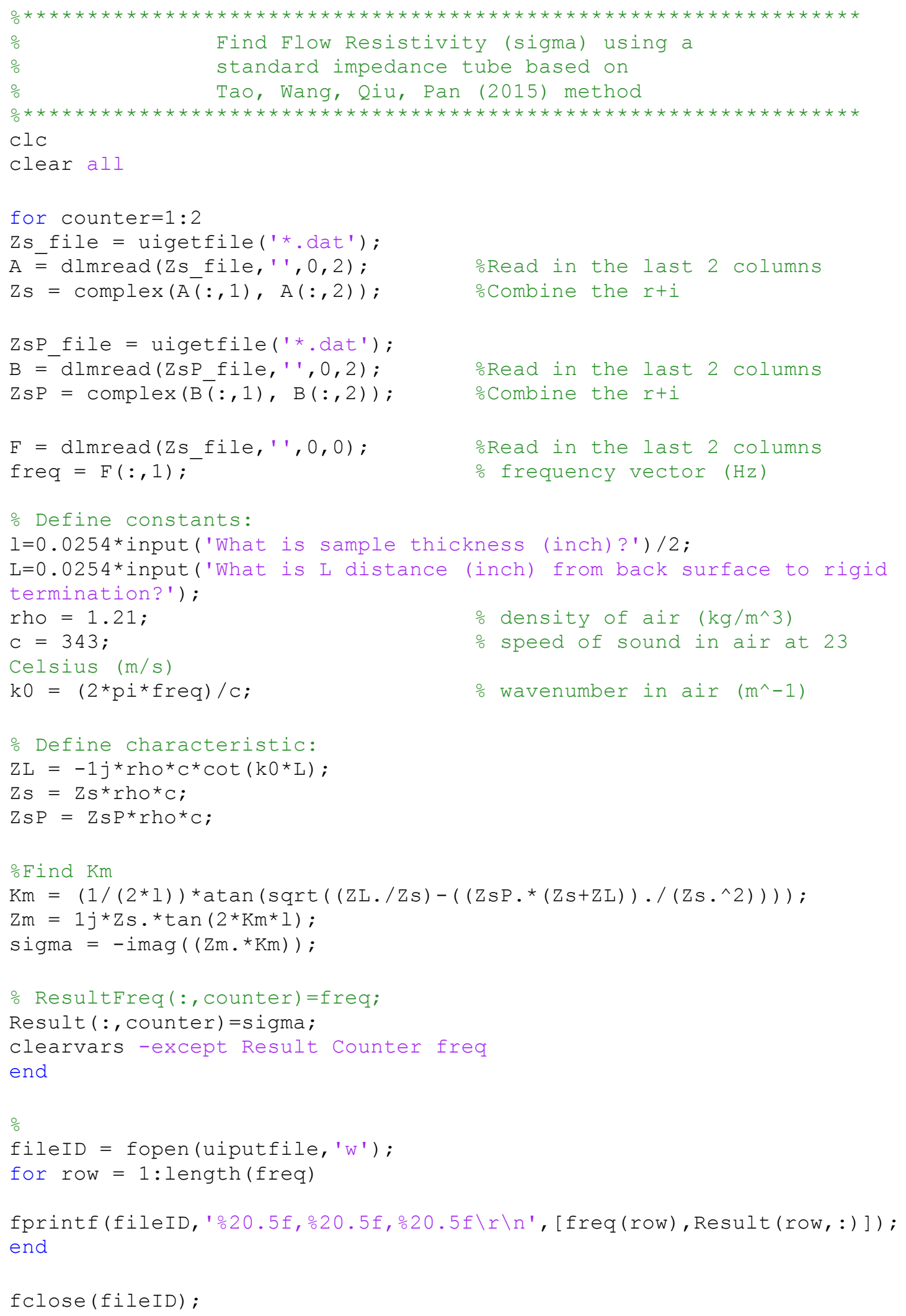

